UNIVERSIDADE DE SÃO PAULO

FACULDADE DE ECONOMIA, ADMINISTRAÇÃO E CONTABILIDADE DE RIBEIRÃO PRETO

DEPARTAMENTO DE ADMINISTRAÇÃO

VINICIUS AKIRA BABA

\title{
DIAGNÓSTICO E ANÁLISE DE OPORTUNIDADE DE MELHORIA EM UM RESTAURANTE UNIVERSITÁRIO POR MEIO DA FILOSOFIA SEIS SIGMA
}

Orientadora: Prof. Dra. Adriana Backx Noronha Viana

Ribeirão Preto 


\author{
Profa. Dra. Suely Vilela \\ Reitora da Universidade de São Paulo
}

Prof. Dr. Rudinei Toneto Júnior

Diretor da Faculdade de Economia, Administração e Contabilidade de Ribeirão Preto

Prof. Dr. Márcio Mattos Borges de Oliveira

Chefe do Departamento de Administração

Profa. Dra. Adriana Backx Noronha Viana

Coordenadora do Programa de Pós Graduação em Administração 
VINICIUS AKIRA BABA

DIAGNÓSTICO E ANÁLISE DE OPORTUNIDADE DE MELHORIA EM UM RESTAURANTE UNIVERSITÁRIO POR MEIO DA FILOSOFIA SEIS SIGMA

Dissertação apresentada ao programa de PósGraduação em Administração de Organizações da Faculdade de Economia, Administração e Contabilidade de Ribeirão Preto da Universidade de São Paulo, como requisito para a obtenção do título de mestre em Administração das Organizações.

Orientadora: Profa.Dra.Adriana Backx Noronha Viana.

\section{Ribeirão Preto}


AUTORIZO A REPRODUÇÃO E DIVULGAÇÃO TOTAL OU PARCIAL

DESTE TRABALHO, POR QUALQUER MEIO CONVENCIONAL OU

ELETRÔNICO, PARA FINS DE ESTUDO E PESQUISA, DESDE QUE

CITADA A FONTE.

FICHA CATALOGRÁFICA

Baba, Vinicius Akira

Diagnóstico e Análise de Oportunidade de Melhoria em um Restaurante Universitário por meio da Filosofia Seis Sigma. Ribeirão Preto, 2008.

100p.: il; $30 \mathrm{~cm}$

Dissertação de Mestrado apresentada à Faculdade de Economia, Administração e Contabilidade de Ribeirão Preto USP. Área de Concentração: Administração de Organizações.

Orientadora: Viana, Adriana Backx Noronha

1. DMAIC. 2. Restaurante. 3. Desperdício de alimentos 


\section{Folha de Aprovação}

Vinicius Akira Baba

Diagnóstico e Análise de Oportunidade de Melhoria em um Restaurante Universitário por meio da Filosofia Seis Sigma

Dissertação apresentada à Faculdade de Economia, Administração e Contabilidade de Ribeirão Preto da Universidade de São Paulo para obtenção do título de Mestre.

Área de concentração: Administração de Organizações

Aprovado em:

\section{Banca examinadora}

Prof. Dr.

Instituição:

Assinatura:

Prof. Dr.

Instituição:

Assinatura:

Prof. Dr.

Instituição: Assinatura: 
Dedico este trabalho aos meus pais que tanto admiro 


\section{AGRADECIMENTOS}

Aos meus amados pais, Eiji e Helena, pelo carinho, compreensão e por todos os sacrifícios que já fizeram para que minha irmã e eu pudéssemos realizar nossos sonhos.

À minha orientadora Adriana Backx Noronha Viana por acreditar em meu potencial, pela oportunidade, confiança, incentivo, paciência, orientações e exemplo de docente, que cativa e motiva seus alunos.

Aos professores membros da banca e a todos os demais professores do Departamento de Administração da Faculdade de Economia, Administração e Contabilidade de Ribeirão Preto da Universidade de São Paulo.

Às funcionárias do Restaurante Central que participaram do projeto, em especial às nutricionistas Marli José Vitório Colombari e Ana Lúcia Eiko Nozaki Sola Losa, pelas importantes contribuições com a pesquisa, pela atenção e carinho com que fui recebido, agradeço a oportunidade e a amizade.

Aos funcionários da FEARP, em especial à Érika Veronese Lima e Eduardo Castaldelli da seção de pós-graduação, pela competência, boa vontade e auxílio nos momentos em que precisei.

Ao meu amigo Luciano Pimentel, que me orientou e ajudou imensamente durante o processo para ingressar no mestrado.

À minha amiga Daielly Mantovani pelos conselhos e ajuda, inestimáveis para a conclusão deste trabalho.

Ao Flávio e ao Magnus pela ajuda na coleta de dados.

Aos meus grandes amigos e companheiros de mestrado, Paulão e Claudinha, pelos momentos de sabedoria filosofando nos botecos e pela amizade verdadeira.

À minha querida irmã Tamie e ao meu cunhado Juan pela ajuda com o abstract.

E por fim, agradeço a todos que participaram e contribuíram para a realização deste trabalho. 


\section{RESUMO}

BABA, Vinicius Akira. Diagnóstico e análise de oportunidade de melhoria em um restaurante universitário por meio da filosofia Seis Sigma. 2008. 100 f. Dissertação (Mestrado) - Faculdade de Economia, Administração e Contabilidade de Ribeirão Preto, Universidade de São Paulo, Ribeirão Preto, 2008.

O método DMAIC do programa de qualidade Seis Sigma reúne um conjunto de métodos e ferramentas estatísticas para o estudo da variabilidade dos processos. Uma vez identificados e estudados os pontos de oportunidade, faz-se o planejamento e a implantação de melhorias, em geral, com significativos benefícios para os resultados da organização. $\mathrm{O}$ processo de produção de refeições também pode ser estudado sob esta ótica, isto é, a redução da variabilidade nos processos pode contribuir como uma estratégia para a melhoria da qualidade e redução dos custos. O objetivo desta dissertação é o de utilizar conceitos da filosofia Seis Sigma para realizar um estudo das oportunidades de melhoria em um restaurante universitário e fazer sugestões de ações que tragam benefícios financeiros e melhorem seus processos. Além da pesquisa bibliográfica sobre o método DMAIC e administração de Unidades de Alimentação e Nutrição (UAN), foi realizado um projeto no Restaurante Central do Campus da USP de Ribeirão Preto, com o objetivo de reduzir o desperdício de alimentos.

Foram coletados dados sobre a aceitação das refeições pelos usuários no refeitório do restaurante central, onde os usuários servem-se em bandejas, e no refeitório II, onde os usuários servem-se em pratos, além do levantamento dos restos em cada refeitório. A análise dos dados sugere que a utilização de pratos ao invés de bandejas pode reduzir o desperdício de alimentos e até aumentar a aceitação dos alimentos pelos usuários, atendendo a dois requisitos importantes do programa de qualidade Seis Sigma: o foco no cliente e o impacto financeiro.

Palavras chave: DMAIC, Restaurante, Desperdício de alimentos. 


\begin{abstract}
BABA, Vinicius Akira. Diagnosis and analysis of improvement opportunity in a university cafeteria through the Six Sigma philosophy. 2008. 100 p. Dissertation (Master Degree) - School of Economy, Business and Accounting of Ribeirão Preto, University of São Paulo, Ribeirão Preto, 2008
\end{abstract}

The DMAIC method from the SIX SIGMA quality program assembles a set of methods and statistics tools for the variability process study. Once the opportunities are identified and studied, the improvements are planned and established, in general, with significant benefit for the entity result. The meal production process can also be studied from this perspective, that is, decreasing process variability can contribute as a strategy for the improvement of quality and cost reduction. The purpose of this thesis is to apply concept from the Six Sigma philosophy to perform a study on the improvement opportunities in a university cafeteria and suggest actions that results in financial benefits and process enhancement. Besides bibliographic research about the DMAIC method and UAN (Unidades de Alimentação e Nutrição) management process, a project was performed at the main cafeteria of the USPRibeirão Preto campus, with the purpose to reduce food waste.

Meal acceptance data were collected from customers at both, the main cafeteria, where the meal is served in a tray, and from the cafeteria II, where the meal is served in a plate, and a survey of the leftover in each site were also performed. The analysis suggests that using plates instead of trays can reduce food waste and even increase the customer's acceptance of the food, fulfilling two important requirements of the Six Sigma quality program: focus on the customer and financial impact.

Keywords: DMAIC, cafeteria, food waste. 


\section{SUMÁRIO}

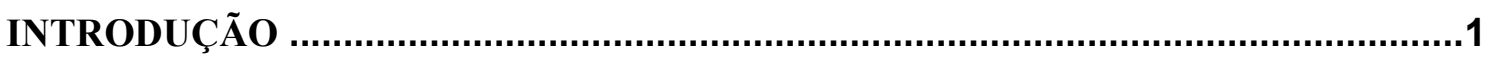

$1.1 \quad$ PROBLEMA DE PESQUISA ...................................................................................................... 2

1.2 OBJETIVO …............................................................................................................................. 2

2 REVISÃO DA LITERATURA..................................................................4

2.1 SEIS SIGMA: DESCRIÇÃO E DEFINIÇÃO ......................................................................... 5

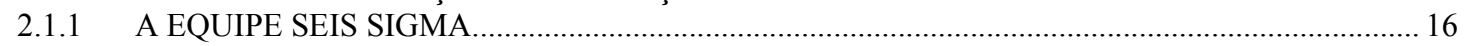

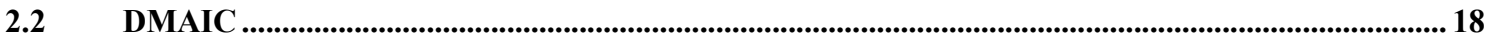

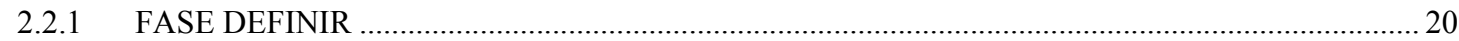

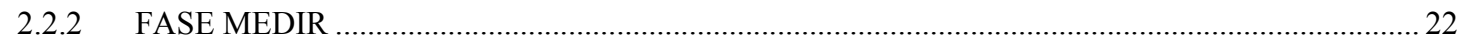

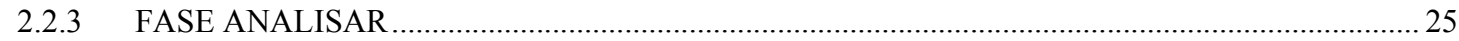

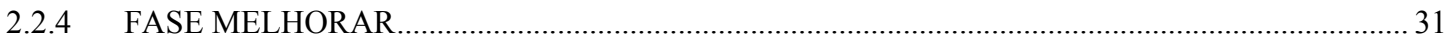

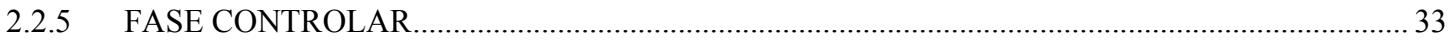

2.3 FERRAMENTAS ESTATÍSTICAS E DA QUALIDADE ...............................................................35

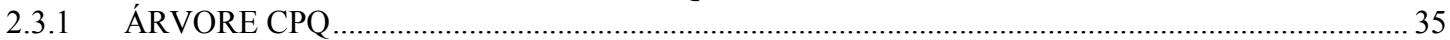

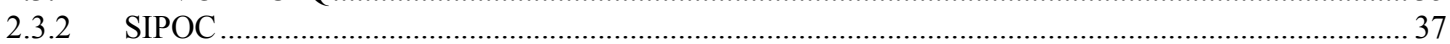

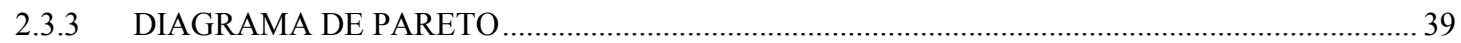

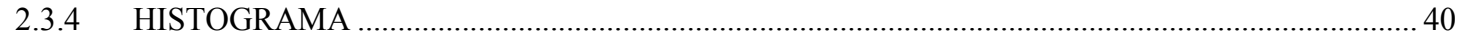

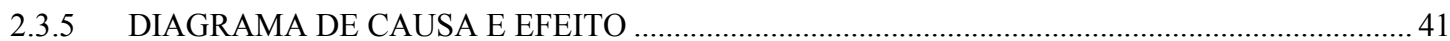

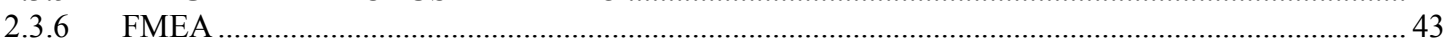

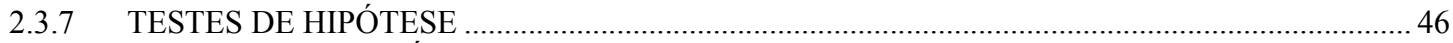

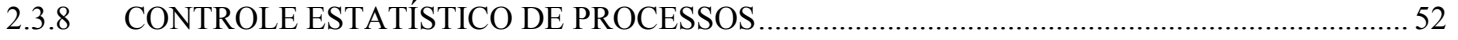

2.4 UNIDADE DE ALIMENTAÇÃO E NUTRIÇÃO …...................................................................57

3 PROCEDIMENTOS METODOLÓGICOS ...............................................63

C.1 CONTEXTUALIZAÇÃO DA PESQUISA ......................................................................................... 64

3.2 ETAPAS DE DESENVOLVIMENTO DO TRABALHO ...............................................................65

$3.3 \quad$ COLETA DE DADOS ................................................................................................................... 69

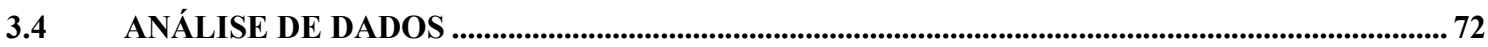

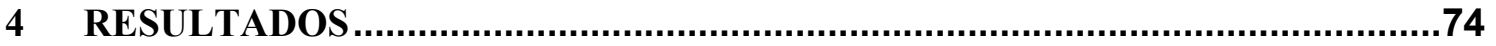

IDENTIFICAÇÃO DA OPORTUNIDADE DE MELHORIA ...........................................................74

4.2 COLETA E ANÁLISE DOS DADOS......................................................................................... 78

4.3 ANÁLISE DAS CAUSAS DO PROBLEMA ……....................................................................................... 87

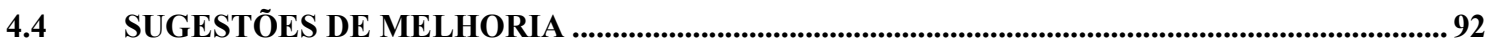

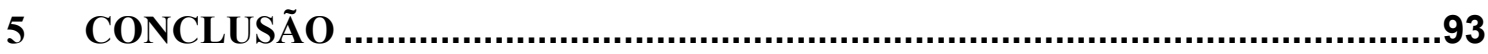


5.1 LIMITAÇÕES E DESENVOLVIMENTOS FUTUROS ..................................................................... 94

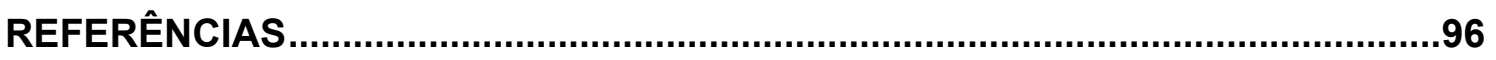




\section{LISTA DE QUADROS}

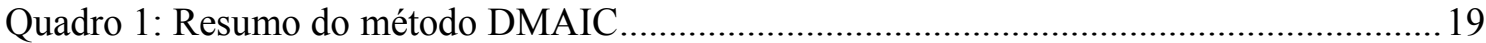

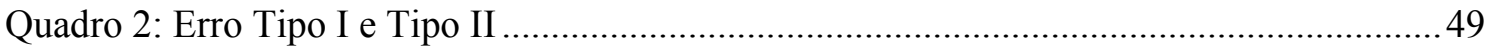

Quadro 3: Técnicas estatísticas recomendadas por nível de mensuração de teste ..................49

Quadro 4: Etapas do desenvolvimento do trabalho e resultados esperados ............................68

Quadro 5: Funcionárias do restaurante que participaram do projeto.................................... 70

Quadro 6: Ferramentas utilizadas na análises dos dados................................................... 73

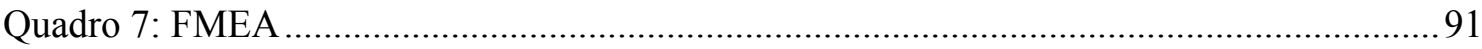




\section{LISTA DE ILUSTRAÇÕES}

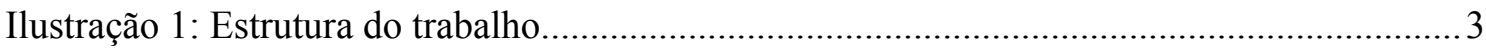

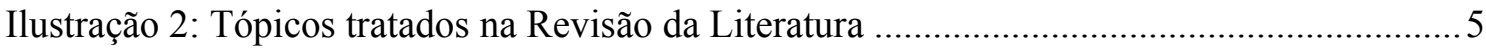

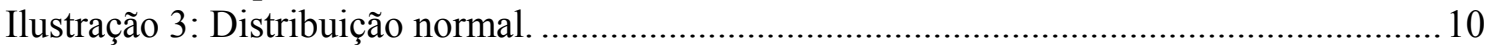

Ilustração 4: Representação do deslocamento de $1,5 \sigma$ da média do processo. ..........................11

Ilustração 5: Análise gráfica de exatidão e precisão................................................................ 15

Ilustração 6: Diagramas de dispersão e descrição do relacionamento linear. ............................ 30

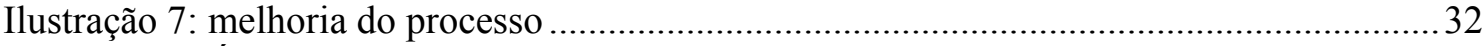

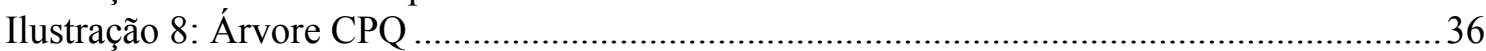

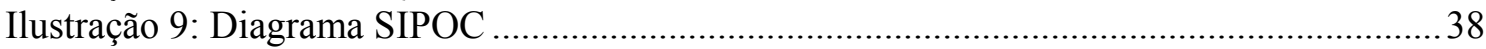

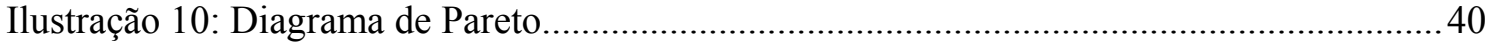

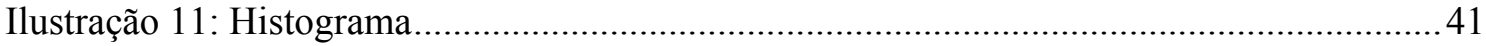

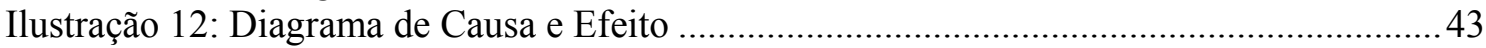

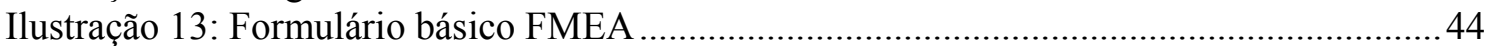

Ilustração 14: Distribuição dividida em regiões de aceitação e rejeição, com valor crítico

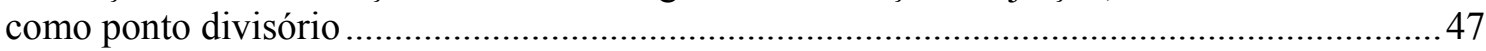

Ilustração 15: Comparação da partição de uma distribuição amostral para testes unilaterais e

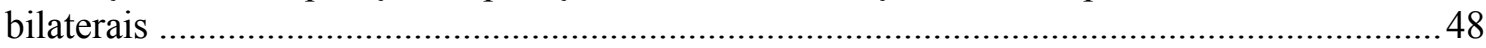

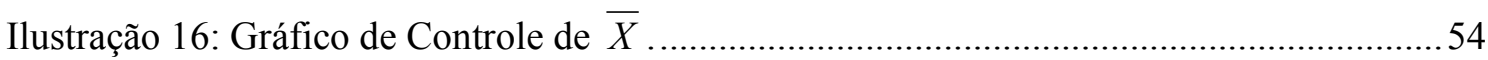

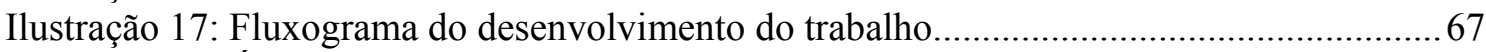

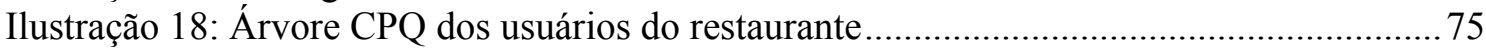

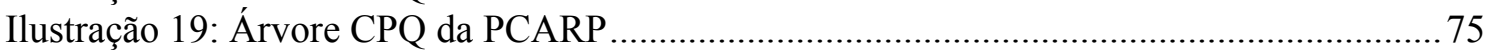

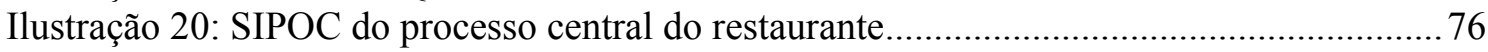

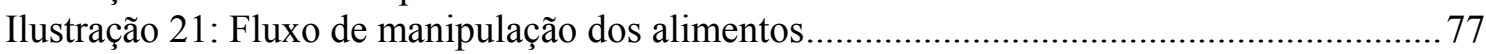

Ilustração 22: Diagrama de Causa e Efeito sobre o desperdício de alimentos ......................... 89

Ilustração 23: Diagrama de Causa e Efeito sobre a qualidade das refeições............................90 


\section{LISTA DE GRÁFICOS}

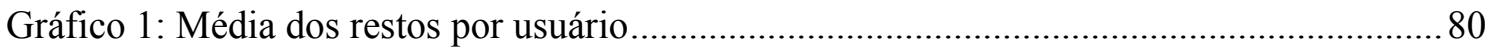

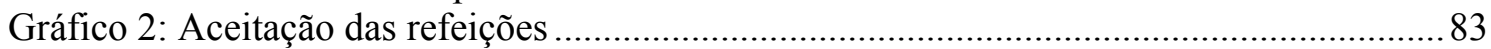

Gráfico 3: Parte da refeição que causou a não aceitação....................................................... 85

Gráfico 4: Motivos da insatisfação com a carne................................................................. 86 


\section{LISTA DE TABELAS}

Tabela 1: Distribuição normal centralizada/descentralizada versus qualidade sigma.............. 11

Tabela 2: Dados sobre os restos dos usuários nos refeitórios I e II......................................... 79

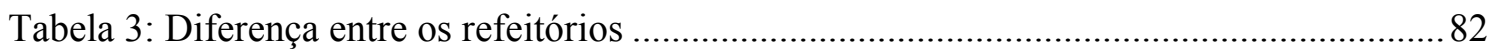

Tabela 4: Resultado da pesquisa sobre a aceitação das refeições em valores absolutos e

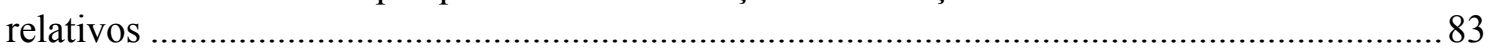

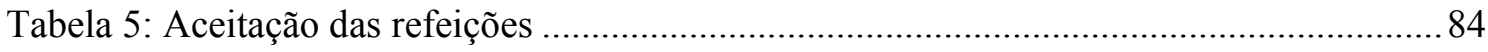




\section{INTRODUÇÃO}

Existem diversas estratégias para a melhoria da qualidade em produtos e serviços. Seis Sigma é uma evolução dessas estratégias, pois inovou a maneira de utilizar diversas ferramentas e conceitos já conhecidos de outros programas de qualidade. Pande et al.(2001) afirmam que a metodologia Seis Sigma é uma adaptação e aprimoramento da gestão da qualidade total. Segundo Rotondaro et al. (2002) as ferramentas e muitos dos métodos aplicados são conhecidos dos profissionais da qualidade, e destaca-se por traduzir os resultados dos projetos para a linguagem financeira, ou seja, torna os ganhos financeiros mais evidentes.

Segundo George (2003), Seis Sigma é uma estratégia gerencial que visa melhorar o resultado operacional das empresas, independente de seu ramo de atuação. $\mathrm{O}$ foco desta estratégia é reduzir a variação percebida pelos clientes, sejam estes internos ou externos. Assim, além dos benefícios financeiros gerados, a metodologia Seis Sigma traz o aumento da satisfação dos empregados com a melhoria nos processos e dos clientes com a melhoria dos produtos e serviços.

Seis Sigma reúne um conjunto de métodos e ferramentas estatísticas para o estudo da variabilidade dos processos. Estas ferramentas estatísticas e outras ferramentas da qualidade são aplicadas em um modelo conhecido pela sigla DMAIC (definir, medir, analisar, melhorar e controlar) que é um método utilizado para a melhoria dos processos. Perez-Wilson (1999), analisando o programa de qualidade Seis Sigma, apresenta sua abordagem do que vem a ser metodologia. Define metodologia como uma maneira ordenada, lógica e sistemática de realizar algo; um conjunto de ferramentas, técnicas, métodos, regras e princípios organizados de forma clara, lógica e sistemática. O método DMAIC define os passos que devem ser seguidos na execução de um projeto Seis Sigma, começando com a identificação do problema e terminando com uma solução de longo prazo. Uma vez identificados e estudados os pontos 
de oportunidade, faz-se o planejamento e a implantação de melhoria, com benefícios significativos para os resultados da organização.

O processo de produção de refeições também pode ser estudado sob esta ótica, isto é, a redução da variabilidade nos processos pode contribuir como uma estratégia para a melhoria da qualidade e redução dos custos.

\subsection{PROBLEMA DE PESQUISA}

O problema de pesquisa pode ser centrado na seguinte questão:

“Quais benefícios podem ser obtidos pela aplicação da filosofia Seis Sigma em um restaurante universitário?”

\subsection{OBJETIVO}

Este projeto de pesquisa pretende, como objetivo geral, aplicar o método DMAIC no diagnóstico e análise de oportunidades de melhoria em um restaurante universitário e avaliar os resultados.

Para isso os objetivos específicos são:

- Estudar e aplicar os procedimentos do método DMAIC no restaurante para realizar o diagnóstico e análise de oportunidades de melhoria;

- Verificar, durante a aplicação do método DMAIC, quais são as ferramentas mais adequadas ao contexto;

- Planejar um projeto de melhoria com foco em um único problema ou oportunidade de melhoria;

- Avaliar os resultados do projeto e identificar os benefícios potenciais que podem ser obtidos;

Considerando o objetivo desse trabalho, faz parte do escopo o diagnóstico, elaboração e planejamento de um projeto de melhoria, seguindo o método DMAIC, porém, a 
implementação das ações que serão sugeridas no projeto de melhoria ficará a critério da gerência do restaurante.

\section{Visão geral da estrutura do trabalho}

A introdução do trabalho apresenta os comentários iniciais, problema de pesquisa e objetivos da pesquisa. A segunda parte, revisão da literatura, apresenta definições e características do programa de qualidade Seis Sigma e do método DMAIC. Apresenta também características das Unidades de Alimentação e Nutrição. A terceira parte do trabalho trata dos procedimentos metodológicos onde é apresentado o contexto metodológico da pesquisa, o delineamento e as etapas do desenvolvimento do trabalho, técnicas de coleta e análise dos dados. O capítulo quatro trata dos resultados da aplicação do método DMAIC no restaurante universitário, apresentando a identificação da oportunidade de melhoria, a análise dos dados, identificação das causas do problema e sugestões de melhoria.

Por fim, o capítulo cinco apresenta as conclusões e limitações da pesquisa.

\begin{tabular}{|c|c|c|}
\hline Capítulo 1 & & Capítulo 4 \\
\hline Introdução & & Resultados \\
\hline $\begin{array}{c}\text { Problema de pesquisa } \\
\text { Objetivos }\end{array}$ & $\begin{array}{l}\text { Capítulo } 3 \\
\text { Procedimento }\end{array}$ & $\begin{array}{l}\text { Identificação da oportunidade } \\
\text { de melhoria }\end{array}$ \\
\hline & Metodológicos & Coleta e análise dos dados \\
\hline Capítulo 2 & $\begin{array}{c}\text { Contextualização da } \\
\text { pesquisa }\end{array}$ & $\begin{array}{l}\text { Análise das causas do } \\
\text { problema }\end{array}$ \\
\hline Revisão da Literatura & Etapas de & Sugestões de melhoria \\
\hline Seis Sigma & pesquisa & \\
\hline DMAIC & Coleta de dados & Capítulo 5 \\
\hline $\begin{array}{c}\text { Ferramentas estatísticas } \\
\text { e da qualidade }\end{array}$ & Analise dos resultados & Conclusões \\
\hline $\begin{array}{c}\text { Unidades de } \\
\text { Alimentação e Nutrição }\end{array}$ & & $\begin{array}{l}\text { Limitações e sugestões para } \\
\text { trabalhos futuros }\end{array}$ \\
\hline
\end{tabular}

Ilustração 1: Estrutura do trabalho 


\section{REVISÃO DA LITERATURA}

Atualmente, a competição por clientes está presente em qualquer tipo de organização. Segundo George (2004), a qualidade é uma das mais importantes armas competitivas. Slack et al. (1996) afirma que cada vez mais as organizações se conscientizam de que bens e serviços de alta qualidade podem trazer considerável vantagem na competição por clientes.

A estratégia Seis Sigma aplicada na produção de bens ou serviços tem estado presente nos últimos anos em programas de qualidade de diversas empresas que estão interessadas em obter ganhos a partir da melhoria de produtos e serviços. Isto porque, segundo Eckes (2001), as empresas estão constantemente em busca de oportunidades para ganhar competitividade utilizando ferramentas já consagradas.

A qualidade mais alta aumenta a lucratividade da empresa, pois as receitas são incrementadas por melhores vendas e preços mais altos, ao mesmo tempo que os custos podem ser reduzidos pela melhor eficiência, produtividade e uso do capital (SLACK et al., 1996).

Hoff (2005) realizou um estudo sobre Seis Sigma aplicado a serviços de alimentação, no qual analisou os resultados da implementação do programa de qualidade Seis Sigma em um restaurante industrial e seus impactos na gestão do negócio por meio da análise de indicadores de desempenho corporativo. Os resultados da pesquisa indicaram ganhos, especialmente em relação à redução dos custos de operação do restaurante, em função da redução ou eliminação do desperdício.

Para que o objetivo geral deste trabalho fosse atingido, foram estudados no referencial teórico as características do programa de qualidade Seis Sigma, o método DMACI e suas ferramentas e por fim as características das Unidades de Alimentação e Nutrição. 


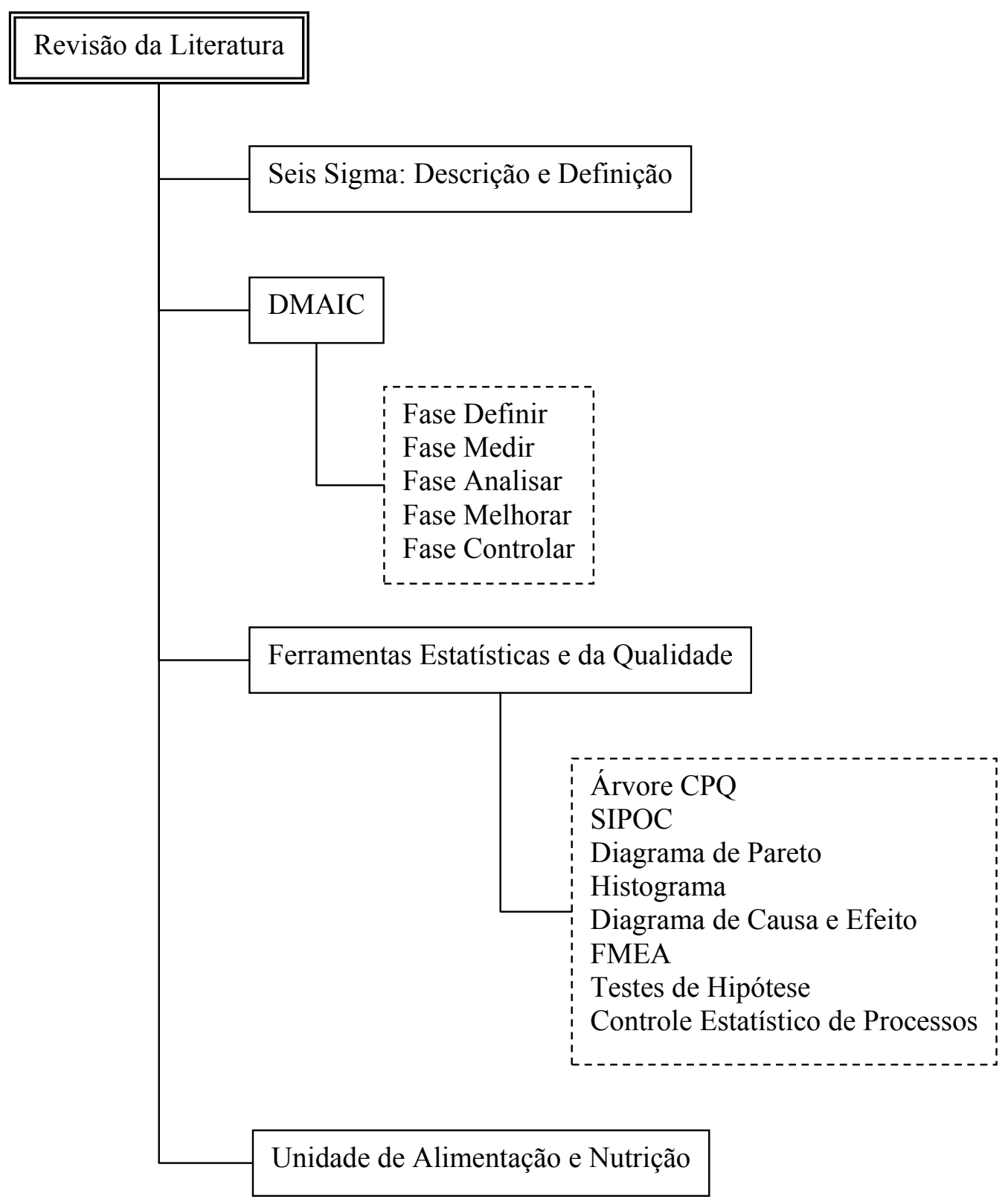

Ilustração 2: Tópicos tratados na Revisão da Literatura

\subsection{SEIS SIGMA: DESCRIÇÃO E DEFINIÇÃO}

O Seis Sigma foi desenvolvido pela empresa norte-americana Motorola visando reduzir os problemas de qualidade e lucratividade da mesma, cuja sobrevivência estava ameaçada pelas suas ineficiências internas. Devido ao sucesso do programa de qualidade Seis Sigma, a Motolora recebeu em 1988 o Prêmio Malcon Baldrigde da Qualidade, fazendo com 
que o Seis Sigma fosse difundido entre as empresas americanas (PANDE et al., 2001). Entretanto, a empresa que se tornou mais evidente na mídia devido à implantação do programa de qualidade Seis Sigma foi a GE (Genaral Eletric), por meio de seu famoso CEO Jack Welch. Em meados de 1990, Jack Welch iniciou a implantação do Seis Sigma na companhia, de modo que os esforços da melhoria da qualidade fossem alinhados com as necessidades do negócio. Os excelentes resultados financeiros divulgados pela GE estimularam outras empresas a adaptar e utilizar esse programa de melhoria da qualidade.

Com esta difusão, Silva (2005) afirma que o Seis Sigma adquiriu um caráter amplo que gerou diversidade no entendimento de sua fundamentação básica. A definição de Seis Sigma passou por uma evolução, indicando a mudança da visão dos estudiosos do assunto que criaram definições para as várias aplicações e adaptações bem sucedidas às idéias iniciais que levaram à concepção do Seis Sigma.

Em uma primeira etapa, a metodologia Seis Sigma era aplicada em processos de manufatura e evoluiu para uma metodologia de melhoria geral do negócio. Agora é utilizada em diversos tipos de indústrias e empresas da área de serviços, desde organizações financeiras a hospitais (GEORGE, 2004).

Segundo Perez-Wilson (1999), Seis Sigma pode ser utilizado sob diversos focos em uma empresa como, por exemplo, um benchmanking, uma meta de qualidade, uma filosofia, uma estatística, uma estratégia ou uma visão.

O programa Seis Sigma tem uma visão mais ampla sobre as atividades de melhoria da qualidade, realizando projetos que tenham impacto sobre os negócios e que estejam alinhados às estratégias de negócio da empresa. A estratégia Seis Sigma é controlar o processo atuando sobre as causas das variações, mantendo o processo estável, com o objetivo de reduzir o número de defeitos nos produtos finais a valores próximos a zero. Mike Harry, um dos criadores do programa de qualidade Seis Sigma, afirma que o programa Seis Sigma é uma 
estratégia que deve permear toda a organização, da manufatura à área de serviços, não ficando restrita apenas a área de qualidade (ROTONDARO et al. 2002).

Seis Sigma é uma filosofia de melhoria contínua do processo e redução da variabilidade visando o zero defeito, sempre buscando a excelência em tudo o que a organização faz (PERES-WILSON, 1999).

Caulcutt (2001) afirma que Seis Sigma é uma metodologia que se baseia em informações para reduzir o desperdício, aumentar a satisfação dos clientes e melhorar os processos, com foco em resultados financeiros. Segundo o mesmo autor, Harry \& Schoeder definem Seis Sigma no livro "Six Sigma Breakthrough Strategy" como uma metodologia disciplinada de coleta de dados e análise estatística para determinar com exatidão os erros e as formas de eliminá-los.

Segundo a Motorola, em seu site corporativo, Seis sigma é em essência uma métrica, uma metodologia e um sistema de gerenciamento. Como uma métrica, Seis Sigma mede o nível de qualidade e representa 3,4 defeitos por milhão de oportunidades (DPMO). Como uma metodologia de melhoria do negócio, foca em conhecer as exigências dos clientes alinhandoas com os processos chave dos negócios; realiza rigorosa análise de dados para minimizar a variação dos processos e leva a uma melhoria rápida e sustentável do negócio. Como um sistema de gerenciamento, alinha os esforços de melhoria com a estratégia de negócios da empresa, mobiliza equipes para trabalharem projetos de alto impacto, acelera resultados e garante melhorias sustentáveis no longo prazo.

Silva (2005) analisou diversos trabalhos publicados desde a década de 1990 e somando a experiência prática de algumas organizações, propôs a seguinte definição:

"Seis Sigma é uma abordagem que impulsiona a melhoria do desempenho do negócio e a valorização da satisfação dos clientes, por meio de um enfoque estratégico de 
gerenciamento; da aplicação do pensamento estatístico em todos os níveis de atividades; do uso de indicadores de desempenho; da utilização de uma metodologia sistematizada que integre técnicas variadas para se avaliar e otimizar processos; e da aprendizagem decorrente da capacitação e comprometimento das pessoas.” (p.26)

Seis Sigma é uma estratégia gerencial disciplinada e quantitativa, que fornece uma metodologia estruturada e incrementa a qualidade por meio da melhoria contínua dos processos envolvidos na produção de bens ou serviços, tendo como objetivo o aumento da lucratividade e a satisfação dos clientes e dos consumidores. Como um programa de melhoria contínua da qualidade, Seis Sigma não é revolucionário, pois se utiliza de conceitos já desenvolvidos e utilizados em outras técnicas, por exemplo, a redução da variação do processo já era defendido há muitos anos por Demming e Taguchi e o foco no processo e nos clientes faz parte do TQM (Total Quality Management), mas mostra-se inovador na medida em que integra diferentes ferramentas de forma estruturada, com foco em resultados financeiros.

Eckes (2001) afirma que, de forma simplificada, o conceito de Seis Sigma é medir quantos sigmas existem a partir da média corrente até que ocorra um defeito, ou seja, a insatisfação do cliente. Quanto maior o número de sigmas dentro das especificações, melhor o nível de qualidade. Rotondaro et al. (2002) coloca o Seis Sigma como uma medida para o nível de qualidade. Um nível de qualidade Seis Sigma apresenta apenas 3,4 falhas por milhão ou 99,99966\% de perfeição. Segundo Perez-Wilson (1998), a principal meta do Seis Sigma é eliminar defeitos ou erros e reduzir o valor do sigma até que \pm 6 sigmas fiquem dentro dos limites de especificação. 
O termo sigma mede a capacidade do processo em trabalhar livre de falhas ou defeitos (ROTONDARO, 2002). Werkema (1995), afirma que os defeitos são resultados da variabilidade que está presente em todos os processos de produção de bens ou fornecimento de serviços. Um defeito ocorre quando um produto ou serviço não atendem a uma determinada especificação das características da qualidade. Mesmo os produtos nãodefeituosos não são exatamente idênticos, pois apresentam variações dentro dos limites de sua especificação. Assim, em um programa de melhoria de qualidade, as técnicas e ferramentas estatísticas são importantes, pois descrevem e interpretam a variabilidade. Segundo Pande et al. (2001) e Rotondaro et al. (2002), Seis Sigma alcança a melhoria de processos por meio da redução da variabilidade dos resultados esperados do processo.

O sigma mede a variabilidade ou não-uniformidade existente em um processo, resposta ou característica. Assim, se o valor do sigma é baixo, significa que há pouca variabilidade no produto, ou seja, quanto menor o valor do sigma, melhor a característica do produto ou processo (PEREZ-WILSON, 1999).

Segundo Stevenson (1981), a letra o, sigma, do alfabeto grego é o símbolo usado na linguagem estatística para representar o desvio padrão de uma população, que é uma medida da dispersão dos dados em relação à média aritmética. Em distribuições normais, a área sob a curva entre a média e um ponto arbitrário é função do número de desvios padrões entre a média e aquele ponto, permitindo calcular probabilidades. Se uma variável tem distribuição normal, cerca de $68,26 \%$ de seus valores encontram-se no intervalo de $\pm 1 \sigma$ (um desvio padrão a contar de cada lado da média); cerca de $95,46 \%$ no intervalo de $\pm 2 \sigma$, e cerca de $99,73 \%$ dentro de $\pm 3 \sigma$ conforme a Ilustração 3 . 


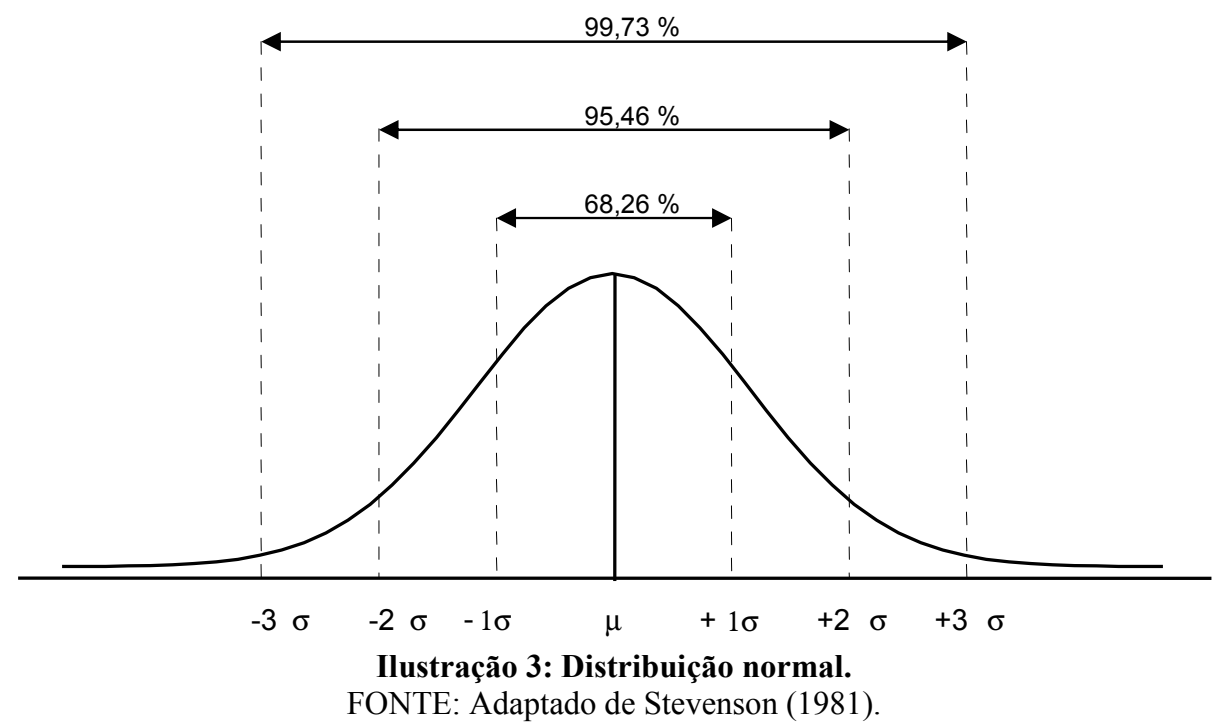

O sigma, ou desvio padrão, é calculado pela seguinte fórmula:

$$
S=\sqrt{\frac{\sum_{i=1}^{n}\left(x_{i}-\bar{x}\right)^{2}}{n-1}} \text {, onde } x_{i} \text { é o valor do iésimo elemento da amostra, } \bar{x} \text { é a média }
$$

aritmética da amostra e $n$ é o número total de elementos da amostra.

Utilizando-se especificações equivalentes a $\pm 3 \sigma$, tem-se uma conformidade de aproximadamente 99,73\% dos processos ou produtos. Quando são utilizadas especificações equivalentes a $\pm 6 \sigma$ o resultado é perto de zero defeito. Baseado na distribuição normal, um processo equivalente a $\pm 6 \sigma$ apresenta $99,9999998 \%$ de conformidade, apenas 0,002 falhas por milhão ou cerca de 2 falhas por bilhão. Entretanto, é comum se encontrar na literatura o Seis Sigma associado a uma taxa de 3,4 defeitos por milhão de oportunidade (DPMO) e a 3,4 ppm (partes por milhão). Segundo Rotondaro et al. (2002), um processo Seis Sigma significa a redução da variação numa taxa de 3,4 falhas por milhão ou 99,99966\% de perfeição. Eckes (2001) e George (2004) afirmam que um processo com capacidade Seis Sigma não gera mais que 3,4 defeitos por milhão de oportunidades.

Perez-Wilson (1999) explica que esta divergência ocorre porque a Motorola afirma em um de seus documentos que um processo Seis Sigma apresenta no máximo 3,4 falhas por 
milhão. Um processo Seis Sigma seria robusto mesmo que o processo sofresse uma variação significativa de 1,5 sigma em torno da média. Os clientes não perceberiam a diminuição na qualidade que, na pior das hipóteses, passaria de zero defeito (0.002 ppm) para 3,4 defeitos a cada milhão. Assim, um processo Seis Sigma considera que pode haver uma oscilação em torno da média de até 1,5 sigma, ficando próximo de $\pm 4,5 \sigma$ no longo prazo. A Ilustração 4 representa um processo Seis Sigma com deslocamento da média do processo e a Tabela 1 apresenta a correspondência entre o nível sigma de qualidade e a correspondente taxa de defeitos (DPMO). O limite inferior de especificação (LIE) e o limite superior de especificação (LSE) representam os limites de especificação do projeto. Quando esses limites são excedidos, significa que o produto falhou nas exigências do seu projeto.

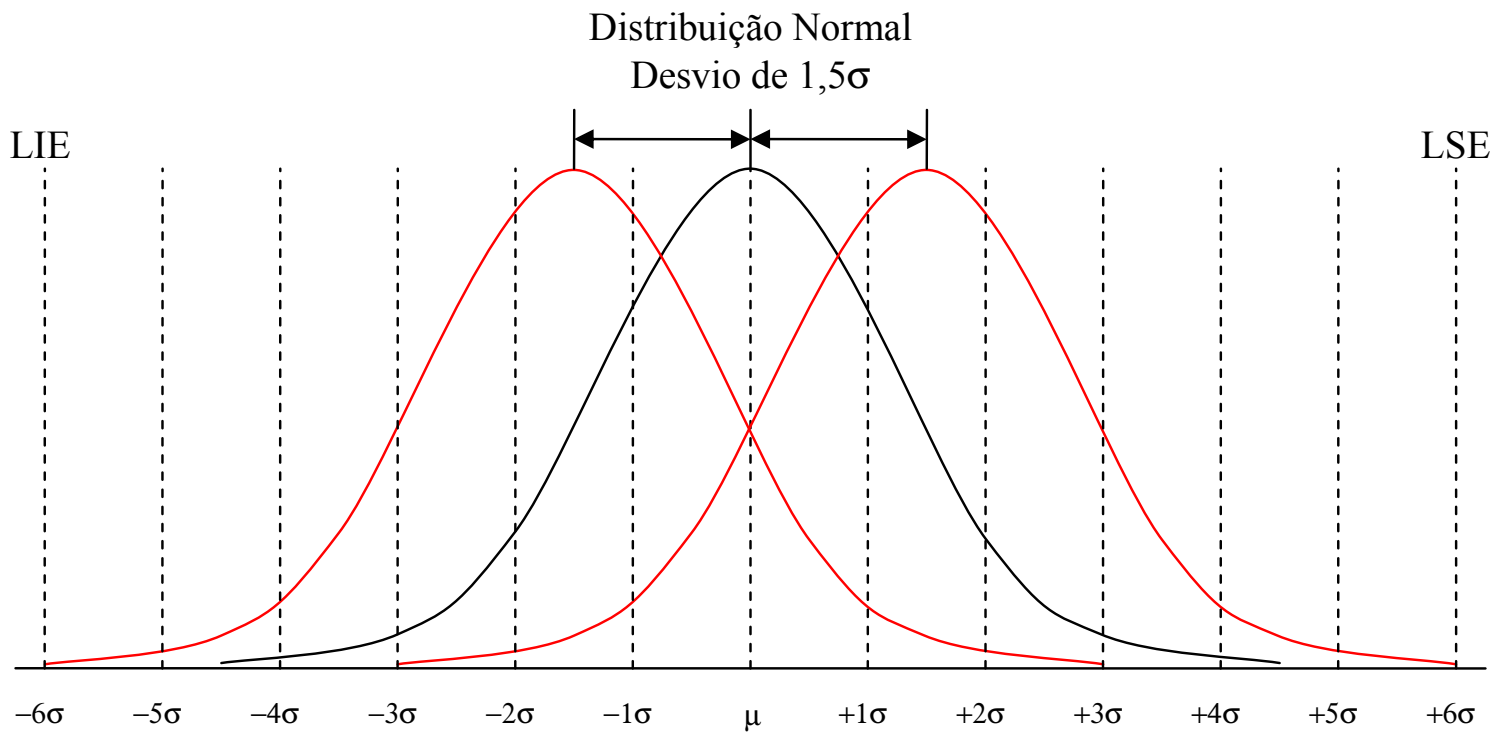

Ilustração 4: Representação do deslocamento de 1,5 $\sigma$ da média do processo.

Tabela 1: Distribuição normal centralizada/descentralizada versus qualidade sigma.

\begin{tabular}{|c|c|c|c|c|c|}
\hline \multicolumn{2}{|c|}{ Distribuição Normal Centralizada } & \multicolumn{2}{c|}{ Distribuição Normal Descentralizada } \\
\hline Processo & Conformidade (\%) & DPMO & Processo & Conformidade (\%) & DPMO \\
\hline $1 \sigma$ & 68,26 & 317.300 & $1 \sigma$ & 30,23 & 697.700 \\
\hline $2 \sigma$ & 95,46 & 45.500 & $2 \sigma$ & 69,14 & 308.538 \\
\hline $3 \sigma$ & 99,73 & 2.700 & $3 \sigma$ & 93,32 & 66.807 \\
\hline $4 \sigma$ & 99,9937 & 63 & $4 \sigma$ & 99,379 & 6.210 \\
\hline $5 \sigma$ & 99,999943 & 0,57 & $5 \sigma$ & 99,9767 & 233 \\
\hline $6 \sigma$ & 99,9999998 & 0,002 & $6 \sigma$ & 99,99966 & 3,4 \\
\hline
\end{tabular}

FONTE: Adaptado de Perez-Wilson (1999). 
A parte esquerda da Tabela 1 (Distribuição Normal Centralizada) apresentada o número de sigma do processo, o percentual de conformidade à especificação e o número de defeitos/falhas/erros baseados na distribuição normal. Na parte da direita (Distribuição Normal Descentralizada) são apresentados os valores correspondentes na visão da metodologia Seis Sigma que considera o deslocamento da média no longo prazo. Assim, pode-se observar que um processo Seis Sigma apresenta apenas 0,002 DPMO, se centralizado, e 3,4 DPMO considerando o deslocamento da média em 1,5 sigma.

A utilização da métrica sigma permite a padronização de diferentes características de desempenho, possibilitando classificar e comparar processos, procedimentos e equipamentos distintos.

Linhas básicas do Seis Sigma: Medidas e coeficientes utilizados para estabelecer a linha base em relação a qual uma organização pode comparar seu desempenho em relação à meta do Seis Sigma. No caso dos dados serem atributos, utiliza-se o DPMO e no caso dos dados serem variáveis, utiliza-se o coeficiente de capacidade do processo.

\section{- DPMO e ppm}

Seis Sigma é associado a 3,4 ppm e a 3,4 DPMO como foi visto na definição de Seis Sigma. É interessante destacar que ppm e DPMO têm significados distintos, o que é explicado por Perez-Wilson (1999).

Na linguagem Seis Sigma fala-se em defeitos por milhão, erros por milhão, falhas por milhão, sendo que a medida ppm se refere ao número de produtos defeituosos por milhão, ou seja, o ppm estima quantos produtos serão defeituosos se um milhão de produtos forem produzidos.

A medida DPMO permite comparar o desempenho de diversas operações pelos seus defeitos considerando também a complexidade. Uma operação é mais complexa quando apresenta mais oportunidades de defeito por unidade. Segundo Rotondaro et al. (2002) as 
oportunidades de defeito são as formas que o processo tem de não atender as especificações em cada unidade. DPMO mede o total de defeitos em um milhão de unidades dividido pelo total de oportunidades de defeitos.

$$
D P M O=\frac{d p m}{N T O D}
$$

Dpm (defeitos por milhão) é o nível de desempenho do processo ou operação. É calculado multiplicando-se os defeitos por unidade por um milhão $(\mathrm{dpm}=\mathrm{dpu} \times 1.000 .000)$. NTOD é o número total de oportunidades de defeito em uma unidade.

Perez-Wilson (1999) e Eckes (2001) fornecem tabelas que permitem converter as medidas ppm e DPMO em níveis de performance sigma.

Um produto é considerado defeituoso quando não atende as especificações. Assim, para um produto ser considerado defeituoso basta que ele apresente apenas um defeito. Defeito é uma única não-conformidade de determinada exigência ou especificação do produto. Segundo George (2004), defeito em serviços pode ser qualquer coisa que deixe o cliente insatisfeito com o resultado.

\section{- Coeficiente de capacidade do processo}

O coeficiente de capacidade do processo ( $\mathrm{Cpk}$ ) mede a habilidade que um processo possui para produzir produtos que estejam dentro dos limites de especificação, levando em conta a tendência central dos dados. O Cpk é a diferença entre a média do processo e o limite de especificação mais próximo, dividido por três vezes o desvio padrão (PEREZ-WILSON, 1999).

$$
C p k=\left(\frac{L S E-\mu}{3 \sigma}\right) \text { ou } C p k=\left(\frac{\mu-L I E}{3 \sigma}\right)
$$

Segundo Perez-Wilson (1999), quanto maior o valor do Cpk, mais uniforme é o processo, pois o Cpk é inversamente proporcional ao desvio padrão. O Cpk varia entre 0 e 2, 
sendo considerando incapaz um processo que tenha $\mathrm{Cpk}$ inferior a 1 ou capaz o processo que tenha o Cpk maior ou igual a 1.

O índice de capacidade sigma é determinado pela diferença entre a média e o limite de especificação, dividido pelo desvio padrão, calculando assim a quantidade de desvios padrão que existe entre a média e o limite de especificação (ROTONDARO et al., 2002).

$$
z=\frac{x-\mu}{\sigma} \searrow_{z_{S}=\frac{L S E-\mu}{z_{I}=\frac{L I E-\mu}{\sigma}}}^{\sigma}
$$

O coeficiente de potencial do processo $(\mathrm{Cp})$ mede a capacidade potencial de um processo, com base na suposição de que esteja centrado, não leva em conta a tendência central dos dados. Segundo Slack et al, (1996), o Cp é a medida da aceitabilidade da variação do processo, calculado pela razão entre a dispersão permitida e a dispersão real. A dispersão permitida é o intervalo entre os limites de especificação e a dispersão real é igual a 6 vezes o desvio padrão.

$$
C p=\frac{L S E-L I E}{6 \sigma}
$$

Um processo é considerado incapaz quando o $\mathrm{Cp}$ é inferior a 1 e capaz quando maior ou igual a 1. Porém um $\mathrm{Cp}$ alto não garante que o processo esteja dentro dos limites de especificação, pois supõe que o processo esteja centralizado. A dispersão real pode não coincidir com os limites de especificação. 


\section{Precisão das medidas}

Segundo Rotondaro et al. (2001), um sistema de medição tem por finalidade fornecer dados precisos e exatos sobre as características de algo que esteja sendo observado. A idéia de precisão e exatidão pode ser compreendida por meio da Ilustração 5.

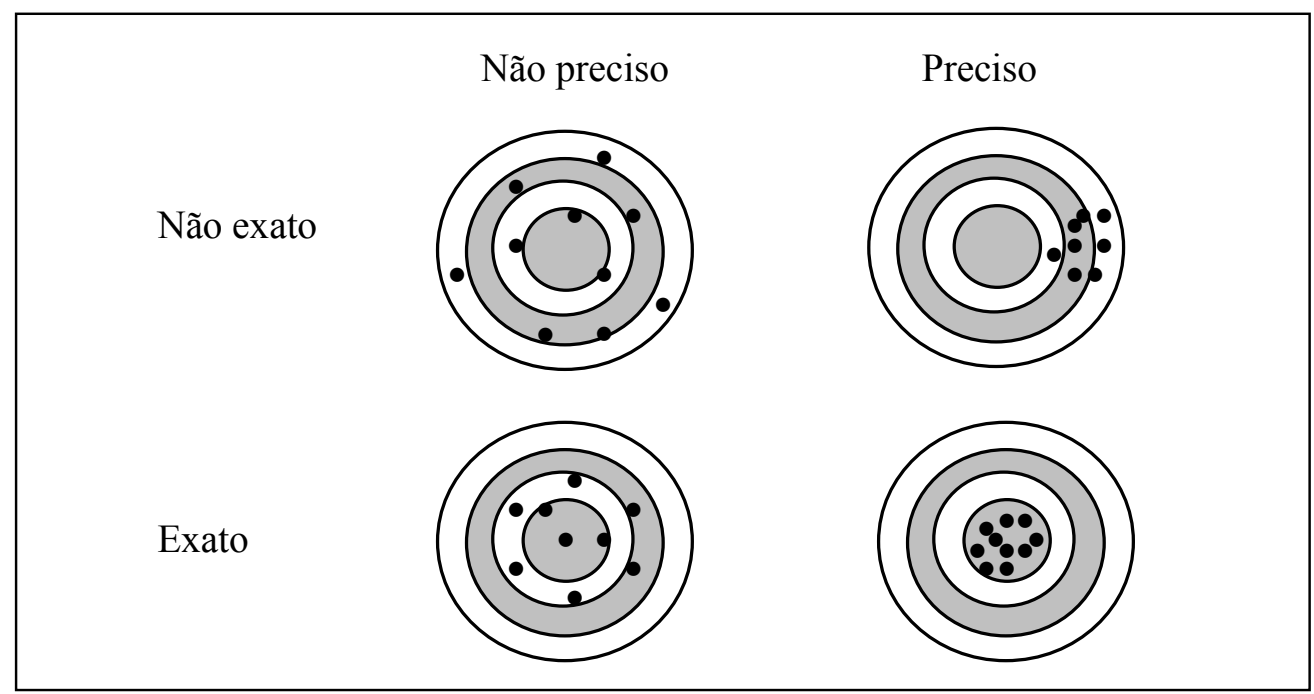

Ilustração 5: Análise gráfica de exatidão e precisão FONTE: Rotondaro et al. (2001), p. 99

Uma das maneiras de verificar a precisão das medidas envolve a repetição de uma medição, por pessoas diferentes e em vários ambientes, para verificar se atendem a quatro critérios: precisão, repetitibilidade, reprodutibilidade e estabilidade (PANDE et al.,2001).

A precisão está ligada ao tipo de escala ou quantidade de detalhes da definição operacional. A repetitibilidade observa se o mesmo resultado será obtido toda vez que uma pessoa ou equipamento de medição medir ou observar o mesmo item mais de uma vez. A reprodutibilidade observa se um mesmo resultado será obtido quando duas ou mais pessoas ou máquinas medirem a mesma coisa e a estabilidade verifica se ao longo do tempo a precisão ou a repetitibilidade mudarão. 


\subsubsection{A EQUIPE SEIS SIGMA}

Eckes (2001), Rotondaro et al. (2002) e George (2004), detalham as características e as funções dos principais profissionais envolvidos no Seis Sigma. Segundo Rotondaro et al. (2002), a equipe Seis Sigma deve ser formada por um núcleo base, de composição fixa, que serão as pessoas responsáveis pelo planejamento e execução do projeto. Além do núcleo base, a equipe necessita de especialistas e de membros temporários, que farão parte da equipe somente em determinadas fases. A nomenclatura dada aos especialistas da equipe Seis Sigma é baseada na graduação utilizada nas artes marciais, pois assim como neste tipo de arte, as diferentes graduações indicam o nível de habilidade que se espera de cada especialista. As hierarquias e atribuições são:

- Executivo líder

A alta gerência é responsável pela implantação bem sucedida do Seis Sigma na organização. Conduz, incentiva e supervisiona as iniciativas Seis Sigma em toda a empresa e verifica se os objetivos financeiros conseguidos por meio dos projetos Seis Sigma estão sendo atingidos. O executivo líder seleciona os executivos que assumirão o papel de campeões.

\section{- Campeões (Champions)}

O Campeão da equipe, ou Patrocinador, é em geral o dono do processo a ser melhorado, seleciona os membros que formarão as equipes, fornece a orientação estratégica e toma as principais decisões na equipe em relação às soluções que serão encontradas (ECKES, 2001).

Segundo Rotondaro (2002), é uma posição ocupada por diretores e gerentes, nomeados pelo Executivo líder. É uma função característica de empresas grandes com várias divisões. O Campeão compreende as teorias, princípios e práticas do Seis Sigma para facilitar a execução dos projetos de melhoria. É dele a responsabilidade de organizar 
e guiar o início, o desdobramento e a implementação do programa Seis Sigma por toda a organização e criar um ambiente propício para as mudanças necessárias.

- Master black belt

Esta também é uma função típica de uma empresa de grande porte. O Master black belt recebe um treinamento intensivo em todas as técnicas e ferramentas que compõe o Seis Sigma. Dedica-se exclusivamente a dar suporte às equipes, está preparado para solucionar problemas estatísticos e fornece a liderança técnica. É o responsável pela criação de mudanças e consolidação da cultura Seis Sigma dentro da organização.

- Black Belts

Trabalham sob as ordens dos Master Black Belts e orientam os Green Belts na condução dos grupos de trabalho. Devem ter conhecimento técnico em sua área de trabalho, ser influentes no setor em que trabalham e ter habilidade para trabalhar em equipe.

Segundo Caulcutt (2001). os Black Belts recebem treinamento em técnicas estatísticas, solução de problemas, habilidades liderança e gerenciamento de projetos.

\section{- Green Belts}

Posição ocupada geralmente pela média gerência da organização. Os Green Belts recebem treinamento em técnicas estatísticas e de solução de problemas, porém de forma menos intensa do que os Black Belts. Sua função é auxiliar os Black Belts na coleta de dados, no desenvolvimento de experimentos e liderar pequenos projetos de melhoria em suas respectivas áreas de atuação. As tarefas ligadas ao programa Seis Sigma são apenas parte de suas atribuições dentro da organização. 


\subsection{DMAIC}

Eckes (2001) afirma que o DMAIC é uma metodologia do processo de melhoria que absorve os processos já existentes. Segundo Rotondaro et al. (2002), o método DMAIC está centrado na identificação dos problemas para a seleção dos projetos a serem executados, na coleta de dados que levem a conhecer o desempenho do processo, na análise dos dados para conhecer as causas dos problemas, na formulação de ações de melhoria e na consolidação e manutenção das melhorias. Além disso, dá grande ênfase ao resultado financeiro obtido.

O método DMAIC está apoiado no uso de técnicas estatísticas e ferramentas de gestão de qualidade que são utilizadas seguindo um método disciplinado dividido em cinco fases: Definir, Medir, Analisar, Melhorar (Improve) e Controlar.

D - Define - Definição dos objetivos da atividade de melhoria. Identificação do problema, suas relações e os envolvidos. É a parte do projeto onde o grupo tem que definir o motivo pelo qual o projeto será levado adiante;

M - Measure - Medição do processo existente. Desdobramento do problema. Servirá para dar a visão de como está o processo e indicar pontos de oportunidade de melhoria;

A - Analyse - Análise do processo medido. Identificação e priorização dos fatores que possuem influência direta no problema;

I - Improve - Melhoria do processo. Estabelecimento e execução do plano de ação. Diversas ferramentas são utilizadas nessa fase com a finalidade de atacar os pontos de oportunidade de melhoria detectados e assim, tornar o processo mais eficiente;

C - Control - Controle do novo processo para garantia da meta no longo prazo.

O modelo DMAIC concentra uma série de ferramentas para sistematizar a definição, a medição, a análise, a identificação e a implementação de melhorias nos processos onde a variabilidade esteja presente gerando a ocorrência de defeitos no produto ou serviço recebido pelo cliente, aqui se considerando tanto o cliente final como o cliente interno do processo. 


\begin{tabular}{|c|c|c|c|}
\hline FASES & OBJETIVO & ATIVIDADES & FERRAMENTAS \\
\hline 关 & $\begin{array}{l}\text { Definir o objetivo da } \\
\text { atividade de melhoria, } \\
\text { identificando o problema, } \\
\text { suas relações e os } \\
\text { envolvidos. }\end{array}$ & $\begin{array}{l}\text { - Identificar processos centrais } \\
\text { de negócios } \\
\text { - Definir saídas de processo e } \\
\text { clientes-chave } \\
\text { - Definir necessidades do } \\
\text { cliente } \\
\text { - Definir escopo do projeto } \\
\text { - Criar mapas de processo } \\
\text { centrais de alto nível }\end{array}$ & $\begin{array}{l}\text { - } \quad \text { SIPOC } \\
\text { - } \quad \text { Voz do Cliente }\end{array}$ \\
\hline 똘 & $\begin{array}{l}\text { Coletar dados sobre o } \\
\text { processo. }\end{array}$ & $\begin{array}{l}\text { Planejar e executar medições } \\
\text { de desempenho relativamente } \\
\text { a requisitos do cliente } \\
\text { - Obter medidas de base de } \\
\text { defeitos e identificar } \\
\text { oportunidades de melhoria }\end{array}$ & $\begin{array}{ll}\text { - } & \text { Formulário de } \\
\text { Coleta de Dados }\end{array}$ \\
\hline 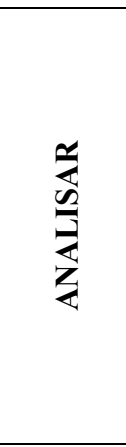 & $\begin{array}{l}\text { Conversão dos dados em } \\
\text { informações que } \\
\text { indiquem soluções. } \\
\text { Identificar e priorizar as } \\
\text { causas-raiz do problema. }\end{array}$ & $\begin{array}{ll}\text { - } & \text { Analisar os dados e o } \\
& \text { processo } \\
\text { - } & \text { Desenvolver hipóteses sobre } \\
& \text { causas do problema } \\
\text { - } & \text { Encontrar soluções } \\
& \text { focalizadas em causas-raiz }\end{array}$ & $\begin{array}{ll}\text { - } & \text { FMEA } \\
\text { - } & \text { Teste de hipótese } \\
\text { - } & \text { Análise de } \\
& \text { variância } \\
\text { - } & \text { Histograma } \\
\text { - } & \text { Diagrama de } \\
& \text { Pareto } \\
\text { - } & \text { Diagrama de Causa } \\
& \text { e Efeito } \\
\text { - } & \text { Mapa de processo } \\
\end{array}$ \\
\hline 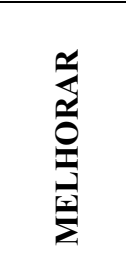 & $\begin{array}{l}\text { Executar ações que } \\
\text { melhorem o processo. }\end{array}$ & $\begin{array}{ll}\text { - } & \text { Testar e avaliar soluções } \\
\text { - } & \text { Implementar soluções } \\
\text { - } & \text { Padronizar } \\
\text { - } & \text { Medir resultados }\end{array}$ & $\begin{array}{ll}\text { - } & \text { Delineamento de } \\
\text { experimentos } \\
\text { (DOE) } \\
\text { - } & \text { Planos de ação } \\
\text { - } & \text { Brainstorming }\end{array}$ \\
\hline 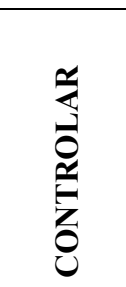 & $\begin{array}{l}\text { Planejar e executar ações } \\
\text { que mantenham a } \\
\text { melhoria a longo prazo. }\end{array}$ & $\begin{array}{l}\text { Implementar medidas em } \\
\text { andamento e ações para } \\
\text { manter a melhoria } \\
\text { Definir responsabilidades } \\
\text { para a propriedade e o } \\
\text { gerenciamento de processo }\end{array}$ & $\begin{array}{ll}\text { - } & \text { Controle } \\
\text { Estatístico do } \\
\text { Processo } \\
\text { - } \\
\text { Gráficos de } \\
\text { controle }\end{array}$ \\
\hline
\end{tabular}

Quadro 1: Resumo do método DMAIC

Entre as fases de medição e análise a ênfase maior se dá nas ferramentas e atividade para caracterização dos processos e, entre as fases de melhoria e controle, priorizam-se as ferramentas e atividades para otimização dos processos. 


\subsubsection{FASE DEFINIR}

Rotondaro et. al (2002) afirma que nessa primeira etapa é definido o objetivo do projeto de melhoria. Deve-se definir qual é o problema, ou efeito indesejável de um processo, que deve ser eliminado ou melhorado pelo projeto, sendo fundamental que esteja relacionado aos requisitos dos clientes e que o projeto seja economicamente vantajoso.

Nesta fase, são determinados o escopo do projeto, identificado(s) o(s) cliente(s) do projeto, definidas quais são suas necessidades e exigências, as características críticas para a qualidade (Critical to Quality - CTQ) e identificados os processos críticos, relacionados aos CTQs do cliente, que estejam gerando resultados ruins (ECKES, 2001; ROTONTADO et al., 2002).

O escopo do projeto determina os limites onde a equipe estará trabalhando e também com o que a equipe não estará trabalhando e deve ser evitado, ou seja, determina o que faz e o que não faz parte do projeto. Além disso, para que o projeto seja gerenciável, o escopo do projeto deve determinar quais são os recursos disponíveis e o tempo necessário para concluir o projeto com sucesso, as áreas envolvidas no processo e as partes interessadas. (ECKES, 2001 e ROTONDARO et al. , 2002)

O cliente, segundo Eckes (2001), é o destinatário do produto ou serviço, podendo ser interno ou externo. O cliente pode ser segmentado em cliente primário, secundário e até terciário, sendo que o cliente primário é o maior interessado no resultado e é a principal consideração no processo. A segmentação dos clientes é importante, pois podem existir diversos clientes em um processo, com necessidades e expectativas que podem ser diferentes. A segmentação permite à equipe decidir quais clientes devem ter tratamento prioritário no caso de conflito de interesses.

Segundo Rotondaro et al. (2002), para se definir o que é crítico para a qualidade (Critical to Quality - CTQ), deve-se definir o que é crítico para o mercado e quais são os 
processos críticos. Procurar o que é crítico para a qualidade é importante para assegurar que os recursos estão sendo bem alocados. As necessidades e expectativas dos clientes podem ser definidas pela Árvore do que é Crítico para a Qualidade (CPQ).

O método DMAIC utiliza medidas financeiras para selecionar os projetos de melhoria. A medida dos custos da qualidade é um indicador dos ganhos que serão conseguidos e permite avaliar se é economicamente vantajoso investir na melhoria de certo processo. Os dados do custo da qualidade são úteis para selecionar o que é importante em relação à satisfação do cliente (ROTONDARO et al., 2002).

A boa qualidade reduz custos de retrabalho, refugo e devoluções e, mais importante, a boa qualidade gera consumidores satisfeitos.

Segundo Rotondaro et al. (2002), os custos da qualidade podem ser classificados da seguinte forma:

- Custos de prevenção: atividades de planejamento, controle do processo e treinamento. São os custos associados às atividades que visam garantir que um processo forneça produtos ou serviços com qualidade.

- Custos de avaliação: atividades de inspeção, testes e auditorias da qualidade. São os custos associados à medição dos níveis de qualidade.

- Custo de falhas internas: custos com retrabalho, reteste, erros ou defeitos nos produtos detectados ainda no interior da empresa. São os custos da correção de um produto ou serviço antes que chegue ao cliente.

- Custos de falhas externas: erros ou defeitos detectados por meio da reclamação dos clientes, gerando custos com garantia, trocas, perda de clientes e de vendas.

A Carta do Projeto (Projetc Chart) é uma ferramenta comumente sugerida nesta fase. É uma espécie de contrato entre a equipe responsável pelo projeto e a gerência da empresa, que permite definir o contexto do projeto, aspectos específicos e planos de melhoria, papéis e 
responsáveis, características do problema e metas, restrições e suposições, plano preliminar e escopo do projeto (PANDE, 2001).

Segundo Eckes (2001), um mapa de processo para o projeto em questão deve ser criado utilizando o diagrama SIPOC. É uma ferramenta que permite visualizar o processo, demonstrando os fornecedores, as entradas, saídas e os clientes do processo.

\subsubsection{FASE MEDIR}

Segundo Robins (apud MACEDO et al., 2007) os gerentes deveriam usar um processo racional de tomada de decisão, porém a capacidade humana para formular e resolver problemas complexos é limitada. Dessa forma, os responsáveis pelas tomadas de decisões operam dentro da "racionalidade limitada", construindo modelos simplificados que captam as características essenciais dos problemas sem considerar toda sua complexidade. As heurísticas, ferramentas cognitivas usadas para simplificar a tomada de decisão, tendem a produzir desvios sistemáticos de julgamento que trazem, quase que inevitavelmente, vieses para o processo de tomada de decisão. Se o tomador de decisão controlar a utilização de vieses, existe uma grande melhoria da qualidade de suas decisões.

O diferencial do programa de qualidade Seis Sigma em relação a outros programas de melhoria da qualidade é a ênfase na tomada de decisões baseadas em dados (ECKES, 2001).

Segundo Eckes (2001), melhorar a eficiência e a eficácia da organização é a meta de um programa de qualidade. Na fase de medição são identificadas as medidas de eficiência e de eficácia, traduzindo-as para o conceito do sigma. A eficiência diz respeito ao tempo, custo ou valor das atividades que levam à satisfação do cliente. A eficácia diz respeito a atingir ou superar as expectativas e necessidades dos clientes.

Pande et al. (2001) relaciona essas medidas pelo foco de quem recebe o beneficio do processo, a organização ou o cliente. Medidas de eficiência estão relacionadas à organização e 
acompanham o volume de recursos consumidos na produção de produtos ou serviços. Processos mais eficientes consomem menos recursos. As medidas de eficácia estão relacionadas ao cliente, medindo se foram atendidas suas necessidades e exigências.

Nesta fase são planejadas e executadas medições de desempenho relativas aos requisitos dos clientes (PANDE, 2001). Segundo Eckes (2001), o Plano de Coleta de Dados é a ferramenta mais importante para que a fase de medição seja eficaz. O Plano de Coleta de dados define "quem", “o que", "onde", "quando" e "como" medir.

Eckes (2001) detalha a elaboração do Plano de Coleta de dados:

O que medir: questões que os dados deverão responder, principalmente as que dizem respeito ao cliente, suas necessidades e expectativas.

Tipo de dado: os dados numéricos, chamados de dados quantitativos, são classificados como dados contínuos ou dados discretos. Os dados não-numéricos, chamados de dados qualitativos ou atributos, são classificados como dados nominais ou dados por postos.

Dados contínuos são dados numéricos que podem assumir qualquer valor em um intervalo contínuo de valores. Dados relativos a peso, velocidade e temperatura, por exemplo, são dados contínuos. Os dados que assumem valores inteiros são chamados de dados discretos, por exemplo, os dados resultantes da contagem de itens. Quando se define categorias tais como binárias (sim/não, ligado/desligado), desempenho (bom, regular, ruim), cores, etc, e conta-se o número de observações pertencentes a cada categoria, surgem os dados nominais. Os dados por postos referem-se a avaliações atribuídas para denotar ordem, dispondo os itens segundo preferência ou desempenho (STEVENSON, 1981).

Definição operacional: Descrição do que será medido para que não haja ambigüidades sobre aquilo que está sendo definido, ou seja, todos os envolvidos têm o mesmo entendimento do que será medido. Segundo Pande et al. (2001) é uma definição clara, 
compreensível e não ambígua daquilo que será medido ou observado, para que todos possam medir consistentemente com base na definição.

Por exemplo, se o CTQ for o tempo de um processo, é definido qual é o ponto de início e final do processo para que qualquer um que colete os dados saiba exatamente quando começar a contar o tempo e quando parar.

Formulário de coleta de dados: $\mathrm{O}$ tipo de dado (qualitativo ou quantitativo) define o formulário de coleta de dados que cria uma tabela de distribuição de freqüência.

Para dados qualitativos, o formulário categoriza os dados coletados pelo tipo de defeito apresentado. O formulário define qual é o defeito, as categorias para o defeito, o período de tempo que os dados serão coletados e cria uma tabela para a coleta dos dados. Essa tabela conta o número de defeitos por categoria, para que se possa criar um Diagrama de Pareto.

Para dados quantitativos cria-se uma tabela de distribuição de freqüência. Segundo Stevenson (1981), numa distribuição de freqüência os dados são agrupados em classes, ou intervalos, de forma que se possa determinar o número ou porcentagem de observações em cada classe. Uma distribuição de freqüência pode ser apresentada de forma tabular ou gráfica (histograma).

Amostragem: Amostra é uma parcela de um conjunto, chamado população ou universo, que será estudado. A amostragem é o processo de coletar apenas uma parte proporcional dos dados da população assegurando que a amostra seja aleatória e representativa da população (ECKES, 2001). Segundo Stevenson (1981), a amostragem tem a finalidade de permitir a inferência estatística que é a formulação de certos julgamentos (generalizações) à cerca da população por meio da análise da amostra. O mesmo autor afirma que apesar de nenhum plano de amostragem garantir que a amostra seja exatamente semelhante à população da qual foi tirada, a amostragem aleatória permite estimar o valor do 
erro possível, mostrando o quanto esta amostra está próxima da população em termos de representatividade.

No caso de dados discretos, uma amostra é aleatória quando qualquer item da população tem a mesma chance de ser incluído na amostra. No caso de dados contínuos, uma amostra é aleatória quando a probabilidade de incluir um intervalo qualquer de valores é igual à porcentagem que esse intervalo representa da população (STEVENSON, 1981).

Segundo Pande et al. (2001) a amostragem sistemática é o método recomendado para muitos tipos de atividades. É um método simples onde amostras são retiradas a determinados intervalos (de tempo ou número de itens) com o cuidado de certificar-se que a freqüência da amostragem não corresponda a algum padrão que produzirá viés nos dados.

\subsubsection{FASE ANALISAR}

Segundo Eckes (2001), esta é considerada a fase mais importante do DMAIC, pois é durante a fase de análise que a causa raiz do problema é descoberta. Para isso são validados um conjunto de variáveis (Xs) que explicam o desempenho atual (Y), formando uma função $Y=f\left(X_{1}, X_{2}, X_{3}, \ldots, X_{n}\right)$. O resultado do processo (Y) é função de uma série de variáveis (Xs) que são os elementos do processo. O objetivo dessa fase é determinar, entre os diversos Xs do processo, quais são os que mais contribuem para o resultado Y. Para isso são realizados dois tipos de análise, dos dados e do processo. A análise dos dados está relacionada às medidas de eficácia (satisfação do cliente) e a análise do processo está relacionada às medidas de eficiência (por exemplo, custo).

\subsubsection{ANÁLISE DOS DADOS}

O objetivo da análise dos dados é encontrar as causas do problema, por meio da análise dos dados coletados na etapa de mensuração. Pode-se criar diversos tipos de gráficos 
que auxiliem na análise dos dados brutos. Segundo Eckes (2001), o diagrama de Pareto e o histograma são ferramentas muito úteis na análise dos dados brutos.

O Diagrama de Pareto, utilizado para dados qualitativos, é um gráfico de barras verticais que apresenta os dados de forma a tornar evidente a priorização de temas, possibilitando concentrar os esforços de melhoria nos pontos que representam as melhores oportunidades, ou seja, onde os maiores ganhos podem ser obtidos.

Com os dados da tabela de distribuição de freqüência, do plano de coleta de dados, pode-se criar um histograma. Rotondaro et al. (2002) define um histograma como uma representação gráfica dos dados quantitativos agrupados em classes de freqüência, que possibilita verificar a forma da distribuição, o valor central e a dispersão dos dados.

\subsubsection{ANÁLISE DO PROCESSO}

A análise do processo detalha e analisa o mapa de processo de alto nível elaborado na fase de definição. O detalhamento das etapas que ocorrem entre o início e o fim do processo, definidos no diagrama SIPOC, é chamado de mapeamento de subprocessos (ECKES, 2001).

Segundo Alvarenga Netto (2004), o mapeamento de processos consiste na criação de um modelo que represente as relações entre as atividades, pessoas, objetos e dados envolvidos na produção de uma determinada saída, tornando mais fácil determinar onde e como melhorálo.

Um mapa de processos é um fluxograma do processo e representa o fluxo do trabalho por meio de uma série de retângulos e losangos ligados por setas. Os retângulos representam as tarefas, os losangos representam os momentos de decisão e as setas mostram o fluxo do trabalho. A validação é realizada verificando-se junto aos que realizam o trabalho se o mapa se equipara a realidade (PANDE et al., 2001). 
Segundo Pande et al. (2001), o mapa do processo pode ser analisado em busca de problemas, tais como:

- Descontinuidades: pontos em que transferências são mal realizadas.

- Gargalos: pontos do processo onde o volume é maior do que a capacidade, retardando o fluxo do trabalho.

- Redundâncias: atividades repetidas no processo.

- Loops de retrabalho: pontos onde partes do trabalho retornam ao processo para serem concertados ou corrigidos.

- Decisões/Inspeções: pontos que intervêm no processo com escolhas, avaliações, verificações ou levantamentos, criando atrasos potenciais.

Segundo Eckes (2001), há três tipos de análise do processo, relacionados à (1) momentos da verdade do processo, à (2) natureza do trabalho e ao (3) ciclo de tempo.

Um momento da verdade em um processo relativo à prestação de serviço, por exemplo, é um momento entre o cliente e o prestador de serviço onde pode se formada uma imagem positiva ou negativa. Momentos da verdade positivos aumentam a lealdade do cliente.

A natureza do trabalho determina quais os passos de um subprocesso que agregam ou não agregam valor ao processo. Uma etapa agrega valor quando atende a três critérios: (1) o cliente está disposto a pagar por aquele passo do processo, (2) a etapa transforma o produto ou o serviço e (3) a atividade é realizada corretamente da primeira vez. Um passo que agrega valor deve atender a todos os três critérios. Entretanto, algumas etapas do processo, que tecnicamente não agregam valor, não são alvo de melhoria, pois são, por exemplo, exigências legais.

O ciclo de tempo é a quantidade de tempo gasto em cada etapa do subprocesso, seja uma etapa que agregue de valor ou não. Este cálculo da quantidade de tempo é chamado de 
análise do fluxo de trabalho. A partir da análise da natureza do trabalho e do fluxo do trabalho elabora-se uma planilha, chamada de planilha de resumo da análise, que relaciona as etapas do processo ao ciclo de tempo e à natureza do trabalho, criando um resumo estatístico da análise do processo.

\subsubsection{ANÁLISE DA RAIZ DO PROBLEMA}

Eckes (2001) divide a análise da raiz do problema em três fases (abertura, afunilamento e fechamento), começando pelo levantamento de todas as idéias que possam explicar o problema, passando pelo afunilamento que vai gerar então uma lista de causas mais prováveis e termina com atividades de validação que reduzem poucas causas essenciais.

Segundo Eckes (2001), o levantamento das idéias que podem explicar o problema é realizado por meio de um Diagrama de Causa e Efeito. O diagrama de causa e efeito, também conhecido como gráfico de Ishikawa ou gráfico espinha de peixe, identifica muitas causas possíveis para um efeito ou problema e classifica as idéias em categorias úteis.

Todas as idéias geradas como possíveis causas do problema devem passar por um processo de afunilamento para reduzir o número de causas prováveis. Eckes (2001) sugere que seja realizado com a equipe um exame da lista original de idéias para: (1) clarificação das idéias, ou seja, para que haja um entendimento das idéias por todos os membros da equipe; (2) identificar possíveis duplicações de idéias e (3) identificar as principais categorias. Por fim a equipe deve fazer uma votação múltipla sobre as causas para reduzi-las baseado no consenso da equipe, enfatizando ao grupo que o exercício de votação múltipla não é um processo de tomada de decisão.

Outra ferramenta que pode ser usada nessa fase é a FMEA (Failure Mode and Effect Analysis). É uma ferramenta qualitativa de caráter preventivo, que analisa como um produto 
ou processo, industrial ou administrativo, pode fracassar em atender os requisitos dos clientes, quais as causas da falhas e como eliminá-las.

\subsubsection{VALIDAÇÃO DA RAIZ DO PROBLEMA}

Para que na fase de melhoria sejam encontradas soluções que eliminem as causas mais profundas do problema, a validação da raiz do problema é fundamental. Eckes (2001) afirma que em alguns casos a validação da raiz do problema pode ser realizada pela simples análise dos dados atuais disponíveis, que podem explicar 99\% do processo. A estatística descritiva dos dados pode, em alguns casos, fornecer informação suficiente para validar uma causa.

O diagrama de dispersão é uma ferramenta que pode ser utilizada quando há a suspeita sobre uma causa potencial do problema precisa ser validada. $\mathrm{O}$ diagrama de dispersão representa graficamente em um plano cartesiano a relação existente entre duas variáveis. É útil para verificar se uma variável de resultado $(Y)$ pode ser explicada, em parte ou totalmente, por uma variável do processo $(\mathrm{X})$. Ter dados que indiquem se há correlação entre as variáveis facilita o trabalho da equipe em validar as causas verdadeiras do problema. Variáveis que não apresentam correlação indicam que não há razões para investigações futuras sobre esse fator (ECKES, 2001). 


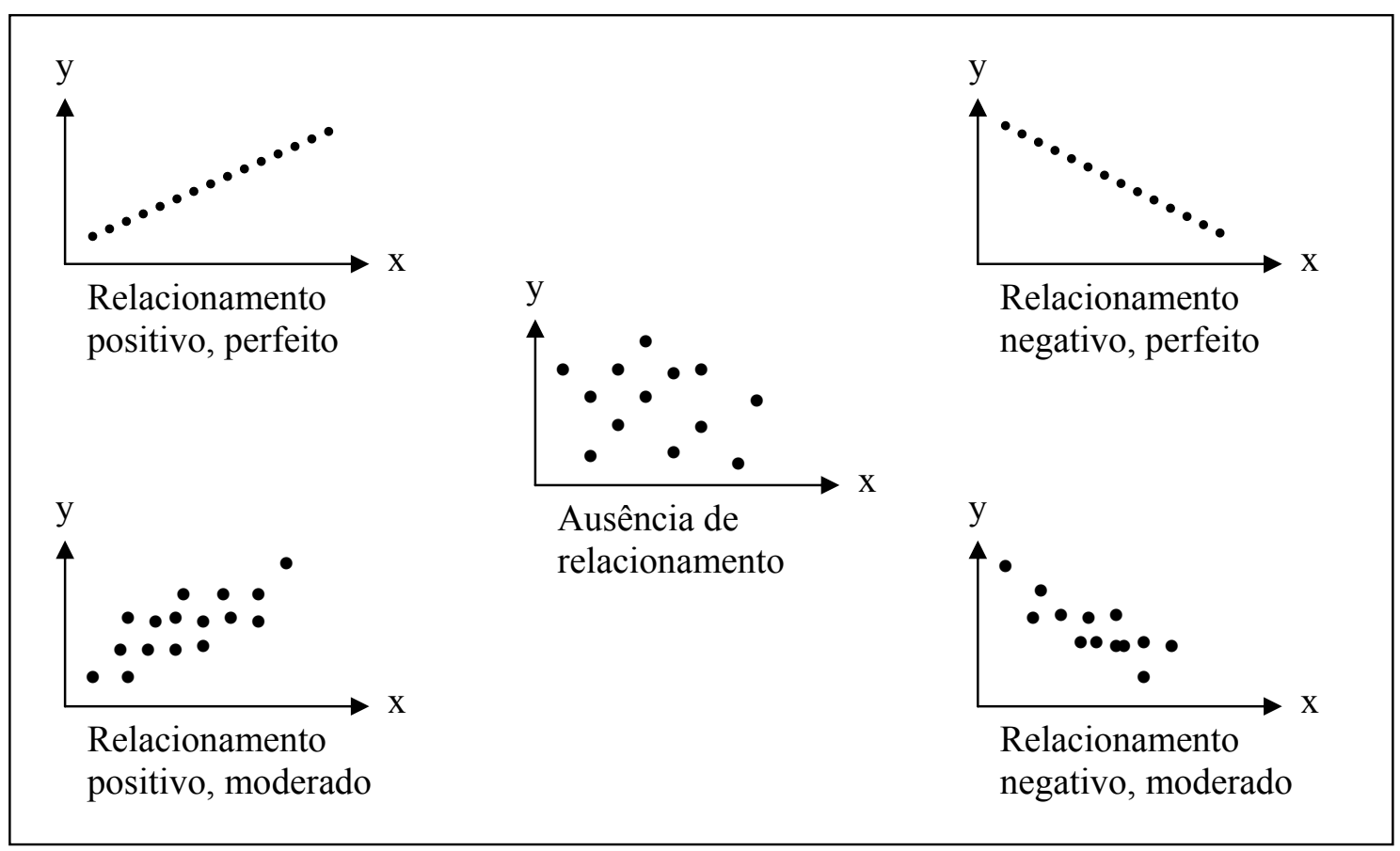

Ilustração 6: Diagramas de dispersão e descrição do relacionamento linear. FONTE: Adaptado de Stevenson (1981)

A existência de correlação entre as variáveis não indica necessariamente causalidade, ou seja, que X é a causa da variação de Y. Muitas vezes uma terceira variável explica a relação mostrada no diagrama de dispersão. É muito raro que apenas um fator (X) explique a variação do resultado $(\mathrm{Y})$, sendo mais provável que haja diversos fatores. Neste caso a validação das causas-raiz pode ser realizada por meio de experimentos planejados (ECKES, 2001).

Um experimento planejado cria eventos para que seja possível observar seus resultados. É um processo de manipulação de fatores controláveis (X) para observar os efeitos sobre um resultado $(\mathrm{Y})$.

Para realizar um experimento planejado são selecionados fatores que possam afetar o resultado e manipulado um deles mantendo os outros constantes para que se possa observar o efeito da variável sobre o resultado. Ao combinar os fatores com as variações de cada um pode-se observar o efeito das interações dos fatores sobre o resultado. 
Pande et al. (2001) sugere que se faça uma análise de causa lógica. Por meio dos dados coletados e outros fatores disponíveis pode-se testar as causas prováveis para verificar se elas se encaixam com os dados. A técnica é impulsionada por perguntas e apoiada em dados sobre o processo, o problema ou o produto. As perguntas típicas da análise lógica são:

- Quais tipos ou categorias de defeitos são mais comuns? O que há de diferente a respeito dos tipos mais comuns?

- Há locais onde o problema é maior? Em que aspectos esses locais, onde o problema ocorre são incomuns?

- Quais as horas, dias, semanas ou condições em que o problema é mais freqüente? O que acontece de singular nesses momentos?

- Que fatores ou variáveis se correlacionam com o problema?

Esses tipos de perguntas restringem o problema, eliminando ou validando causas possíveis.

\subsubsection{FASE MELHORAR}

O objetivo da fase de melhoria é selecionar e implementar soluções, focadas nas causas-raiz validadas na fase anterior, capazes de impactar na causa do problema, eliminando a causa do problema ou minimizando seus efeitos.

Nesta fase a equipe deve gerar muitas idéias sobre como a abordar a causa-raiz do problema, refinar essas idéias para abordagens viáveis que possam ser implementadas no processo, e selecionar as soluções que mais provavelmente alcançarão a meta (PANDE et al., 2001). As soluções que levam a um bom controle do processo devem levar em conta a redução da variância dos resultados e a centralização da média dos resultados entre os limites de especificação. A ilustração abaixo representa a melhoria de um processo por meio da centralização da média ou da redução da variabilidade dos resultados. 


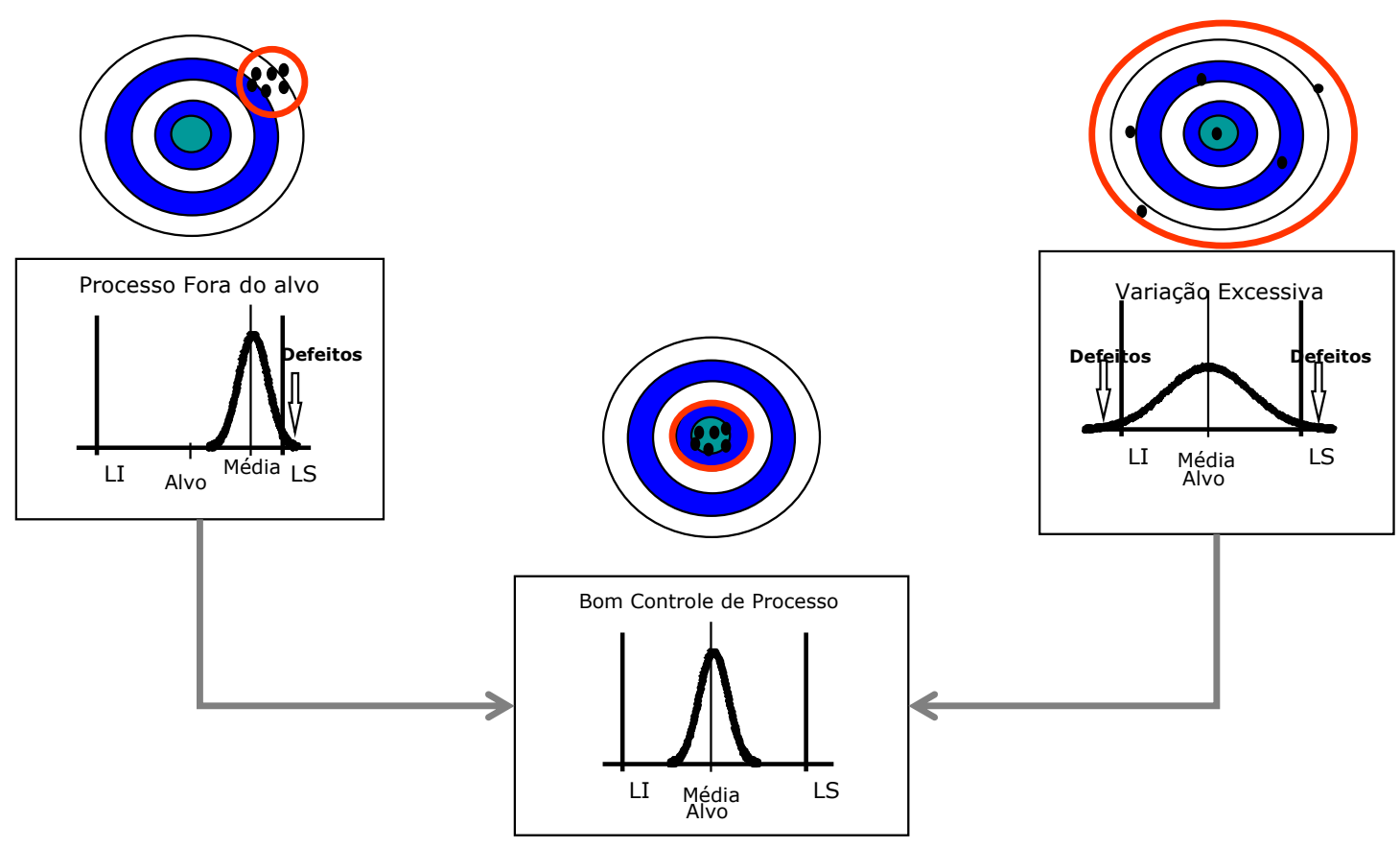

Ilustração 7: melhoria do processo

Segundo Eckes (2001), o conceito de Abertura-Afunilamento-Fechamento também é utilizado nessa fase. $\mathrm{Na}$ fase de abertura são levantadas o maior número possível de idéias sobre o que possam impactar na causa do problema. Na fase de afunilamento as idéias são explicadas (clarificação) para que todos compreendam as idéias e procura-se por duplicações para reduzir o número de soluções possíveis. Em seguida é realizada uma votação múltipla para que a equipe chegue a um consenso sobre as principais idéias que possam solucionar o problema.

O fechamento busca priorizar soluções por meio da aplicação de uma série de critérios. Eckes (2001) sugere a aplicação dos critérios "precisar" e "querer". O critério “precisar” filtra as idéias verificando se as sugestões atendem a requisitos mínimos para serem consideradas, ou seja, o que a idéia de solução "precisa ser”. Caso uma sugestão não atenda a algum dos requisitos, deve ser descartada das soluções principais. O critério "querer" busca motivar todos os afetados pelo problema e os membros da equipe envolvendo a todos na seleção da idéias. Aspectos considerados desejáveis na solução são escolhidos como critérios 
e recebem pesos em relação a sua importância. Os membros da equipe classificam as idéias, atribuindo notas aos critérios que avaliam o quanto cada critério é atendido. As idéias são classificadas de acordo com a pontuação recebida em cada critério, considerando os pesos relativos. Assim, as idéias com a maior pontuação devem ser priorizadas. Segundo Pande et al. (2001), alguns critérios que podem ser utilizados para a escolha da solução mais adequada são:

- Custo da implementação.

- Custo operacional.

- Facilidade de implementação.

- Probabilidade de alcançar a meta do projeto.

- Benefícios adicionais de longo prazo.

- Adesão da organização.

Eckes (2001) e Pande et al. (2001) afirmam que é necessário realizar um teste piloto antes de implementar as possíveis soluções, pois é alta a probabilidade de ocorrer problemas imprevistos. O teste piloto experimenta as soluções em pequena escala para determinar se conduzirão à melhoria esperada, permitindo corrigir ou modificar as propostas do projeto.

\subsubsection{FASE CONTROLAR}

Durante a fase de controle, última fase do método DMAIC, são realizadas atividades que visam assegurar o funcionamento das soluções, manutenção da melhoria alcançada no processo e dos ganhos resultantes da melhoria no decorrer do tempo.

Segundo Eckes (2001), a fase de controle atua em dois níveis: nível tático ou do projeto e nível estratégico. O controle no nível estratégico diz respeito ao trabalho contínuo dos executivos para sustentar o Seis Sigma dentro da organização. Os executivos devem ter em 
vista a criação e manutenção de sistemas e estruturas na organização que ofereçam suporte ao Seis Sigma.

No nível de projeto existem dois métodos de controle, um quantitativo e um qualitativo. O método qualitativo de controle no nível do projeto é o plano de resposta. É ferramenta que gera um plano constante de ações que orientam os participantes do processo sobre como agir, mesmo que não tenham participado do projeto. Um plano de resposta inclui um mapa do processo aprimorado, identifica mensurações, especificações, alvos do processo, tipos de controle e as melhorias que estão sendo alcançadas ou serão no curto prazo (ECKES, 2001). Segundo Pande et al. (2001), um plano de resposta fornece "Alarmes de ação", tais como padrões do processo ou medições do desempenho, que indiquem a ocorrência de um problema, que medidas corretivas devem ser tomadas e diretrizes para concertos de curto prazo ou de emergência, permitindo que um problema seja solucionado sem a presença de uma equipe especializada e sem gerar "efeitos colaterais" resultantes de soluções provisórias.

O método quantitativo depende da extensão da padronização do processo e do índice de processamento. Em geral, se a fase de melhoria é concluída satisfatoriamente, o processo está padronizado. Um processo considerado não padronizado apresenta passos imprevisíveis dentro do processo e/ou passos não repetitivos, ou seja, passos que mudam a cada vez que o processo ocorre. O índice de processamento está relacionado ao volume de produtos ou serviços gerados por um determinado processo. A grande maioria dos processos apresentam alta padronização e alto índice de processamento, levando aos gráficos de controle como método preferencial de controle estatístico (ECKES, 2001). Os gráficos de controle utilizam a média e o desvio padrão dos dados para fornecer a probabilidade da ocorrência de itens ficarem fora dos limites de controle, além da variação dos dados em relação ao tempo, tendências e padrões incomuns, indicando quando surgem os defeitos no processo ou a 
ocorrência de mudanças. A identificação das causas das mudanças ou defeitos e a tomada de ações corretivas é um meio de manutenção das melhorias.

\subsection{FERRAMENTAS ESTATÍSTICAS E DA QUALIDADE}

Algumas ferramentas da qualidade e estatísticas, utilizadas no método DMAIC, são apresentadas de forma mais detalhada.

\subsection{1 ÁRVORE CPQ}

Segundo Eckes (2001), é uma ferramenta simples que auxilia a equipe a partir das necessidades gerais dos clientes para os requisitos mais específicos, de ordem comportamental.

A Ilustração 8 mostra uma árvore CPQ de três níveis para um processo de serviço de quarto. O nível 1 identifica o cliente e suas necessidades. Neste exemplo não houve a necessidade de segmentação dos clientes. Os elementos do nível 2 são os requisitos que determinam se o cliente está ou não satisfeito com o processo. Tais requisitos são validados junto ao cliente. O nível 3 é o desdobramento do elemento do nível 2, caso necessite de mais um nível de especificação. Salienta-se que os elementos da árvore CPQ não representam a forma como a necessidade será medida. 


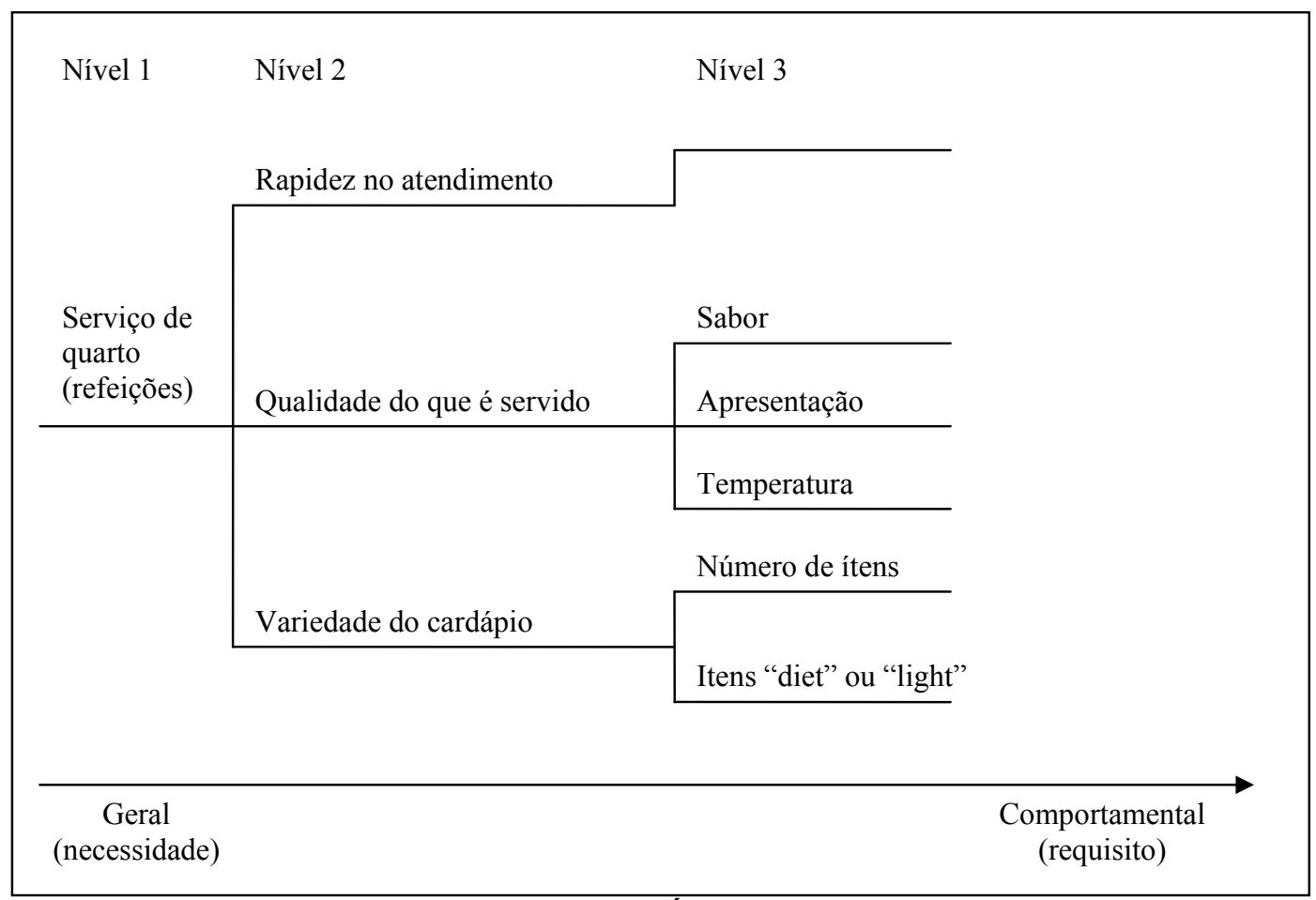

Ilustração 8: Árvore CPQ

FONTE: ECKES, 2001, p. 66

A validação dos requisitos junto ao cliente pode ser realizada de diversas maneiras:

- Entrevistas com os clientes,

- Enquetes,

- Grupos de foco,

- Colocar-se no lugar do cliente e observar o cliente,

- Reclamações dos clientes.

A vantagem das entrevistas individuais é a possibilidade de conseguir junto ao cliente respostas mais detalhadas sobre suas necessidades. As enquetes trazem um conjunto de perguntas por escrito que são enviadas e respondidas pelos clientes. Sua vantagem está na oportunidade de gerar dados e a capacidade de priorizar as necessidades dos clientes a partir de perguntas diretas e não a partir de respostas que precisam ser interpretadas. Grupos de foco reúnem um grupo de clientes que respondem a uma série de perguntas, possibilitando desdobrar questões baseado nas respostas dos participantes e compreender a linguagem 
corporal, o que fornece uma compreensão das necessidades dos clientes em um nível altamente detalhado. Entretanto, deve ser realizada por um facilitador competente para que consiga bons resultados (ECKES, 2001). Pande et al. (2001) chama de "Voz do Cliente" ou VOC (voice of customer) a estratégia e sistema de coletar dados sobre as necessidades dos clientes

\subsubsection{SIPOC}

O diagrama SIPOC é uma ferramenta utilizada para identificar elementos relevantes de um projeto de melhoria de processo, por meio da construção de um mapa de processo de alto nível. O objetivo é criar uma representação de como o processo opera no momento para que se possa determinar o que não está funcionando corretamente (ECKES, 2001 e GEORGE, 2004). Segundo Pande et al. (2001), este mapa define apenas as atividades principais do processo, não entrando em detalhes como pontos de decisão ou loops de retrabalho. O mapeamento do processo mais detalhado é realizado na fase de análise.

SIPOC é uma sigla que significa:

Fornecedores (Suppliers): pessoas ou grupos que fornecem as entradas do processo.

Entrada (Input): materiais, informações ou outros recursos.

Processo (Process): seqüência de atividades organizadas que transformam as entradas dos fornecedores em saídas para os clientes com valor agregado gerado pela unidade (SLACK et al., 1996).

Saída (Output): produto, serviço ou informações que são enviadas ao cliente.

Clientes (Client): pessoa, grupo ou processo que recebe a saída.

A definição do processo a ser mapeado e o estabelecimento dos pontos de início e fim do processo devem ser cuidadosos para que não fujam ao escopo do projeto (ECKES, 2001). 
O diagrama SIPOC também pode ajudar a definir o escopo do projeto, caso o escopo ainda não esteja bem definido (SIMON, 2007).

Segundo Eckes (2001) e Simon (2007), os requisitos do cliente também podem ser acrescentados ao final do diagrama SIPOC, como pode ser observado na Ilustração 9:

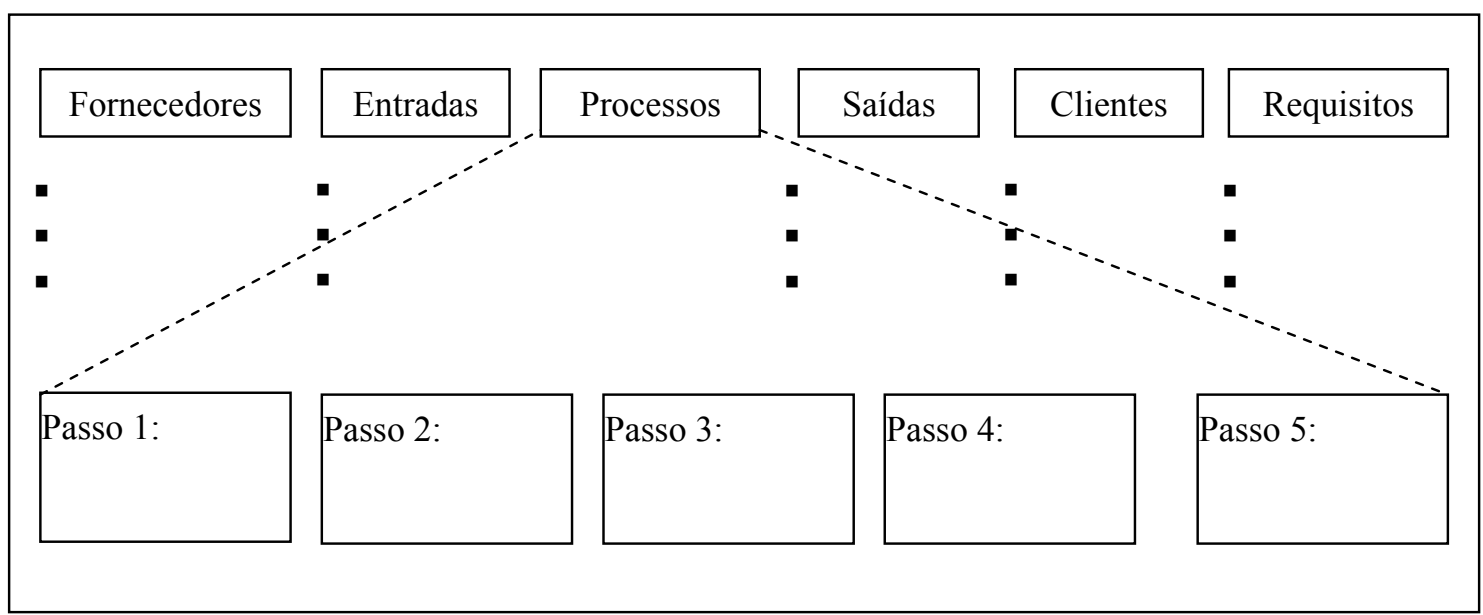

Ilustração 9: Diagrama SIPOC

FONTE: Adaptado de Simon (2007).

Segundo Eckes (2001), a criação de um diagrama SIPOC começa pela definição do processo a ser mapeado e dos ponto de início e fim do processo, de modo que não fuja ao escopo do projeto, seguido pela definição do resultado do processo, da maneira mais simples possível, podendo haver mais do que um resultado, mas reduzindo ao resultado principal que deve ser atingido. A definição dos clientes e seu requisitos, já devem estar prontos na árvore CPQ, que é feita no início da fase de definição, bastando copiar para o diagrama os dados da árvore $\mathrm{CPQ}$.

As entradas fornecidas ao processo são os materiais, informações ou outros recursos que são trabalhados pelo processo, sendo consumidas ou transformadas em saídas para o cliente. Deve-se concentrar nas entradas mais críticas, aquelas que são essenciais ao trabalho, sem as quais o trabalho não poderia ser bem feito (PANDE et al., 2001).

Os últimos passos são identificar os fornecedores das entradas e completar o mapa do processo com os passos de alto nível que ocorrem entre o início e o fim do processo. Eckes 
(2001) sugere de 5 a 7 passos e Pande et al. (2001) sugere limitar em 10 para evitar muitos detalhes. Deve-se tomar o cuidado para que o mapa represente o processo como ele é na realidade e não o mapa de como o processo deveria ser. O mapa de como o processo deveria ser será criado na fase de melhoria do processo.

Por fim, é necessário validar o processo, pois a representação de como a equipe acredita que seja o processo pode não representar o processo real. Por meio da validação é representado o verdadeiro mapa do processo. Para isso a equipe deve conversar com as pessoas que fazem parte do processo.

\subsubsection{DIAGRAMA DE PARETO}

O Diagrama de Pareto é um gráfico de barras verticais que apresenta os dados de forma a tornar evidente a priorização de temas, possibilitando concentrar os esforços de melhoria nos pontos que representam as melhores oportunidades, ou seja, onde os maiores ganhos podem ser obtidos.

O gráfico apresenta, de forma geral:

- No eixo horizontal as classes (problemas ou causas) que serão comparadas;

- No eixo vertical a freqüência acumulada representada por colunas verticais em cada uma das classes, dispostas em ordem decrescente; e

- Uma curva que representa a freqüência acumulada das classes. 


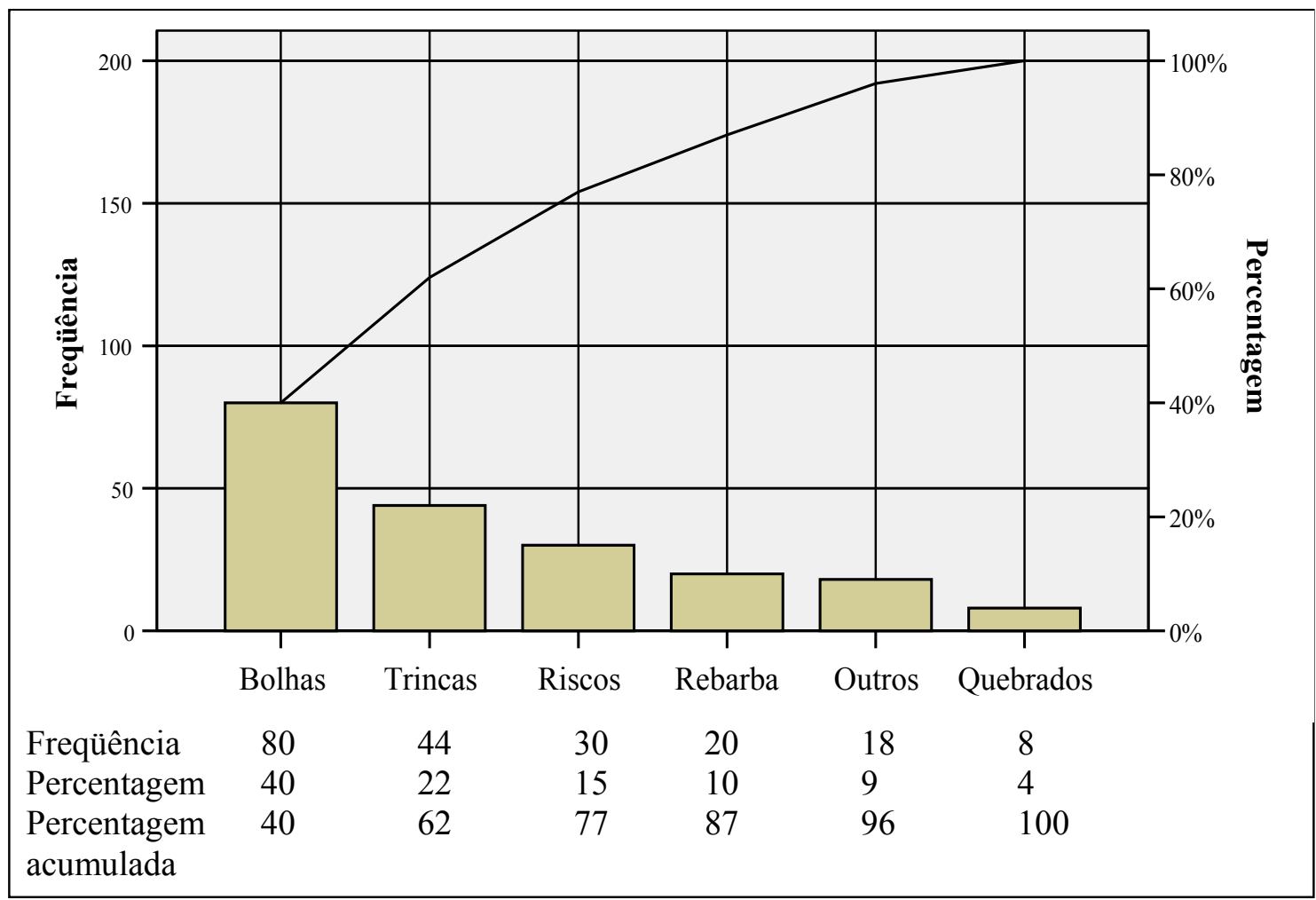

Ilustração 10: Diagrama de Pareto

FONTE: Adaptado de Rotondaro et al. (2002)

Os itens de maior impacto são indicados à esquerda do diagrama e representam as principais oportunidades de melhoria. Tipicamente, apenas alguns itens representam a maior parte do problema. Assim, a equipe a focaliza nas causas ou componentes que mais contribuem para um problema.

Segundo Rotondaro et al. (2002), as vantagens do diagrama de Pareto são que os gráficos transmitem informações de forma mais simples do que as tabelas e que todos na organização, em qualquer nível hierárquico, entenderão o gráfico da mesma maneira.

\subsubsection{HISTOGRAMA}

Rotondaro et al. (2002) define um histograma como uma representação gráfica dos dados quantitativos agrupados em classes de freqüência, que possibilita verificar a forma da distribuição, o valor central e a dispersão dos dados. A forma da distribuição diz respeito à 
amplitude total, que é o tamanho da variação, e a simetria da distribuição. A simetria indica que o processo segue uma distribuição normal. Colocando os limites de especificação do processo no histograma é possível verificar se os produtos atendem as especificações e se a média dos valores está centralizada em relação aos limites de especificação. Assim, é possível verificar se o processo é capaz de atender às especificações e se as não-conformidades estão relacionadas à média e/ou à dispersão do processo.

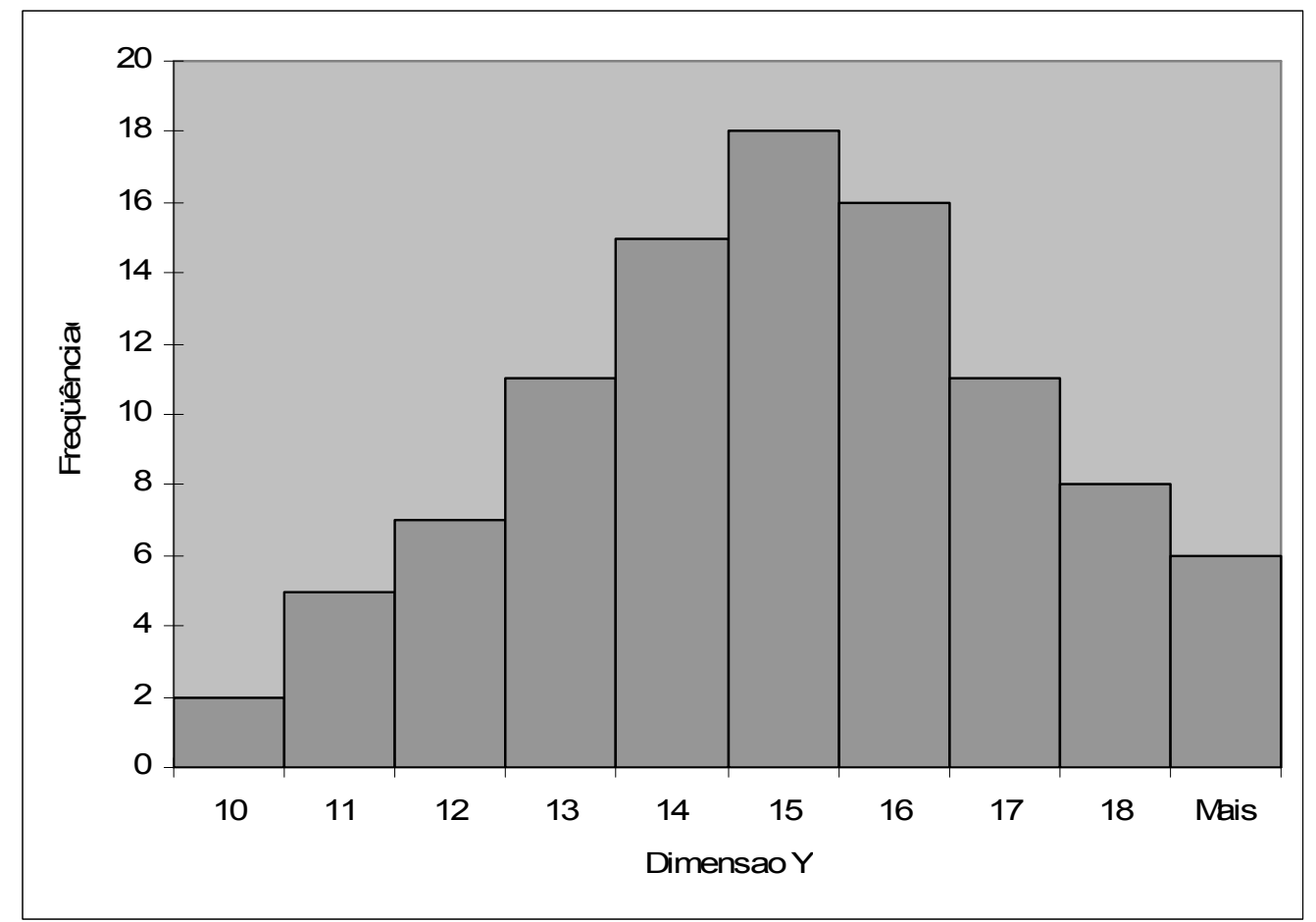

Ilustração 11: Histograma

\subsubsection{DIAGRAMA DE CAUSA E EFEITO}

O diagrama de causa e efeito, também conhecido como gráfico de Ishikawa ou gráfico espinha de peixe, identifica muitas causas possíveis para um efeito ou problema e classifica as idéias em categorias úteis.

Segundo Werkema (1995), esta ferramenta é utilizada para apresentar a relação existente entre o resultado de um processo (efeito) e os fatores (causas) desse processo que 
podem afetar o resultado, ou seja, o problema a ser solucionado é relacionado aos fatores do processo que podem causá-lo. Assim, atua como um guia para a identificação da causa fundamental do problema e para a determinação de ações a serem adotadas.

O diagrama de causa e efeito é a ferramenta ideal quando se quer garantir, no brainstorming, que o máximo de idéias sobre as causas potenciais para o problema sejam capturadas (ECKES, 2001).

O diagrama de causa e efeito é formado por flechas, que registram um conjunto de causas, dispostas de forma que, seguindo seu sentido, apresentam maiores níveis de agregação, até que todas convirjam ao efeito que está sendo analisado (ROTONDARO et al., 2002).

Não há uma regra para a definição dos ramos principais, sendo que os critérios mais comumente empregados são chamados de "6 Ms":

- Mão-de-obra;

- Materiais (componentes);

- Máquinas (equipamentos);

- Métodos (procedimentos de operação ou de controle);

- Meio ambiente e

- Medição (sistema de medição). 


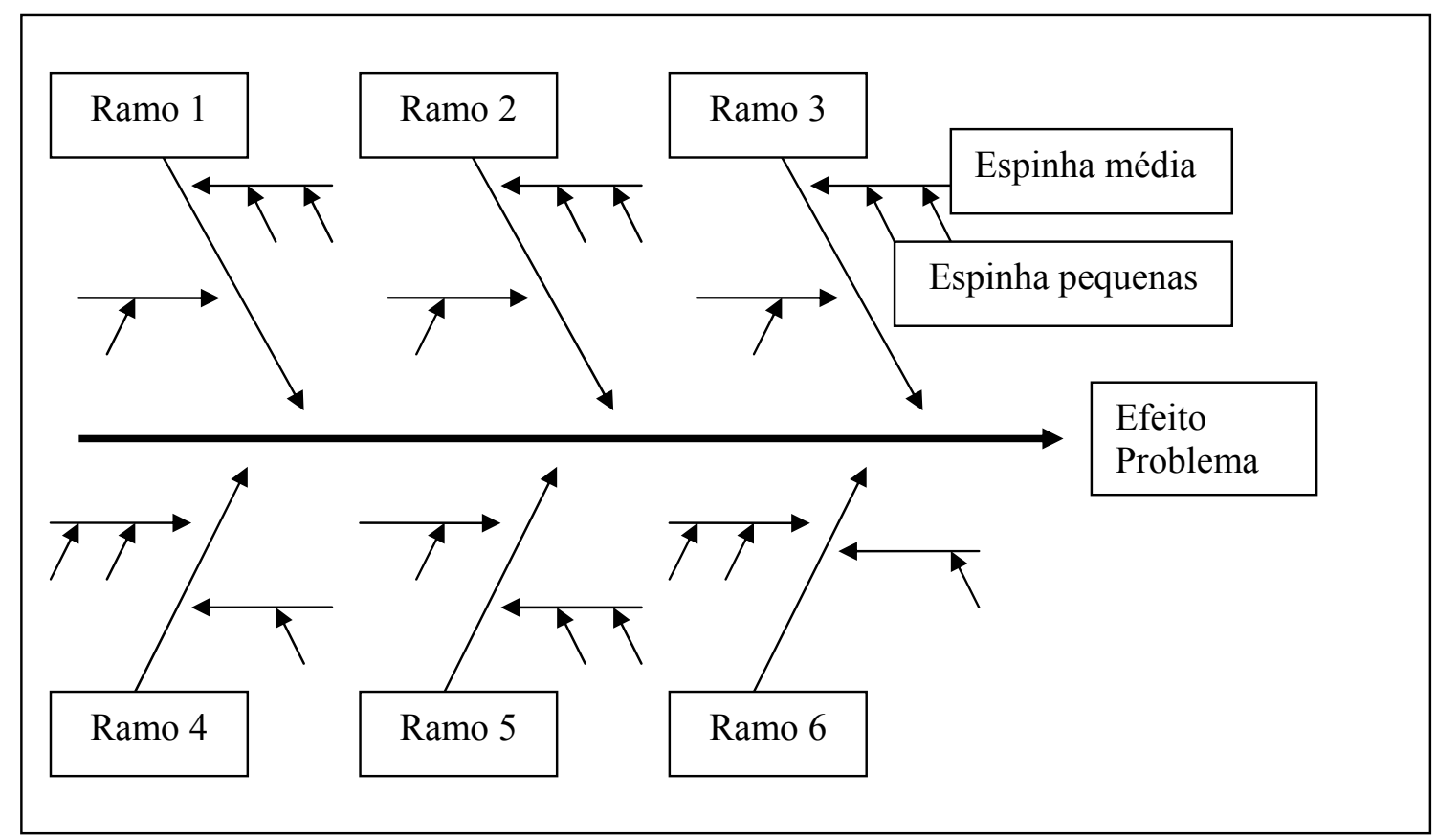

Ilustração 12: Diagrama de Causa e Efeito

FONTE: Adaptado de Rotondaro et al. (2002)

\subsubsection{FMEA}

FMEA (Failure Mode and Effect Analysis) é uma ferramenta qualitativa de caráter preventivo, que analisa como um produto ou processo, industrial ou administrativo, pode fracassar em atender os requisitos dos clientes, quais as causas da falhas e como eliminá-las. Assim, a FMEA é um método estruturado para:

- Identificar os potenciais tipos (modos) de falha;

- Determinar o efeito de cada falha sobre o desempenho;

- Priorizar as falhas em função de seus efeitos, da freqüência com que ocorrem e da capacidade de controle (prevenção ou detecção) que evita que a falha chegue ao cliente; e

- Identificar ações que eliminem ou reduzam a possibilidade de uma falha ocorrer.

Segundo Rotondaro et al. (2002), esta ferramenta apresenta melhores resultados quando desenvolvida em equipe, pois levanta maior número de informações e considerações, 
aumentando o escopo e profundidade da análise. Utilizando-se o conhecimento do grupo, pode-se identificar as diversas variáveis (entradas) que mais afetam as saídas dos processos e já listar as de influência óbvia sobre os CTQs. Outro resultado importante da utilização da ferramenta é a troca de experiências e o aprendizado em conjunto.

A FMEA de processo focaliza as falhas potenciais referentes à produção do bem ou serviço, assumindo que o produto é capaz de atender às necessidades do cliente. Assim, busca oportunidades e alternativas para melhorar o processo em si e não em identificar alterações do produto para que os efeitos da deficiência sejam reduzidos.

Basicamente, é uma tabela que relaciona os tipos de potenciais falhas a três critérios em uma escala de 1 a 10 :

1. Ocorrência da falha $(1=$ pouco provável a $10=$ quase certa $)$

2. Detecção da falha $(1=$ muito provável a $10=$ pouco provável de ser detectada $)$

3. Severidade da falha $(1=$ pouco impacto a $10=$ impacto extremo, com danos pessoais ou elevada perda financeira).

Rotondaro et al. (2002) descreve o formulário básico - FMEA:

\begin{tabular}{|c|c|c|c|c|c|c|c|c|c|c|c|c|c|c|c|}
\hline \multirow{2}{*}{$\begin{array}{l}\text { Função } \\
\text { do } \\
\text { processo }\end{array}$} & \multirow{2}{*}{$\begin{array}{l}\text { Modo de } \\
\text { falha } \\
\text { potencial }\end{array}$} & \multirow{2}{*}{$\begin{array}{l}\text { Efeito(s) } \\
\text { potencial(is) } \\
\text { da falha(s) }\end{array}$} & \multirow[b]{2}{*}{ 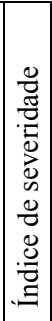 } & \multirow{2}{*}{$\begin{array}{l}\text { Causa(s) e } \\
\text { mecanismo(s) } \\
\text { potencial(is) }\end{array}$} & \multirow[b]{2}{*}{ 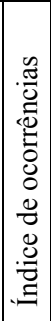 } & \multirow{2}{*}{$\begin{array}{l}\text { Controles } \\
\text { atuais do } \\
\text { processo }\end{array}$} & \multirow[b]{2}{*}{ 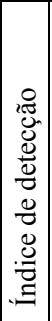 } & \multirow{2}{*}{\begin{tabular}{|l|} 
\\
$\frac{\alpha}{z}$ \\
$z$ \\
$z$
\end{tabular}} & \multirow[t]{2}{*}{\begin{tabular}{|l|} 
Ações \\
recomendadas
\end{tabular}} & \multirow[b]{2}{*}{ 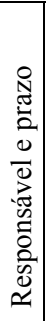 } & \multirow[t]{2}{*}{$\begin{array}{l}\text { Ações } \\
\text { tomadas }\end{array}$} & \multicolumn{4}{|c|}{$\begin{array}{c}\text { Resultados das } \\
\text { ações } \\
\end{array}$} \\
\hline & & & & & & & & & & & & 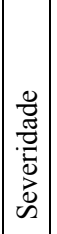 & 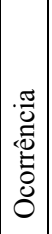 & ص̊. & 竞 \\
\hline & & & & & & & & & & & & & & & \\
\hline & & & & & & & & & & & & & & & \\
\hline & & & & & & & & & & & & & & & \\
\hline & & & & & & & & & & & & & & & \\
\hline & & & & & & & & & & & & & & & \\
\hline
\end{tabular}

Ilustração 13: Formulário básico FMEA FONTE: ROTONDARO et al., 2002, p. 156

Função do processo: Título dado a etapa do processo ou uma breve descrição da operação em análise. 
Modo de falha potencial: Apresenta-se como uma situação concreta, em geral fisicamente observável, descrevendo uma não-conformidade da operação, da forma que o cliente a percebe. Consideram-se todos os possíveis tipos de falhas, mesmo aquelas que não ocorram efetivamente.

Efeito(s) potencial(is) da falha: Conseqüência da falha para o cliente, caso o Modo de falha não seja prevenido ou corrigido. Identifica o impacto do Modo de falha sobre os requisitos do cliente.

A análise de Modo e Efeito da falha é uma ferramenta de planejamento que ajuda equipes a anteciparem e evitarem problemas. Para cada passo em um processo a equipe pergunta o que pode dar errado e decide o que pode fazer.

Índice de severidade: Avaliação da gravidade do efeito da falha para o cliente, em função da conseqüência da falha.

Causa(s) potencial(is) de falha: Identifica a causa fundamental da falha em termos de algo que possa se corrigido ou controlado.

Índice de ocorrência: Indica a probabilidade de uma causa de falha ocorrer e, caso ocorra, gerar a falha em si.

Controles atuais do processo: Controles que sejam capazes de detectar o Modo de falha e a Causa da falha e de prevenir a ocorrência do Modo de falha.

Índice de detecção: Indica a probabilidade dos controles atuais evitarem que as falhas cheguem ao cliente.

Número de prioridade de risco (NPR): Indicador geral da importância da falha e serve de critério para a escolha das ações de melhoria. Quanto maior o valor do NRP, mais alta é a prioridade. É calculado pelo produto dos indicadores de severidade (S), ocorrência (O) e detecção (D).

$$
N R P=(S) \times(O) \times(D)
$$


Ações recomendadas: Registro das ações corretivas propostas para os itens que foram selecionados pelo NRP.

Responsável e prazo: Define o responsável pela realização das ações recomendadas, acompanhamento das atividades de forma sistemática e atualização das informações.

Ações tomadas: Descrição das ações efetivamente tomadas, caso não sejam as mesmas das ações recomendadas.

NRP resultante: Reavaliação do NRP após as ações corretivas.

\subsubsection{TESTES DE HIPÓTESE}

Os testes de hipótese, ou de significância (STEVENSON, 1981), têm por finalidade avaliar se uma afirmação sobre determinado parâmetro populacional é verdadeiro, ou seja, este teste verifica se a diferença entre um parâmetro populacional e o valor de uma estatística teste pode ser atribuída à variabilidade amostral.

A afirmação a ser testada em um teste de hipótese é chamada de hipótese nula. O objetivo do teste é avaliar a força da evidência contra a hipótese nula (MOORE, 1995). São utilizados dois tipos de hipóteses sobre a afirmação inicial: a hipótese nula $\left(\mathrm{H}_{0}\right)$, que sugere ser verdadeira a afirmação, ou seja, não há diferença significativa, e a hipótese alternativa $\left(\mathrm{H}_{1}\right)$, sugerindo que a afirmação não é verdadeira, ou seja, que a diferença é significativa. A aceitação da hipótese alternativa acarreta a rejeição da hipótese nula (STEVENSON, 1981).

O nível de significância de um teste, designado pela letra grega $\alpha$ (alfa), representa a probabilidade de uma hipótese nula ser rejeitada, quando verdadeira.

Em linhas gerais, um teste de significância divide uma distribuição amostral em duas regiões, uma região de aceitação e outra de rejeição, separadas por um valor crítico baseado no valor de alfa. A estatística teste que excede o valor crítico sugere a rejeição da hipótese 
nula, enquanto que uma estatística teste com valor inferior ao valor crítico sugere que a hipótese nula seja aceita (STEVENSON, 1981).

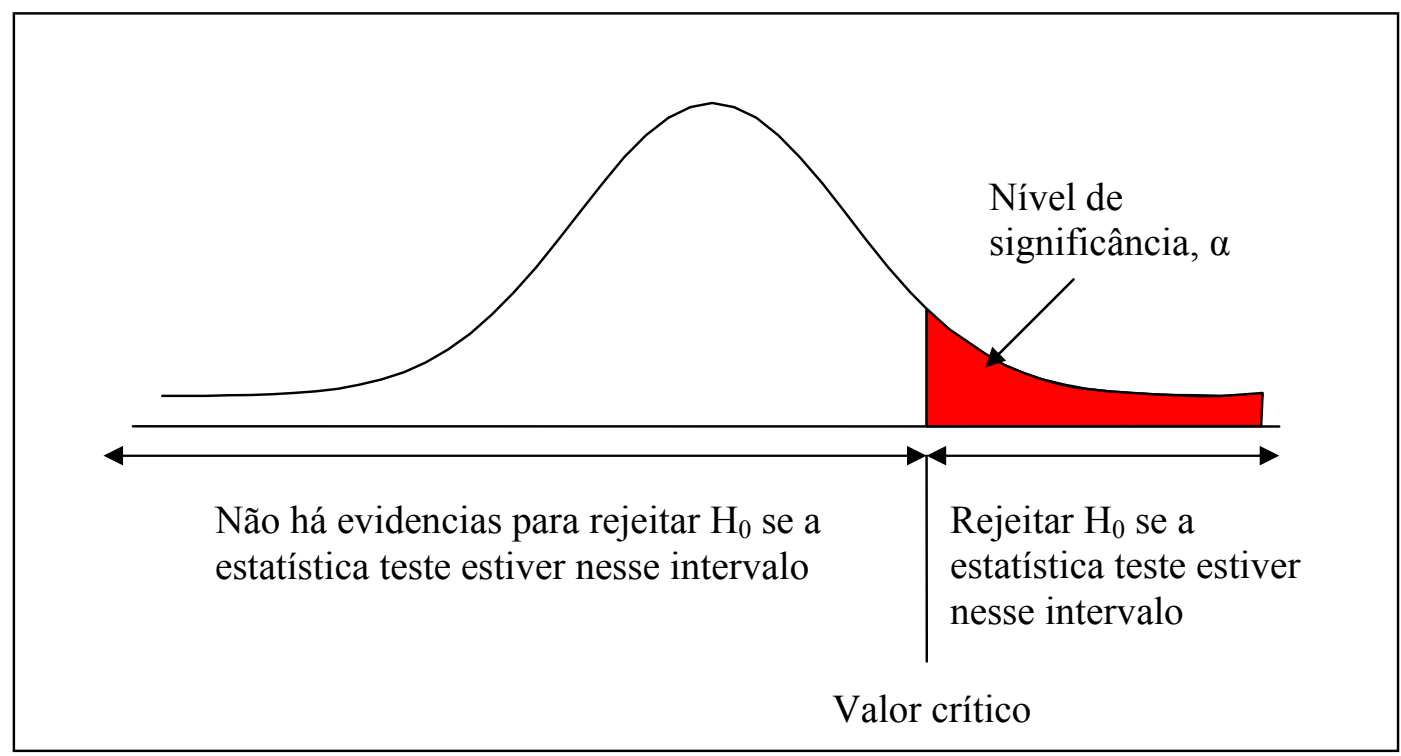

Ilustração 14: Distribuição dividida em regiões de aceitação e rejeição, com valor crítico como ponto divisório

FONTE: (STEVENSON, 1981)

A hipótese alternativa indica qual aspecto do desvio não-aleatório (significativo) de determinado parâmetro que está sendo comparado, podendo envolver desvios em ambas as direções ou apenas em uma direção. Assim, há três casos possíveis: teste bilateral, teste unilateral à direita e teste unilateral à esquerda (Ilustração 15) 


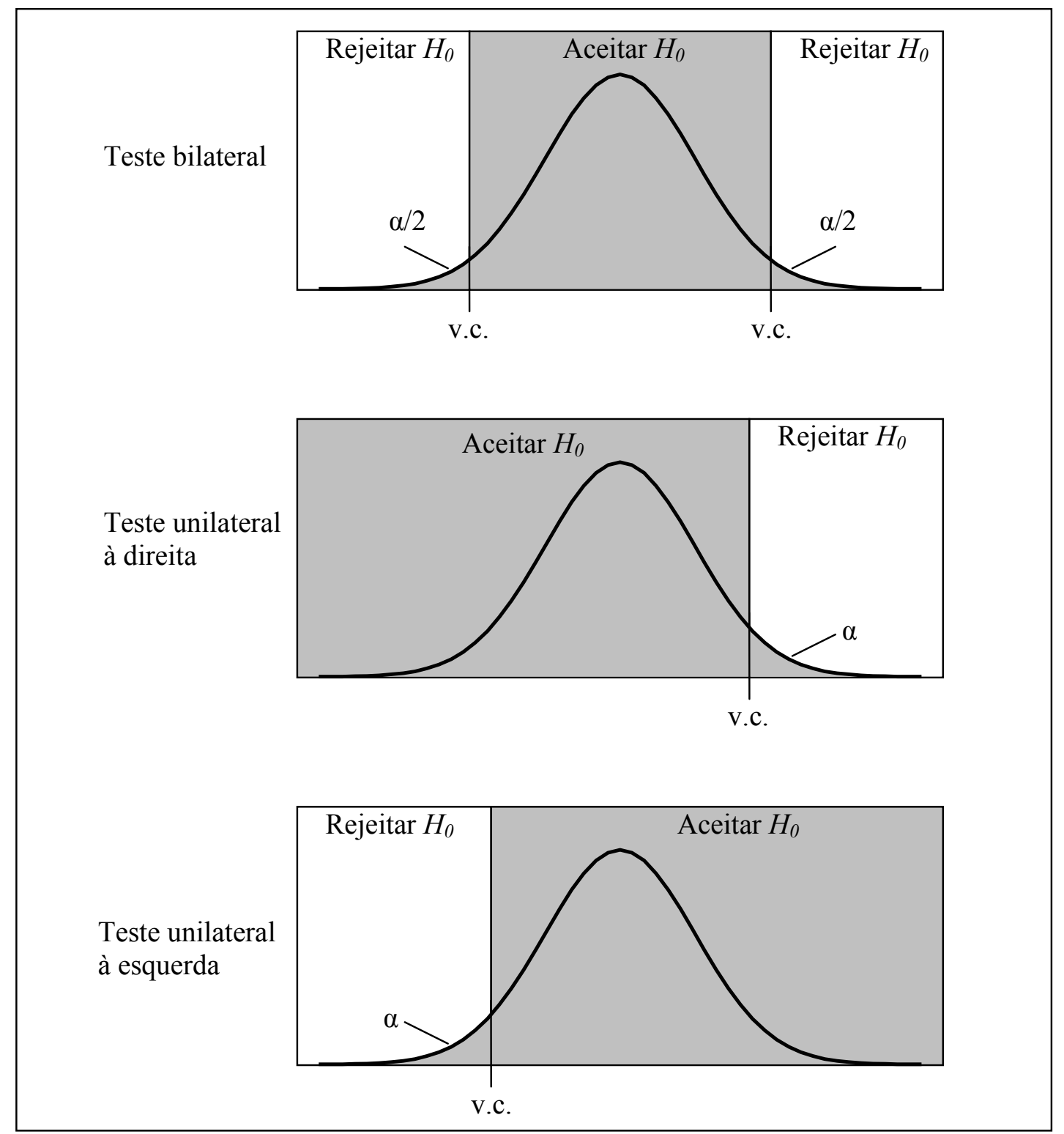

Ilustração 15: Comparação da partição de uma distribuição amostral para testes unilaterais e bilaterais FONTE: Adaptado de Stevenson (1981); Cooper e Schindler (2003)

Há quatro resultados possíveis em um teste de hipótese (Quadro 2). Uma hipótese nula pode ser aceita, quando deveria ser rejeitada, ou rejeitada, quando deveria ser aceita. Aceitando ou rejeitando a hipótese nula, a decisão pode estar incorreta (COOPER; SCHINDLER, 2003). 


\begin{tabular}{|c|c|c|}
\cline { 2 - 3 } \multicolumn{1}{c|}{} & Aceitar $H_{0}$ & Rejeitar $H_{0}$ \\
\hline$H_{0}$ verdadeira & Decisão correta & $\begin{array}{c}\text { Erro Tipo I } \\
\alpha\end{array}$ \\
\hline$H_{0}$ falsa & $\begin{array}{c}\text { Erro Tipo II } \\
\beta\end{array}$ & Decisão correta \\
\hline
\end{tabular}

Quadro 2: Erro Tipo I e Tipo II

$\mathrm{O}$ erro Tipo I representa a probabilidade de rejeitar $H_{0}$ quando $H_{0}$ é verdadeira. O nível de significância $\alpha$ é a probabilidade de um erro Tipo I. O erro Tipo II representa a probabilidade de aceitar $H_{0}$ quando $H_{0}$ não é verdadeira (MOORE, 1995; STEVENSON, 1981).

A escolha de um teste deve considerar pelo menos três questões (COOPER; SCHINDLER, 2003):

- O número de amostras envolvidas no teste (uma, duas ou $k$ amostras),

- No caso de duas ou mais amostras, o relacionamento das amostras (independentes ou relacionadas)

- A escala de mensuração (nominal, ordinal, intervalar ou razão).

\begin{tabular}{|c|c|c|c|c|c|}
\hline \multirow{2}{*}{$\begin{array}{c}\text { Tipo de } \\
\text { mensuração }\end{array}$} & \multirow{2}{*}{$\begin{array}{c}\text { Caso de uma } \\
\text { amostra }\end{array}$} & \multicolumn{2}{|c|}{ Caso de duas amostras } & \multicolumn{2}{|c|}{ Caso de $k$ amostras } \\
\hline & & Relacionadas & Independentes & Relacionadas & Independentes \\
\hline Nominal & $\begin{array}{l}\text { Binomial } \\
\text { Uma amostra } \\
\chi^{2}\end{array}$ & McNemar & $\begin{array}{l}\text { Teste exato de } \\
\text { Fisher } \\
\text { Teste com duas } \\
\text { amostras } \chi^{2}\end{array}$ & Q de Cochran & $\begin{array}{l}\chi^{2} \text { para } k \\
\text { amostras }\end{array}$ \\
\hline Ordinal & $\begin{array}{l}\text { Teste de uma } \\
\text { amostra de } \\
\text { Kolmogorov- } \\
\text { Smirnov } \\
\text { Teste Runs }\end{array}$ & $\begin{array}{l}\text { Teste com } \\
\text { sinais Wilcoxon } \\
\text { pares } \\
\text { semelhantes }\end{array}$ & $\begin{array}{l}\text { Teste da } \\
\text { mediana } \\
\text { Teste de U de } \\
\text { Mann-Whitney } \\
\text { Kolmogorov- } \\
\text { Smirnov } \\
\text { Wald- } \\
\text { Wolfowitz }\end{array}$ & $\begin{array}{l}\text { ANOVA de } \\
\text { fator duplo } \\
\text { Friedman }\end{array}$ & $\begin{array}{l}\text { Extensão da } \\
\text { mediana } \\
\text { Kruskal-Wallis } \\
\text { ANOVA de um } \\
\text { fator }\end{array}$ \\
\hline $\begin{array}{l}\text { Intervalar ou } \\
\text { razão }\end{array}$ & $\begin{array}{l}\text { Teste } t \\
\text { Teste } Z\end{array}$ & $\begin{array}{l}\text { Teste } t \text { para } \\
\text { amostras } \\
\text { emparelhadas }\end{array}$ & $\begin{array}{l}\text { Teste } t \\
\text { Teste Z }\end{array}$ & $\begin{array}{l}\text { ANOVA com } \\
\text { mensurações } \\
\text { repetidas }\end{array}$ & $\begin{array}{l}\text { ANOVA de um } \\
\text { fator } \\
\text { ANOVA de } \\
\text { formato } n\end{array}$ \\
\hline
\end{tabular}

Quadro 3: Téenicas estatísticas recomendadas por nível de mensuração de teste

FONTE: Cooper e Schindler, 2003, p. 399

Serão detalhados a seguir os dois tipos de testes de hipótese utilizados nesta pesquisa. 


\subsubsection{TESTE DE DUAS AMOSTRAS PARA MÉDIAS}

O objetivo dos testes de significância de duas amostras para médias é decidir se as médias de duas populações são iguais (STEVENSON, 1981).

A hipótese nula considera que as médias das duas populações são iguais:

$H_{0}: \mu_{1}=\mu_{2}$

Onde:

$\mu_{1}=$ média da população 1

$\mu_{2}=$ média da população 2

As hipóteses alternativas possíveis são:

$H_{1}: \mu_{1} \neq \mu_{2} \quad H_{0}: \mu_{1}>\mu_{2} \quad H_{0}: \mu_{1}<\mu_{2}$

A primeira alternativa sugere um teste bilateral, enquanto que a segunda alternativa sugere um teste unilateral na cauda direita e a terceira um teste unilateral na cauda esquerda.

Quando os desvios padrões populacionais são conhecidos, a estatística teste é a seguinte:

$z_{\text {teste }}=\frac{\bar{x}_{1}-\bar{x}_{2}}{\sqrt{\frac{\sigma_{1}^{2}}{n_{1}}+\frac{\sigma_{2}^{2}}{n_{2}}}}$

Onde:

$\bar{x}_{1}=$ média da amostra 1

$\bar{x}_{2}=$ média da amostra 2

$n_{1}=$ número de observações na amostra 1

$n_{2}=$ número de observações na amostra 2

$\sigma_{1}=$ desvio padrão da população 1

$\sigma_{2}=$ desvio padrão da população 2

O valor crítico é encontrado na tabela $Z$, baseado em $\alpha$, por exemplo, para $\alpha=0.05$ o valor crítico é de 1,65 . 
Quando os desvios padrões populacionais são desconhecidos, a estatística teste é a seguinte:

$t_{\text {teste }}=\frac{\bar{x}_{1}-\bar{x}_{2}}{\sqrt{\frac{S_{x 1}^{2}}{n_{1}}+\frac{S_{x 2}^{2}}{n_{2}}}}$

Onde:

$S_{x 1}^{2}=$ variância da amostra 1

$S_{x 2}^{2}=$ variância da amostra 2

Quando os tamanhos das amostras não são iguais e a soma de $n_{1} \operatorname{com} n_{2}$ é menor do que 30, a estatística teste é:

$t_{\text {teste }}=\frac{\bar{x}_{1}-\bar{x}_{2}}{\sqrt{\left[\frac{\left(n_{1}-1\right) S_{X 1}^{2}+\left(n_{2}-1\right) S_{X 2}^{2}}{n_{1}+n_{2}-2}\right]\left(\frac{1}{n_{1}}+\frac{1}{n_{2}}\right)}}$

Quando a soma de $n_{1}$ com $n_{2}$ é menor do que 30, o valor crítico é encontrado na tabela $t$, considerando o valor de $\alpha$ e com $n_{1}+n_{2}-2$ graus de liberdade. Quando $n_{1}+n_{2}$ é maior do que 30, a distribuição $z$ se aproxima da distribuição $t(z \approx t)$

\subsubsection{TESTE DE DUAS AMOSTRAS PARA PROPORÇÕES}

O objetivo de um teste de duas amostras para proporções é decidir se duas amostras independentes foram extraídas de duas populações que possuem a mesma proporção de elementos com determinada característica (STEVENSON, 1981).

A hipótese nula considera que as duas proporções são iguais:

$H_{0}: p_{1}=p_{2}$

Onde:

$p_{1}=$ proporção de elementos na amostra 1

$p_{2}=$ proporção de elementos na amostra 2

As hipóteses alternativas possíveis são: 
$H_{1}: p_{1} \neq p_{2} \quad H_{1}: p_{1}>p_{2} \quad H_{1}: p_{1}<p_{2}$

A primeira alternativa sugere um teste bilateral, enquanto que a segunda alternativa sugere um teste unilateral na cauda direita e a terceira um teste unilateral na cauda esquerda.

A estatística teste é representada pela fórmula:

$z=\frac{\left(x_{1} / n_{1}\right)-\left(x_{2} / n_{2}\right)}{\sqrt{p(1-p)\left[\left(1 / n_{1}\right)+\left(1 / n_{2}\right)\right.}}$

onde:

$p=\frac{x_{1}+x_{2}}{n_{1}+n_{2}}$

$x_{1}=$ número de sucessos na amostra 1

$x_{2}=$ número de sucessos na amostra 2

$n_{1}=$ número de observações na amostra 1

$n_{2}=$ número de observações na amostra 2

$\mathrm{O}$ valor crítico é encontrado na tabela $\mathrm{Z}$, baseado em $\alpha$, por exemplo, para $\alpha=0.05$ o valor crítico é de 1,65 .

\subsubsection{CONTROLE ESTATÍSTICO DE PROCESSOS}

O permanente controle dos processos é condição básica para a manutenção da qualidade de bens e serviços. O Controle Estatístico de Processos aplica técnicas estatísticas para medir e analisar as variações nos processos (COSTA; EPPRECHT; CARPINETTI, 2004). Todos os processos são sujeitos à variabilidade, sendo que uma variabilidade excessiva pode gerar a ocorrência de defeitos.

O controle estatístico de processos é utilizado na fase de controle para monitorar o processo e mante-lo com um desempenho adequado e previsível, evitando-se que as melhorias obtidas na fase anterior se percam (ROTONDARO et al, 2002). 
Os processos apresentam variações naturais, presentes mesmo que todas as operações sejam executadas com métodos padronizados. São causadas por pequenas perturbações, chamadas de causas aleatórias, contra as quais pouco ou nada pode ser feito (COSTA; EPPRECHT; CARPINETTI, 2004). Considera-se que a variabilidade de um processo mantém-se num nível estável quando o processo está sujeito apenas às causas aleatórias. Nesta situação o processo está sob controle estatístico, apresentando um comportamento estável e previsível (WERKEMA, 1995).

Os processos também estão sujeitos a perturbações maiores, chamadas de causas especiais, que fazem o processo sair de seu padrão natural de operação. Processos sujeitos às causas especiais, normalmente apresentam uma variabilidade muito maior do que a variabilidade natural e são denominados de processos fora de controle. As causas especiais são problemas no processo que podem ser corrigidos ou eliminados do processo (COSTA; EPPRECHT; CARPINETTI, 2004).

Por meio da eliminação das causas especiais e da redução das causas aleatórias, podese reduzir a variabilidade dos processos. As variações podem ser quantificadas pelo uso de amostragem e estimativas dos parâmetros da distribuição estatística. As mudanças na distribuição dos dados do processo podem ser reveladas pelo gráfico desses parâmetros no decorrer do tempo. Tais gráficos são chamados de Gráficos de Controle, ferramentas utilizadas para monitorar os processos e indicar a presença de causas especiais (WERKEMA, 1995).

Os gráficos de Controle apresentam uma linha média (LM), um limite superior de controle (LSC), um limite inferior de controle (LIC) e os valores da característica de qualidade traçados no gráfico. A linha média representa o valor médio (ou esperado) da característica de qualidade correspondente à situação do processo sob controle estatístico e os limites de controle são usualmente estabelecidos a três desvios-padrão do valor médio. Os 
valores de característica de qualidade traçados no gráfico indicam a situação do processo no que diz respeito ao controle estatístico.

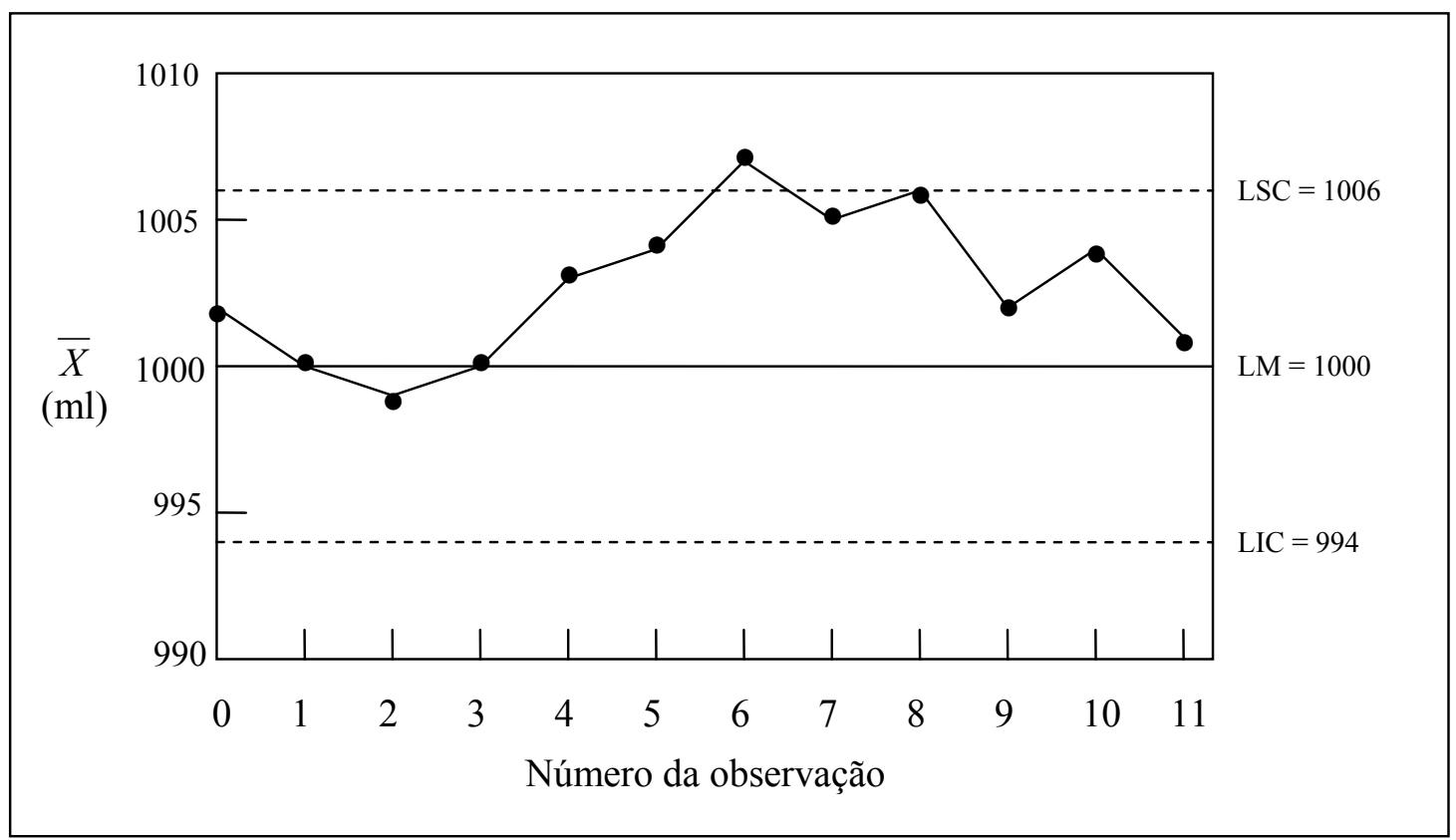

Ilustração 16: Gráfico de Controle de $\bar{X}$.

FONTE: Adaptado de Costa; Epprecht; Carpinetti (2004)

Os limites do gráfico de controle são definidos com base na média e no desvio-padrão da distribuição da variável, correspondente à característica da qualidade analisada, quando o processo está isento de causas especiais. As observações obtidas de processos fora de controle não são apropriados para a construção dos gráficos, pois os limites de controle e a linha média calculados com base nestes valores teriam valores diferentes dos ideais.

Enquanto os pontos no gráfico estiverem distribuídos aleatoriamente em torno da LM, não se deve intervir no processo. Contudo, pontos acima do LSC ou abaixo do LIC são interpretados como sinal de que o processo deve estar fora de controle e alguma ação corretiva é necessária.

Dois tipos de dados podem ser analisados com os gráficos de controle. Os dados variáveis, que exigem medições em escalas contínuas, geram os gráficos de controle para variáveis. Os dados que exigem somente uma classificação, tais como “defeituoso" ou não, dão origem aos gráficos de controle por atributos. 


\subsubsection{GRÁFICOS DE CONTROLE PARA VARIÁVEIS}

Os gráficos de controle mais utilizados quando a variável a ser controlada é uma variável contínua, são os que monitoram a centralidade e a dispersão da variável. Em geral, os gráficos utilizados, simultaneamente, são o da média amostral $\bar{X}$ para monitorar a centralidade, e o da amplitude amostral $R$ para monitorar a dispersão (COSTA; EPPRECHT; CARPINETTI, 2004).

Os valores da linha média e dos limites de controle para o gráfico de controle de $\bar{X}$ são obtidos pelas expressões:

$$
\begin{aligned}
& L S C_{\bar{X}}=\hat{\mu}_{0}+3 \frac{\hat{\sigma}_{0}}{\sqrt{n}} \\
& L M=\hat{\mu}_{0} \\
& L I C_{\bar{X}}=\hat{\mu}_{0}-3 \frac{\hat{\sigma}_{0}}{\sqrt{n}}
\end{aligned}
$$

Onde:

$\hat{\mu}_{0}=$ estimativa da média da variável isenta de causas especiais.

$\hat{\sigma}_{0}=$ estimativa do desvio-padrão da variável isenta de causas especiais.

$n=$ tamanho da amostra

Os valores da linha média e dos limites de controle para o gráfico de controle de $R$ são obtidos pelas expressões:

$$
\begin{aligned}
& L S C_{R}=d_{2} \hat{\sigma}_{0}+3 d_{3} \hat{\sigma}_{0} \\
& L M_{R}=d_{2} \hat{\sigma}_{0} \\
& L I C_{R}=d_{2} \hat{\sigma}_{0}-3 d_{3} \hat{\sigma}_{0}{ }^{1}
\end{aligned}
$$

Onde as constantes $d_{2}$ e $d_{3}$ dependem do tamanho da amostra $n$.

\footnotetext{
${ }^{1}$ Quando o valor de $\mathrm{LIC}_{\mathrm{R}}$ calculado for negativo, adota-se $\mathrm{LIC}_{\mathrm{R}}=0$.
} 
Tabela 2: Valores das constantes $d_{2}$ e $d_{3}$

\begin{tabular}{|c|c|c|c|c|c|c|c|c|c|c|c|c|c|c|}
\hline$n$ & 2 & 3 & 4 & 5 & 6 & 7 & 8 & 9 & 10 & 11 & 12 & 13 & 14 & 15 \\
\hline$d_{2}$ & 1,128 & 1,693 & 2,059 & 2,326 & 2,534 & 2,704 & 2,970 & 3,078 & 3,336 & 3,407 & 3,258 & 3,336 & 3,407 & 3,472 \\
\hline$d_{3}$ & 0,853 & 0,888 & 0,880 & 0,864 & 0,848 & 0,833 & 0,820 & 0,808 & 0,797 & 0,787 & 0,778 & 0,770 & 0,763 & 0,756 \\
\hline
\end{tabular}

FONTE: Costa; Epprecht; Carpinetti (2004)

\subsubsection{GRÁFICOS DE CONTROLE POR ATRIBUTOS}

Os gráficos de controle utilizados quando a variável é um atributo do produto são o gráfico de controle do número de defeituosos (gráfico de np), utilizado quando a característica da qualidade de interesse é representada pelo número de defeituosos, gráfico de controle da fração defeituosa (gráfico de p), utilizado para controlar a fração de defeituosos, e o gráfico de controle para o número de não-conformidades (gráfico c), utilizado para controlar o número total de defeitos em uma unidade do produto.

Os valores dos limites de controle e da média são obtidos pelas expressões:

- Gráfico np

$$
\begin{aligned}
& L S C_{n p}=n \bar{p}+3 \sqrt{n \bar{p}(1-\bar{p})} \\
& L M_{n p}=n \bar{p} \\
& L I C_{n p}=n \bar{p}-3 \sqrt{n \bar{p}(1-\bar{p})}
\end{aligned}
$$

Onde:

$\bar{p}=$ estimativa da probabilidade de ocorrer um defeito quando o processo está isento de causas especiais.

- Gráfico $\mathrm{p}$

$$
\begin{aligned}
& L S C_{p}=\bar{p}+3 \sqrt{\frac{\bar{p}(1-\bar{p})}{n}} \\
& L M_{p}=\bar{p}
\end{aligned}
$$




$$
L I C_{p}=\bar{p}-3 \sqrt{\frac{\bar{p}(1-\bar{p})}{n}}
$$

- Gráfico c

$$
\begin{aligned}
L S C_{c} & =\bar{c}+3 \sqrt{\bar{c}} \\
L M_{c} & =\bar{c} \\
L I C_{c} & =\bar{c}-3 \sqrt{\bar{c}}
\end{aligned}
$$

$\bar{c}=$ estimativa do número médio de não-conformidade por unidade quando o processo está sob controle.

\subsection{UNIDADE DE ALIMENTAÇÃO E NUTRIÇÃO}

O mercado de alimentação pode ser segmentado em alimentação coletiva e alimentação comercial, sendo que os estabelecimentos que atuam nesse mercado recebem a denominação de Unidades Produtoras de Refeições (UPRs). A diferença entre os dois segmentos refere-se ao grau de autonomia que o indivíduo possui em relação ao serviço, ou seja, se um usuário do serviço pode escolher em alimentar-se na unidade ou não (SOUSA, RIEKES, VEIRO E PROENÇA, 2005).

O serviço de alimentação comercial abrange as modalidades de restaurantes comerciais, lanchonetes, serviços de hotelaria, além de outras modalidades de serviço de alimentação. Nestes casos os usuários não apresentam nenhum grau de dependência em relação à unidade. No segmento de alimentação coletiva, as pessoas apresentam certo nível de dependência em relação à UPR, que recebe a designação de Unidade de Alimentação e Nutrição (UAN). O nível de dependência das pessoas em relação à UAN vai desde a dependência quase total, caso de hospitais, creches ou locais de trabalho isolados, até a dependência relativa, caso de restaurantes universitários, por exemplo. 
As Unidades de Alimentação e Nutrição são estabelecimentos que trabalham com a produção e distribuição de alimentos para coletividades, podendo estar estabelecidas em indústrias, empresas e escolas. Consiste de um serviço organizado que fornece refeições balanceadas, dentro dos padrões dietéticos e higiênicos, visando atender as necessidades nutricionais de seus clientes, de modo que se ajuste aos limites financeiros da instituição (ABREU et al. 2003).

Teixeira et al. (2004), define UAN como uma unidade de trabalho ou órgão de uma empresa, que desempenha atividades relacionadas à alimentação e nutrição independente da situação que ocupa na escala hierárquica da entidade, seja como divisão, seção, setor etc.

Segundo Proença (1996), os estabelecimentos que trabalham com produção e distribuição de alimentação para coletividades recebiam a denominação de Serviço de Alimentação e Nutrição (SAN) quando ligados a coletividades sadias e Serviço de Nutrição e Dietética (SND), quando ligados a coletividades enfermas. Atualmente, observa-se a tendência de utilização de uma denominação comum, Unidade de Alimentação e Nutrição.

Segundo Teixeira et al. (2004), uma UAN pode ser considerada um subsistema desempenhando atividades fins ou meios. No primeiro caso, como atividades fins, podem ser citados os serviços ligados a hospitais e centros de saúde, que colaboram diretamente com a consecução do objetivo final da instituição, uma vez que correspondem a um conjunto de bens e serviços destinados a prevenir, melhorar e/ou recuperar a população que atendem.

No segundo caso, ou seja, como órgãos meios, podem ser citados os serviços ligados a indústrias, instituições escolares e quaisquer outras que reúnem pessoas por um período de tempo que justifique o fornecimento de refeições. Nesses, desenvolvem-se atividades que procuram colaborar para que sejam realizadas, da melhor maneira possível, as atividades fins da entidade. 
Em ambos os casos, os estabelecimentos de alimentação coletiva podem ter gestão própria ou serem concedidos a terceiros. A primeira alternativa é o que se chama comumente de autogestão. Nesse sistema, a própria empresa encarrega-se de providenciar instalações e equipamentos, contratar e treinar equipe especializada, adquirir matéria prima e gerir todo o processo. Quando todos os trâmites acima descritos são considerados pela empresa como encargos muito pesados e distantes de sua atividade fim, entra a segunda alternativa. Essa consiste na contratação de empresas no ramo de administração de serviços de alimentação, denominadas concessionárias ou cozinhas industriais.

Segundo Abreu et al. (2003), uma UAN pode apresentar as seguintes formas de gerenciamento:

- Auto-gestão - A UAN é gerenciada pela própria empresa onde está estabelecida, produzindo as refeições que serve a seus funcionários.

- Concessão - A empresa cede seu espaço de produção e distribuição a uma empresa especializada na produção de refeições.

- Refeição transportada - A UAN transporta e distribui refeições para um local conveniado que não dispõe de cozinha, somente de refeitório.

O objetivo de uma Unidade de Alimentação e Nutrição é o fornecimento de uma refeição equilibrada nutricionalmente, apresentando bom nível de sanidade, e que seja adequada ao comensal, denominação dada tradicionalmente ao consumidor em alimentação coletiva. Esta adequação deve ocorrer tanto no sentido da manutenção e/ou recuperação da saúde do comensal, como visando a auxiliar no desenvolvimento de hábitos alimentares saudáveis, a educação alimentar e nutricional. Além desses aspectos ligados à refeição, uma Unidade de Alimentação e Nutrição objetiva, ainda, satisfazer o comensal no que diz respeito ao serviço oferecido. Este item engloba desde o ambiente físico, incluindo tipo, conveniência 
e condições de higiene de instalações e equipamentos disponíveis, até o contato pessoal entre operadores da UAN e comensais, nos mais diversos momentos (Proença, 1997).

Segundo Abreu et al. (2003), a UAN precisa satisfazer o cliente tanto por aspectos tangíveis como intangíveis da qualidade. Os aspectos tangíveis da qualidade estão relacionados às características físicas dos produtos, como o cardápio, a apresentação dos alimentos, a aspectos físicos do restaurante. As características intangíveis da qualidade estão incorporadas nas expectativas, percepções, desejos conscientes e inconscientes, incluindo-se aqueles de natureza emocional, tais como o atendimento, as características sensoriais dos alimentos e outros. A qualidade final resulta da combinação, aos olhos do cliente, dos aspectos tangíveis e intangíveis da qualidade.

A qualidade em uma Unidade de Alimentação e Nutrição significa o fornecimento de refeições com alto valor nutritivo, adequadas a sua clientela e com o menor custo. Desta forma, qualidade em nutrição sugere a busca constante de melhorias contínuas nas áreas: nutricional, sensorial e microbiológica, na produção de alimentos e na prestação de serviços para a coletividade. A qualidade da refeição vai depender dos padrões e características, como peso, textura, sabor, cor, aroma, volume e da aceitação junto ao cliente (BRADACZ, 2003). Segundo Abreu et al. (2003), a dificuldade de se definir qualidade está na conversão das necessidades dos clientes em características mensuráveis, de forma que o produto possa ser planejado e modificado para dar satisfação por um preço que o usuário pague.

As Unidades de Alimentação e Nutrição são órgãos de estrutura administrativa simples, porém de funcionamento complexo, visto que, em geral, neles são desenvolvidas atividades que se enquadram nas funções técnicas, administrativas, comerciais, financeira contábil e de segurança (Texeira, 2000).

Segundo Proença (1997), a UAN também se caracteriza como uma empresa: a partir de um processo de produção de etapas definidas, que conta com pessoal técnico especializado, 
transforma matéria-prima em produto e que tem por estágio final o consumidor (comensal). Segundo Abreu et al. (2003), uma UAN apresenta características tanto de operações de produção de bens, quanto de serviços, o que torna necessária uma adaptação dos programas de qualidade, que normalmente são delineados para operações que produzem apenas bens ou apenas serviços. Muitas das ferramentas de qualidade, anteriormente exclusivas a grandes empresas, têm sido aplicadas com sucesso pelas empresas fornecedoras de refeições. A busca pela qualificação tem exigido das empresas a adoção de um modelo administrativo com ênfase na qualidade, produtividade e envolvimento dos membros da organização com os objetivos propostos.

\section{O RESTAURANTE UNIVERSITÁRIO}

O restaurante central do campus da USP de Ribeirão Preto é administrado pela Seção de Alimentação da Prefeitura do Campus e funciona em sistema de auto-gestão, produzindo e distribuindo refeições para alunos, funcionários e outros usuários.

A seção de alimentação não tem fins lucrativos, sendo que as refeições dos alunos são subsidiadas pela prefeitura do campus de Ribeirão Preto (PCARP). O setor financeiro da PCARP é o responsável por todos os custos do restaurante. Os gêneros alimentícios são adquiridos por meio de requisições ao setor de compras, que realiza pregões para contratar fornecedores.

O restaurante universitário do campus é dividido em duas unidades, o restaurante central, onde o usuário é servido em bandejas e o refeitório II, onde o usuário é servido em pratos.

Os alimentos são preparados na cozinha do restaurante central e uma parte é transportada para o refeitório II. De janeiro a novembro de 2007 o restaurante atendeu uma média de 1945 usuários por dia, sendo no almoço 1107 no restaurante central e 417 no refeitório II, e mais 421 refeições servidas durante o jantar no restaurante central. 
Seus processos não são documentados e há um baixo grau de padronização e formalização. Além disso, não há um sistema de coleta de dados que permita utilizar indicadores de eficiência. A gerência do restaurante reconhece que há diversas oportunidades de melhoria em seus processos e necessitam de uma ferramenta que os auxiliem a encontrar soluções eficientes e viáveis. 


\section{PROCEDIMENTOS METODOLÓGICOS}

Metodologia significa, etimologicamente, o estudo dos métodos, dos caminhos usados para se realizar uma pesquisa científica. Por sua vez, o método representa um procedimento racional e ordenado sendo constituído por instrumentos básicos, o que implica utilizar a reflexão e a experimentação, para alcançar os objetivos estabelecidos no planejamento de uma pesquisa (TEIXEIRA, 2006).

Segundo Rodrigues (2006), o método científico é um caminho planejado a ser seguido na investigação científica, ou seja, é um conjunto de procedimentos racionais e sistemáticos que possibilitam alcançar determinado objetivo.

A finalidade de uma pesquisa é descobrir respostas para algumas questões, mediante a aplicação de métodos científicos, que são desenvolvidas para intensificar a probabilidade de as informações obtidas serem utilizadas nas questões apresentadas e de serem seguras e imparciais. Embora uma pesquisa não resulte, necessariamente, em uma informação imparcial, os métodos científicos têm maior probabilidade de êxito do que qualquer outro sistema conhecido (COOPER; SCHINDLER, 2003).

Sendo assim, ao se planejar uma pesquisa científica faz-se necessário examinar seus objetivos para com isso determinar o método mais apropriado para alcançá-los.

O problema de pesquisa deste trabalho se enquadra na proposta sugerida por Marconi e Lakatos (2002), devendo ser analisado sob o aspecto de sua valoração quanto à viabilidade (pode ser eficazmente resolvido por meio da pesquisa), relevância (estar adequado ao estágio atual da evolução científica), novidade (é capaz de trazer conhecimentos novos), exeqüibilidade (pode levar a uma conclusão válida) e oportunidade (pode atender a interesses particulares gerais). 
Podem-se dividir os procedimentos metodológicos em duas partes. A primeira parte consiste na contextualização da pesquisa, onde se define o tipo de pesquisa. A segunda parte apresenta os passos propriamente ditos.

\subsection{CONTEXTUALIZAÇÃO DA PESQUISA}

Considerando-se o objetivo deste trabalho, que é o realizar um diagnóstico e análise de oportunidade de melhoria em um restaurante universitário por meio da aplicação do método DMAIC, tem-se que a pesquisa é exploratória e descritiva.

De acordo com Gil (2002, p. 41), uma pesquisa exploratória "tem como objetivo proporcionar maior familiaridade com o problema, com vista a torná-lo mais explícito ou a construir hipóteses".

A pesquisa exploratória pode ser realizada em área na qual há pouco conhecimento acumulado e sistematizado, e por sua natureza de sondagem, não comporta hipóteses ou proposições que, todavia, poderão surgir durante ou ao final da pesquisa (VERGARA, 2000). O seu principal objetivo é prover compreensão do problema enfrentado, sendo utilizada em casos nos quais é necessário definir o problema em estudo com maior precisão, identificar cursos relevantes de ação ou obter dados adicionais antes que se possa desenvolver uma abordagem. A pesquisa exploratória realiza descrições precisas da situação e visa descobrir as relações existentes entre os elementos componentes da mesma. (CERVO; BERVIAN, 2002).

O estudo exploratório é recomendado nos casos em que o conhecimento sobre determinado assunto é reduzido, como é o caso dessa pesquisa no que se refere à utilização das ferramentas do método DMAIC no contexto de um restaurante universitário.

De acordo com Gil (2002, p. 42), uma pesquisa descritiva "tem como objetivo primordial a descrição das características de determinada população ou fenômeno ou, então, o estabelecimento de relação entre variáveis." 
Segundo Richardson (1999), os estudos de natureza descritiva visam descobrir as características de um fenômeno e podem ser considerados como objeto de estudo um indivíduo, um grupo ou uma situação específica. Esse tipo de estudo deve ser realizado quando o pesquisador deseja obter melhor entendimento do comportamento de diversos fatores e elementos que influem sobre determinado fenômeno.

Segundo Gil (2002) as pesquisas descritivas têm como objetivo descrever características de determinada população ou fenômeno ou estabelecer relações entre variáveis. A pesquisa descritiva observa, analisa e correlaciona fatos ou fenômenos (variáveis) sem manipulá-los, procurando descobrir a natureza e características do fenômeno (CERVO, 2002).

Como esta pesquisa pretende descrever a utilização do método DMAIC no diagnóstico e avaliação de oportunidade de melhoria em um restaurante universitário, avaliar os resultados e identificar os benefícios potenciais que podem ser obtidos, tem-se então uma pesquisa descritiva.

Apresentam-se no item 3.2 as etapas de desenvolvimento do trabalho:

\subsection{ETAPAS DE DESENVOLVIMENTO DO TRABALHO}

Com base nos procedimentos técnicos a serem utilizados, o delineamento desta pesquisa será desenvolvido como uma pesquisa de campo com duas etapas.

Pesquisa de campo é a investigação empírica realizada no local onde ocorre ou ocorreu o fenômeno ou que dispõe de elementos para explicá-lo (VERGARA, 2002). Segundo Ruiz (2002), a pesquisa de campo consiste na observação dos fatos tal como ocorrem espontaneamente e permite o estabelecimento de relações entre determinadas condições, as variáveis independentes, e determinados eventos, as variáveis dependentes. Inicialmente deve-se realizar uma revisão da literatura sobre o assunto em questão e após isso determinar as técnicas que serão utilizadas na coleta de dados, as fontes de amostragem, técnicas de registro dos dados e técnicas de análise posteriores. 
A primeira etapa do trabalho consistiu no estudo do método DMAIC, que verificou quais ferramentas e procedimentos eram mais adequados para a utilização no contexto do restaurante. Foi realizada uma revisão na literatura para identificar as principais abordagens relativas ao planejamento e condução de estudos que seguem o método DMAIC, seguido da aplicação dos procedimentos e técnicas no restaurante. Durante a aplicação do método DMAIC, foram verificadas quais ferramentas e procedimentos melhor se ajustavam ao contexto do restaurante.

Segundo Pande et. al (2001), o método DMAIC deve ser adaptado às necessidades, desde que continue compreensível a todos e que não leve a conclusões erradas. As ferramentas mais básicas devem ser usadas com mais freqüência e a escolha da ferramenta depende do objetivo a ser alcançado. Geralmente há mais de uma ferramenta que pode ser útil e caso uma ferramenta não forneça as respostas procuradas, não deve ser utilizada ou pode ser substituída por outra.

A segunda etapa do trabalho consistiu no planejamento de um projeto de melhoria no restaurante e na apresentação dos resultados da utilização do método DMAIC.

As duas etapas do trabalho ocorreram simultaneamente, o planejamento do projeto de melhoria foi realizado juntamente com a aplicação do método DMAIC no restaurante universitário, pois os resultados da aplicação do método DMAIC no restaurante levaram ao projeto de melhoria.

Assim, a aplicação do método DMAIC e o planejamento do projeto de melhoria ocorreram da seguinte forma:

- Revisão da literatura sobre as principais abordagens e aplicações do método DMAIC e aplicações no contexto de um restaurante.

- Revisão da literatura sobre administração de UANs 
- Criação de um grupo formado por funcionários do restaurante que colaboraram no planejamento do projeto de melhoria.

- Definição da oportunidade de melhoria

- Definição de um plano de coleta de dados

- Análise do processo e dos dados

- Formulação de propostas de melhoria do processo.

O fluxograma da Ilustração 17 e as etapas ilustradas no Quadro 4 foram delineados para que se alcance o objetivo proposto.

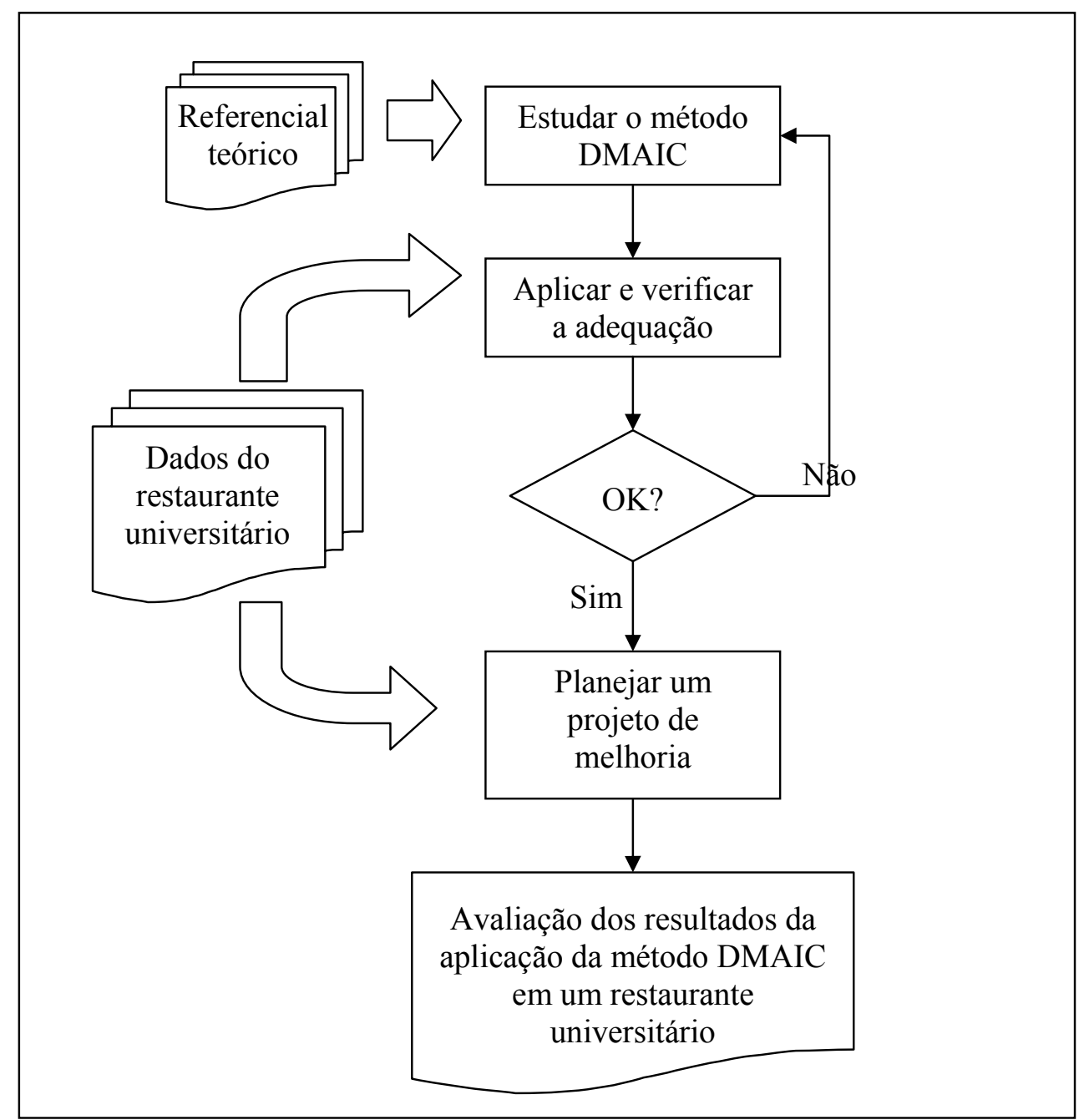

Ilustração 17: Fluxograma do desenvolvimento do trabalho 


\begin{tabular}{|c|l|l|}
\hline & Desenvolvimento & Resultados \\
\hline Etapa 1 & $\bullet \begin{array}{l}\text { Revisão da } \\
\text { literatura. } \\
\text { Aplicação do } \\
\text { método DMAIC. }\end{array}$ & $\begin{array}{l}\text { Método DMAIC e } \\
\text { ferramentas para o } \\
\text { contexto do restaurante. }\end{array}$ \\
\hline Etapa 2 & $\begin{array}{l}\text { Desenvolvimento } \\
\text { de um projeto de } \\
\text { melhoria. }\end{array}$ & • $\begin{array}{l}\text { Avaliação dos resultados da } \\
\text { utilização do DMAIC em um } \\
\text { restaurante universitário. }\end{array}$ \\
\hline
\end{tabular}

Quadro 4: Etapas do desenvolvimento do trabalho e resultados esperados

Apresenta-se, a seguir, um detalhamento destas etapas.

\section{Etapa 1: pesquisa exploratória}

Esta etapa da pesquisa tem as características de uma pesquisa exploratória, pois buscou uma melhor compreensão do método DMAIC e sua aplicação no contexto de um restaurante universitário.

A fim de se alcançar o primeiro objetivo específico, que é o de estudar e aplicar o método DMAIC, foi realizada uma pesquisa bibliográfica em livros, dissertações, teses e outras publicações científicas.

A pesquisa bibliográfica busca conhecer e analisar as contribuições culturais ou científicas do passado existentes sobre um determinado assunto, tema ou problema (CERVO; BERVIAN, 2002). Segundo Vergara (2000), fornece instrumento analítico para qualquer outro tipo de pesquisa e pode ser realizado com base na consulta de material publicado em livros, revistas, jornais, redes eletrônicas, isto é, material acessível ao público em geral.

Por meio da observação dos processos do restaurante e da revisão da literatura sobre administração de Unidades de Alimentação e Nutrição, foram verificadas as ferramentas que poderiam ser utilizadas no contexto de um restaurante universitário, chegando ao segundo objetivo específico da pesquisa. Segundo Pande et al. (2001), a utilização das ferramentas disponíveis no DMAIC devem ser adequadas ao contexto da aplicação. 


\section{Etapa 2: pesquisa descritiva}

Esta etapa da pesquisa tem as características de uma pesquisa descritiva, pois deverá descrever as características de uma aplicação do método DMAIC em um restaurante universitário.

Para atingir o terceiro objetivo específico, foi realizado um estudo para desenvolver projeto de melhoria no restaurante universitário, utilizando os procedimentos e ferramentas do método DMAIC, que resultou em propostas de ações para a resolução de um problema, chegando ao último objetivo específico.

Os resultados da aplicação do modelo teórico no restaurante universitário levaram ao projeto de melhoria. Sendo assim, o planejamento de um projeto de melhoria foi realizado juntamente com a aplicação do modelo teórico no restaurante universitário.

\subsection{COLETA DE DADOS}

Estudou-se neste projeto o restaurante central do campus da USP/Ribeirão Preto que incluem dois refeitórios. O primeiro deles encontra-se junto à cozinha do restaurante central, onde os usuários servem-se em bandejas. Este refeitório foi chamado de refeitório I durante a descrição da pesquisa. O outro refeitório, chamado de refeitório II, funciona apenas no almoço, possui menor porte e os usuários servem-se em pratos. As refeições distribuídas em ambos os refeitórios são preparadas na cozinha do restaurante central.

Tendo em vista que o refeitório II não são servidas refeições no jantar, foram coletados dados apenas do almoço em ambos os refeitórios.

A coleta de dados foi realizada entre os dias 18/09/2007 e 27/09/2007, apenas nos dias úteis. Os dados sobre os restos dos alimentos distribuídos e não consumidos do dia 21/09, coletados no refeitório I não puderam ser utilizados na análise devido à uma falha na coleta.

Foram utilizadas diversas técnicas de coletas de dados: 
- Entrevista não estruturada

A entrevista não estruturada visa descobrir os aspectos que o entrevistado considera mais relevantes sobre determinado problema, por meio de uma conversação guiada (RICHARDSON, 1999). O que a distingue de uma simples conversa é que tem o objetivo de coletar dados (GIL, 2002). Foram realizadas entrevistas com as responsáveis pela administração do restaurante e com as funcionários envolvidas na produção durante o desenvolvimento do projeto de melhoria no restaurante.

A pesquisa no restaurante e a aplicação do método DMAIC foram desenvolvidas em cooperação com funcionários da gerência do restaurante universitário, funcionários responsáveis por processos-chave e outros funcionários, conforme a necessidade do trabalho. Foi formada uma equipe principal composta pelas principais responsáveis pela administração e funcionamento do restaurante. Os nomes e funções de cada membro da equipe são apresentados no Quadro 5.

\begin{tabular}{|l|l|}
\hline Nome & Função \\
\hline Ana Lúcia Eiko Nozaki Sola Losa & Chefe técnica da seção de alimentação \\
\hline Marli José Vitório Colombari & Nutricionista \\
\hline Rosiclair Saores Benedetti & Técnica de nutrição e dietética \\
\hline Sonia Maria de Carvalho & Responsável pelo refeitório II \\
\hline
\end{tabular}

Quadro 5: Funcionárias do restaurante que participaram do projeto

Foram realizadas reuniões periódicas com os colabores do restaurante para que recebessem orientações sobre os fundamentos do método DMAIC. Eles participaram das atividades de definição do problema, coleta de dados, mapeamento e análise do processo e descoberta de possíveis soluções.

Segundo Eckes (2001), todo programa de qualidade precisa incluir a liderança da empresa. Para isso o programa de qualidade precisa ser visto com um meio para que os objetivos negociais da organização sejam alcançados. 
- Formulário

Segundo Gil (2002), formulário é uma técnica de coleta de dados em que o pesquisador faz perguntas previamente definidas e anotas as respostas dos questionados. Esta técnica é adequada para pesquisas de opinião pública e de mercado, sendo utilizada freqüentemente em situações não muito favoráveis, tais como, filas de ônibus e saídas de cinema.

O formulário (Apêndice) foi composto de perguntas simples, visando a repostas objetivas e únicas, buscando-se conhecer a aceitação do respondente em relação à refeição que estava sendo servida no dia da pesquisa. A coleta de dados procurou responder às seguintes questões:

- Qual é a quantidade de alimentos distribuídos e não consumidos?

- Qual a proporção que usuários que gostam das refeições servidas nos refeitórios?

- Quais são, entre os principais itens que compõe as refeições, os que possuem maior impacto na aceitação das refeições?

O usuário era questionado se havia gostado da refeição. No caso da resposta ser negativa, ele listava a razão de seu descontentamento. Descontentamento esse relacionado, conforme ressaltado anteriormente, à aceitação do que estava sendo servido. Não foram mensurados outros critérios, tais como a satisfação e seus motivos, visto que fogem do escopo da pesquisa.

Para realizar uma amostragem sistemática na coleta de dados sobre a aceitação das refeições pelos usuários dos refeitórios, seria necessário que dois pesquisadores, um em cada refeitório, coletassem dados durante todo o horário de almoço, das $11 \mathrm{~h}$ às 14 h. Porém, para evitar vieses, os pesquisadores não poderiam ser funcionários do restaurante. Este fato inviabilizou a realização de uma amostragem sistemática, pois não foram encontrados pesquisadores dispostos a participar da coleta de dados realizada dessa forma. 
Portanto, para que fosse possível realizar a pesquisa sobre a aceitação, foi utilizada uma amostra não probabilística por conveniência.

O pesquisador abordava os usuários que saíam do refeitório durante o almoço, das 11:30h às 12:30h, por ser um horário em que o volume de usuários que saem do refeitório é menor, sendo possível assim, conhecer a opinião de quase $100 \%$ dos usuários que saíram nesse intervalo, ou até que o número de respondentes chegasse ao limite estabelecido no formulário. Foram entrevistados 1049 usuários no refeitório I e 788 no refeitório II.

- Levantamento do peso dos restos de alimentos distribuídos e não consumidos do almoço

Durante o período especificado para a coleta de dados um funcionário de cada refeitório foi orientado e supervisionado pelo pesquisador na coleta de pesagem dos restos do almoço, registrando estes valores em uma planilha fornecida pelo pesquisador.

- Observação não participante do processo produtivo

A observação não participante, segundo Alencar (1999), é aquela em que o pesquisador permanece onde se encontram os indivíduos que estão sendo observados. No entanto, não se faz passar por um deles. Neste estudo o pesquisador realizou observações com o intuito de conhecer o caso estudado bem como o processo produtivo do restaurante de forma a adquirir maior familiaridade e assim aplicar o método DMAIC com maior destreza.

\subsection{ANÁLISE DE DADOS}

Para a análise dos dados coletados e do processo estudado no restaurante utilizaram-se testes estatísticos, estatísticas descritivas e ferramentas da qualidade, conforme o Quadro 6. 


\begin{tabular}{|l|l|l|}
\hline FERRAMENTAS & OBJETIVOS & FONTE DOS DADOS \\
\hline Teste de médias & $\begin{array}{l}\text { Verificar a existência de diferenças } \\
\text { significativas nas médias dos restos } \\
\text { por usuário nos refeitórios I e II }\end{array}$ & Levantamento dos pesos \\
\hline Teste de proporção & $\begin{array}{l}\text { Verificar a existência de diferenças } \\
\text { significativas na proporção da } \\
\text { aceitação da refeição pelos usuários } \\
\text { nos refeitórios I e II }\end{array}$ & Formulário \\
\hline Métodos Gráficos & Descrever as variáveis & $\begin{array}{l}\text { Formulário e levantamento } \\
\text { dos pesos }\end{array}$ \\
\hline $\begin{array}{l}\text { Estatísticas } \\
\text { Descritivas }\end{array}$ & $\begin{array}{l}\text { Descrição das variáveis em termos } \\
\text { numéricos. }\end{array}$ & $\begin{array}{l}\text { Formulário e levantamento } \\
\text { dos pesos }\end{array}$ \\
\hline $\begin{array}{l}\text { Diagrama de } \\
\text { Pareto }\end{array}$ & $\begin{array}{l}\text { Identificar o motivo que gerou a maior } \\
\text { parte da insatisfação do usuário }\end{array}$ & $\begin{array}{l}\text { Entrevistas não estruturadas e } \\
\text { observação não participante }\end{array}$ \\
\hline FMEA & $\begin{array}{l}\text { Identificar problemas e seus efeitos } \\
\text { Fntrevistas não estruturadas e } \\
\text { observação não participante }\end{array}$ \\
\hline $\begin{array}{l}\text { Diagrama Causa e } \\
\text { Efeito }\end{array}$ & $\begin{array}{l}\text { Identificar os fatores relacionados ao } \\
\text { problema }\end{array}$ & $\begin{array}{l}\text { Entrevistas não estruturadas e } \\
\text { observação não participante }\end{array}$ \\
\hline
\end{tabular}




\section{RESULTADOS}

Neste capítulo serão descritos os resultados da aplicação do método DMAIC no restaurante. Inicia-se com a discussão dos critérios utilizados na identificação da oportunidade de melhoria, seguido pela descrição das análises dos dados e do processo. Por fim, trata das propostas de melhoria.

\subsection{IDENTIFICAÇÃO DA OPORTUNIDADE DE MELHORIA}

As atividades para definir a oportunidade de melhoria começaram pela identificação do processo central do restaurante e de seus clientes.

O processo central de um restaurante é a produção e distribuição de refeições, tendo assim, como saída do processo os alimentos preparados. À primeira vista, pode-se pensar que os únicos clientes desse processo são os usuários que compram e consomem as refeições. No caso do restaurante do campus, a PCARP pode ser vista como a principal interessada nos resultados do serviço de alimentação fornecido pelo restaurante. A PCARP gerencia todos os recursos financeiros utilizados pelo restaurante central do campus, além de subsidiar as refeições servidas aos alunos. Dessa forma, foram definidos dois clientes do processo: os usuários do restaurante e a PCARP.

Definidos os clientes, foram verificadas as necessidades dos clientes e criadas as árvores do que é crítico para a qualidade (CPQ), como sugere Eckes. Foram definidos três requisitos principais que influenciam na satisfação dos usuários: a qualidade da refeição, a higiene dos utensílios e a variação no cardápio (Ilustração 18). A PCARP apresentou como requisitos principais a qualidade das refeições, satisfação dos usuários e baixo custo (Ilustração 19). 


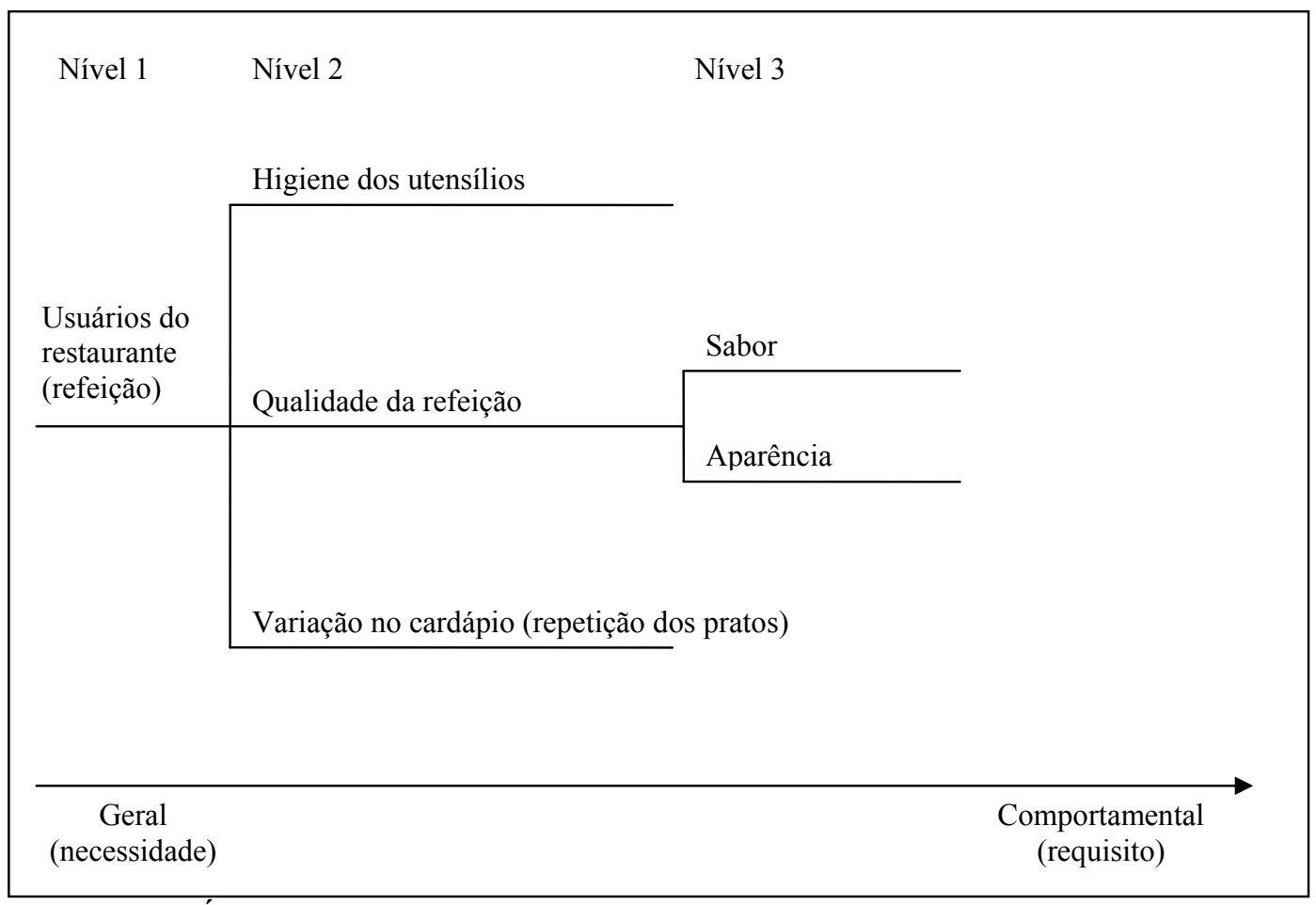

Ilustração 18: Árvore CPQ dos usuários do restaurante

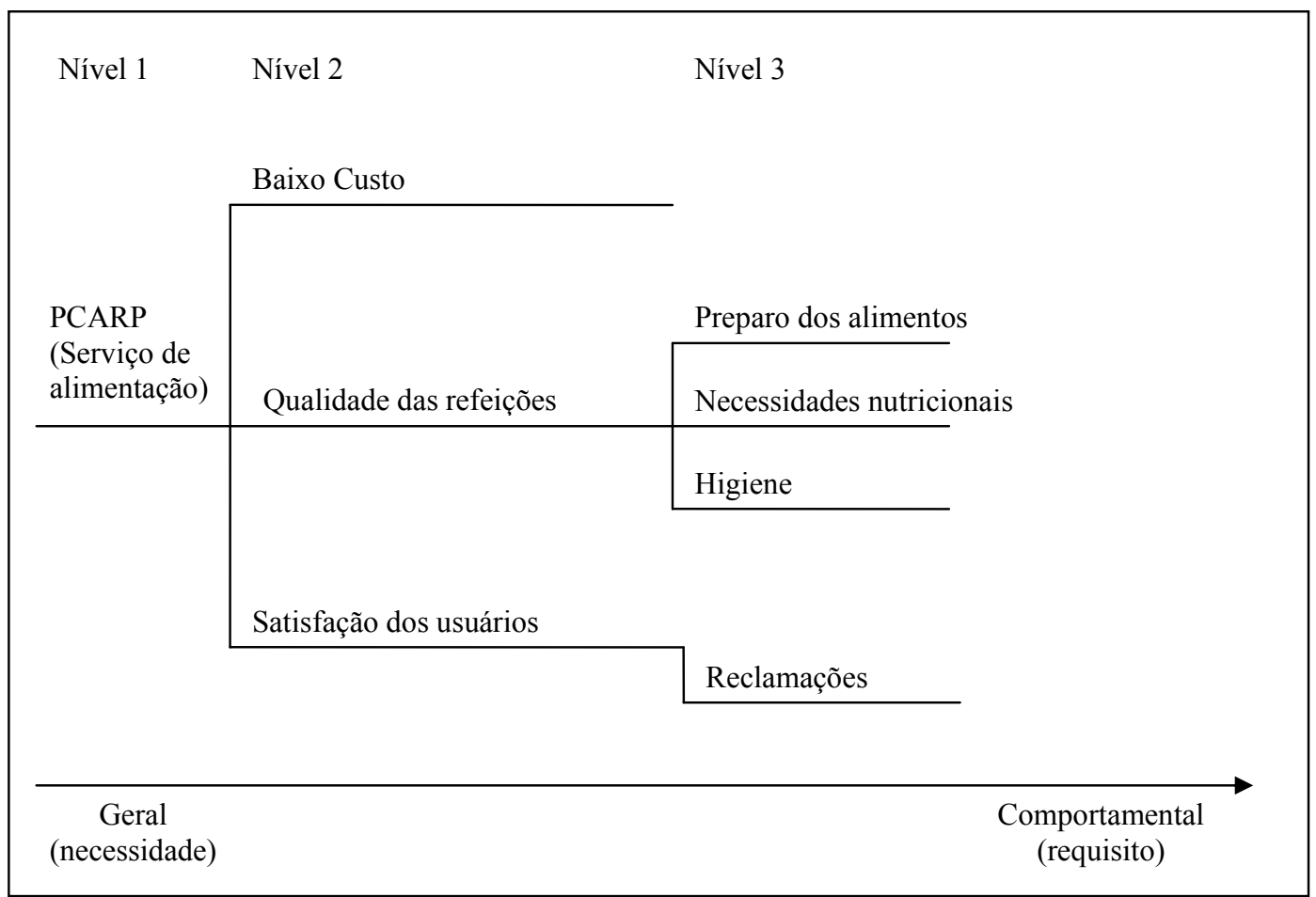

Ilustração 19: Árvore CPQ da PCARP

O passo seguinte foi a criação do mapa SIPOC (Ilustração 20), que identificou as atividades principais do restaurante, assim como os interessados e seus requisitos. 


\begin{tabular}{|c|c|c|c|c|c|}
\hline Fornecedores & Entradas & Processos & Saídas & Clientes & Requisitos \\
\hline $\begin{array}{l}\text { - Setor de } \\
\text { compras da } \\
\text { PCARP } \\
\text { - Seção de } \\
\text { alimentação }\end{array}$ & $\begin{array}{ll}\text { - } & \text { Gêneros } \\
& \text { alimentícios } \\
\text { - } & \text { Funcionários } \\
\text { - } & \text { Equipamentos }\end{array}$ & $\begin{array}{l}\text { - Requisição } \\
\text { - Recebimento } \\
\text { - Pré-preparo } \\
\text { - Preparo } \\
\text { - Distribuição } \\
\text { - Higienização }\end{array}$ & - Refeições & - Usuários & $\begin{array}{l}\text { - } \text { Qualidade das } \\
\text { refeições } \\
\text { - } \text { Higiene dos } \\
\text { utensílios } \\
\text { - Variação no } \\
\text { cardápio }\end{array}$ \\
\hline & & & & - PCARP & $\begin{array}{l}\text { - Baixo custo } \\
\text { - Qualidade das } \\
\text { refeições } \\
\text { - Satisfação dos } \\
\\
\text { usuários }\end{array}$ \\
\hline
\end{tabular}

Ilustração 20: SIPOC do processo central do restaurante

Um ponto importante foi a necessidade de que o projeto de melhoria estivesse alinhado aos objetivos do restaurante. O restaurante central do campus desenvolve um projeto de minimização de resíduos, em parceria com a PCARP e o USP Recicla, e já implantou a utilização de canecas duráveis e o self-service no restaurante. A utilização das canecas duráveis reduziu o lixo resultante do descarte de copos descartáveis, além de gerar redução de custos por não oferecer mais os copos descartáveis aos usuários. O self-service foi implantado devido ao fato de que muitos usuários jogavam comida fora por receberem porções maiores do que desejavam comer.

Assim, o objetivo da atividade de melhoria focou na redução do desperdício de alimentos no restaurante. O mapeamento do processo indicou que a redução do desperdício está ligada a um requisito de qualidade da PCARP, que é o de manter baixo o custo no serviço de alimentação.

Segundo Abreu, Spinelli e Zanardi (2003), o desperdício de alimentos está relacionado a três fatores principais:

- A perda das partes não-comestíveis que são retiradas dos alimentos.

- Alimentos produzidos e não distribuídos.

- Alimentos distribuídos e não consumidos.

Para que estes fatores de desperdício de alimentos fossem observados no processo, foi realizado o mapeamento do fluxo de manipulação dos alimentos (Ilustração 21). 


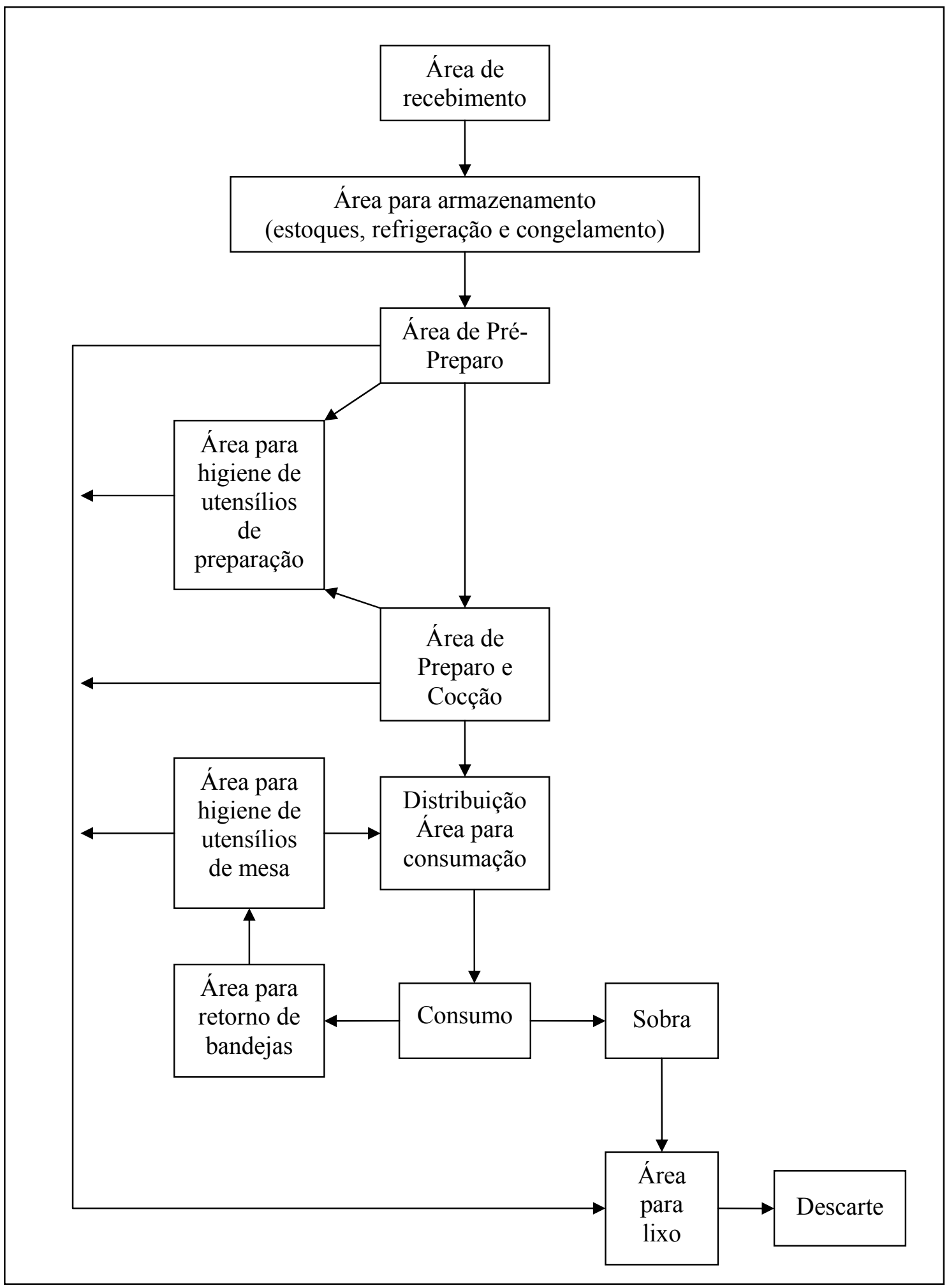

Ilustração 21: Fluxo de manipulação dos alimentos

Havia um interesse especial em reduzir os restos de alimentos descartados pelos usuários do restaurante, ou seja, os alimentos distribuídos e não consumidos. A implantação 
do self-sevice foi uma medida que visou a redução desse tipo de desperdício, mas não foram realizados outros estudos que indicassem medidas viáveis de serem aplicadas.

Assim, a redução do desperdício de alimentos pelos usuários mostrou-se uma oportunidade de melhoria alinhada com objetivos do restaurante e cuja solução não era predeterminada ou óbvia.

\subsection{COLETA E ANÁLISE DOS DADOS}

As variáveis da coleta de dados foram definidas a partir da revisão da literatura sobre as UANs, identificando as principais causas do desperdício de alimentos. Abreu et al. (2003) afirmam que, partindo do princípio de que as refeições estão bem preparadas, os restos devem ser próximos de zero, visto que em restaurantes com refeições pagas pelo peso, o cliente serve-se apenas da quantidade que consegue comer. No caso de restaurantes onde o usuário pode comer à vontade, o tamanho do prato, das vasilhas e dos utensílios usados para pegar a comida pode induzir os clientes a se servirem de uma quantidade maior que a possibilidade de consumo. Segundo Bradacz (2003), o controle dos restos não é uma atividade simples de ser realizada porque envolve o usuário e sua relação com o alimento. Um alto índice de restos inegavelmente significa insatisfação com a comida ou com o serviço de algum modo.

Considerado que o restaurante central distribui as refeições em bandejas no refeitório I e em pratos no refeitório II, decidiu-se verificar se os restos de alimentos distribuídos e não consumidos apresenta diferença significativa entre os dois refeitórios, ou seja, se o tamanho do prato está influenciando no desperdiço de alimentos, visto que as refeições servidas nos dois refeitórios são iguais e de mesma qualidade. Para isso, foram coletados os pesos dos restos de alimentos distribuídos e não consumidos nos dois refeitórios.

A outra variável da coleta de dados foi a aceitação das refeições pelos usuários. Primeiramente, esta variável tenta explicar o motivo da não aceitação das refeições pelos 
usuários. Ademais, procurou verificar se a utilização de bandeja ou prato influencia a aceitação das refeições pelos usuários, tendo em vista que a comida é a mesma

Os dados coletados sobre os restos de alimentos distribuídos e não consumidos nos dois refeitórios do restaurante universitário podem ser observados na Tabela 3:

Tabela 3: Dados sobre os restos dos usuários nos refeitórios I e II

\begin{tabular}{|c|c|c|c|c|c|c|c|}
\hline & \multicolumn{3}{|c|}{ Refeitório I } & \multicolumn{3}{|c|}{ Refeitório II } \\
\cline { 2 - 4 } DATA & Restos & $\begin{array}{c}\text { Número } \\
\text { de } \\
\text { (Kg) }\end{array}$ & $\begin{array}{c}\text { Média dos } \\
\text { restos por } \\
\text { usuários } \\
\text { usuário } \\
(\mathrm{Kg})\end{array}$ & & $\begin{array}{c}\text { Restos } \\
(\mathrm{Kg})\end{array}$ & $\begin{array}{c}\text { Número } \\
\text { de } \\
\text { usuários }\end{array}$ & $\begin{array}{c}\text { Média dos } \\
\text { restos por } \\
\text { usuário } \\
(\mathrm{Kg})\end{array}$ \\
\hline $18 / 9$ & 113 & 1649 & 0,069 & & 10,03 & 429 & 0,023 \\
\hline $19 / 9$ & 217,5 & 1429 & 0,152 & & 22,6 & 468 & 0,048 \\
\hline $20 / 9$ & 122,5 & 1456 & 0,084 & & 8,62 & 456 & 0,019 \\
\hline $21 / 9$ & - & - & - & & 14,65 & 344 & 0,043 \\
\hline $24 / 9$ & 132 & 1289 & 0,102 & & 8,29 & 390 & 0,021 \\
\hline $25 / 9$ & 127,5 & 1671 & 0,076 & & 6,1 & 463 & 0,013 \\
\hline $26 / 9$ & 140 & 1504 & 0,093 & & 10,63 & 510 & 0,021 \\
\hline $27 / 9$ & 224 & 1387 & 0,161 & & 12,7 & 463 & 0,027 \\
\hline $28 / 9$ & 154,5 & 1254 & 0,123 & & 13,1 & 400 & 0,033 \\
\hline TOTAL & 1231 & 11639 & 0.106 & & 106,72 & 3923 & 0,027 \\
\hline
\end{tabular}

Comparando-se a média de restos por usuário nos dois refeitórios, observa-se que a média do refeitório I é expressivamente maior do que no refeitório II, quase quatro vezes maior para a média total.

Destaca-se que os pesos dos restos incluem os resíduos não consumíveis dos alimentos, como cascas de frutas e ossos, pois não foi possível separá-los no momento da devolução dos utensílios. Sendo assim, estes valores não representam o desperdício real de alimentos pelos usuários. Porém, serve de parâmetro para comparar a discrepância entre os valores nos dois refeitórios.

No dia 21/09 houve uma falha na coleta de dados no refeitório I e não puderam ser utilizados nas análises. 
Nos dias em que o desperdício médio diário foi superior ao desperdício médio geral do período de coleta dos dados, o cardápio ${ }^{2}$ continha alimentos cujos resíduos não consumíveis eram mais pesados, tais como melão e carnes com ossos, o que pode justificar em parte o valor acima da média.

Em todos os dias da amostra, as médias de restos por usuário foram maiores no refeitório I, como pode ser observado no Gráfico 1.

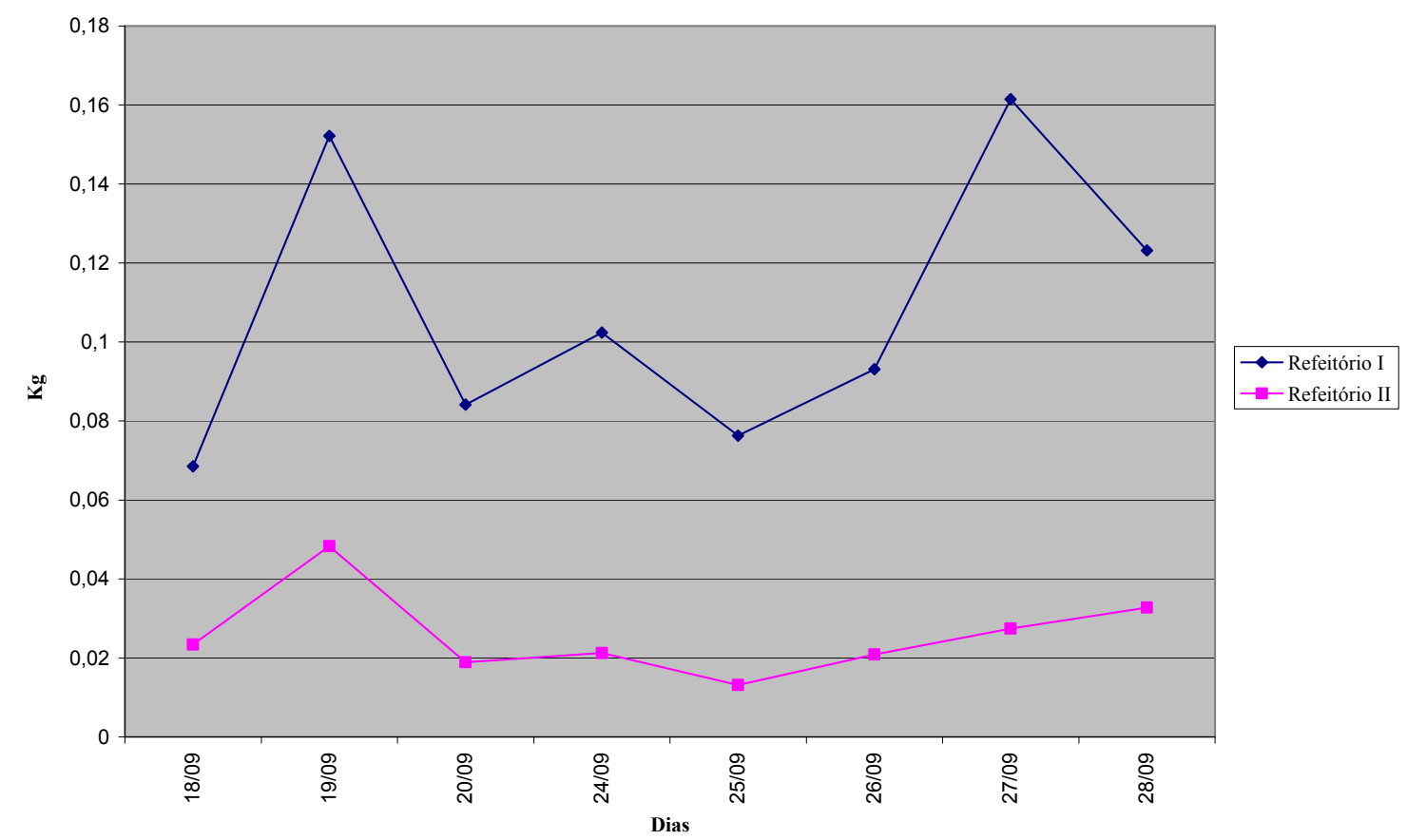

Gráfico 1: Média dos restos por usuário

Para verificar se os restos dos usuários são realmente maiores no refeitório I ou se a diferença é casual, foi realizado o teste de amostras para médias. Este teste exige que a população apresente uma distribuição normal, assim, foi considerado que os pesos dos restos dos usuários apresentam uma distribuição normal, apesar de não haver dados para essa afirmação.

\footnotetext{
${ }^{2} \mathrm{O}$ cardápio dos dias da coleta de dados estão no anexo.
} 
A hipótese nula foi a de que as médias dos restos nos dois refeitórios são iguais e a hipótese alternativa foi a de que a média dos restos no refeitório I é maior do que no refeitório II.

$$
\begin{aligned}
& H_{0}: \mu_{1}=\mu_{2} \\
& H_{1}: \mu_{1}>\mu_{2}
\end{aligned}
$$

A tabela abaixo apresenta a média, variância e números de elementos das amostras dos refeitórios I e II:

\begin{tabular}{|c|c|c|c|}
\hline & Média $\left(\bar{x}_{i}\right)$ & Variância $\left(S_{X i}^{2}\right)$ & Elementos $\left(n_{i}\right)$ \\
\hline Refeitório I & 0,10767 & 0,001205 & 9 \\
\hline Refeitório II & 0,027624 & 0,000133 & 8 \\
\hline
\end{tabular}

Foi utilizada a estatística teste para desvio padrão populacional desconhecido, com tamanho de amostras diferentes e soma das amostras menor do que 30, como se segue:

$$
\begin{aligned}
& t_{\text {teste }}=\frac{\bar{x}_{1}-\bar{x}_{2}}{\sqrt{\left[\frac{\left(n_{1}-1\right) S_{X 1}^{2}+\left(n_{2}-1\right) S_{X 2}^{2}}{n_{1}+n_{2}-2}\right]\left(\frac{1}{n_{1}}+\frac{1}{n_{2}}\right)}} \\
& t_{\text {teste }}=\frac{0,10767-0,027624}{\sqrt{\left[\frac{(9-1) 0,001205+(8-1) 0,000133}{9+8-2}\right]\left(\frac{1}{9}+\frac{1}{8}\right)}} \\
& t_{\text {teste }}=6,546
\end{aligned}
$$

Como a soma de $n_{1}$ e $n_{2}$ é menor do que 30, foi encontrado o valor crítico na tabela $t$ com $n_{1}+n_{2}-2$ graus de liberdade, com $\alpha=0,05$.

Valor crítico: $t_{0,05 ; 15 \text { g.l. }}=1,753$

A estatística teste foi maior do que o valor crítico, caindo na área de rejeição da hipótese nula, indicando que há evidências de que a média dos restos é maior no refeitório I. 
Tabela 4: Diferença entre os refeitórios

\begin{tabular}{|c|c|c|c|}
\hline \multicolumn{2}{|c|}{$\begin{array}{c}\text { Média dos restos por } \\
\text { usuário(Kg) }\end{array}$} & $\begin{array}{c}\text { Diferença entre o refeitório I } \\
\text { e o refeitório II }\end{array}$ \\
\hline Refeitório I & Refeitório II & $\mathrm{Kg}$ & $\begin{array}{c}\text { Percentual } \\
\text { em relação ao } \\
\text { refeitório I }\end{array}$ \\
\hline 0,069 & 0,023 & 0,046 & $65,88 \%$ \\
\hline 0,152 & 0,048 & 0,104 & $68,27 \%$ \\
\hline 0,084 & 0,019 & 0,065 & $77,53 \%$ \\
\hline 0,102 & 0,021 & 0,081 & $79,24 \%$ \\
\hline 0,076 & 0,013 & 0,063 & $82,73 \%$ \\
\hline 0,093 & 0,021 & 0,072 & $77,61 \%$ \\
\hline 0,161 & 0,027 & 0,134 & $83,02 \%$ \\
\hline 0,123 & 0,033 & 0,090 & $73,42 \%$ \\
\hline
\end{tabular}

O valor relativo da diferença entre os dois refeitórios mostra que os restos do refeitório I podem ser reduzidos entre $70,68 \%$ e $81,24 \%{ }^{4}$, se reduzidos aos mesmos níveis do refeitório II.

Os dados sobre a aceitação das refeições pelos alunos indicam que a proporção de usuários que disseram ter gostado da comida foi maior no refeitório II em sete dias dos nove pesquisados (Gráfico 2).

Considerando-se todo o período da coleta de dados, o refeitório II apresentou uma proporção maior de usuários que disseram ter gostado das refeições servidas no restaurante, $88,51 \%$ no refeitório I e $94,87 \%$ no refeitório II, conforme se observa na Tabela 5.

Nos dias em que a aceitação foi menor, verificou-se que o motivo citado pelos usuários foram a carne com muita gordura no dia 19, o tipo do peixe servido no dia 21 e a carne com muita gordura e nervos nos dias 18 eROTONDARO et al., 2002 27. Observa-se nos cardápios dos dias 18 e 27 que foi servido picadinho de carne, indicando que é um prato com baixa aceitação entre os usuários.

\footnotetext{
${ }^{3}$ Porcentagem em relação aos valores do refeitório I. Foi obtida pela divisão da diferença entre os refeitórios pelo peso médio dos restos no refeitório I.

${ }^{4}$ A fórmula do cálculo do intervalo de confiança é $\bar{x} \pm t \frac{S x}{\sqrt{n}}$ com $95 \%$ de confiança e 7 graus de liberdade.
} 
Tabela 5: Resultado da pesquisa sobre a aceitação das refeições em valores absolutos e relativos

\begin{tabular}{|c|c|c|c|c|c|c|c|c|}
\hline \multirow{2}{*}{ DATA } & \multicolumn{2}{|c|}{ Refeitório I } & \multicolumn{2}{|c|}{ Refeitório II } & \multicolumn{2}{|c|}{ Refeitório I } & \multicolumn{2}{|c|}{ Refeitório II } \\
\hline & Sim & Não & Sim & Não & Sim & Não & Sim & Não \\
\hline $18 / 09$ & 95 & 26 & 66 & 15 & $78,51 \%$ & $21,49 \%$ & $81,48 \%$ & $18,52 \%$ \\
\hline $19 / 09$ & 105 & 52 & 69 & 21 & $66,88 \%$ & $33,12 \%$ & $76,67 \%$ & $23,33 \%$ \\
\hline $20 / 09$ & 113 & 16 & 90 & 3 & $87,60 \%$ & $12,40 \%$ & $96,77 \%$ & $3,23 \%$ \\
\hline $21 / 09$ & 77 & 34 & 47 & 24 & $69,37 \%$ & $30,63 \%$ & $66,20 \%$ & $33,80 \%$ \\
\hline $24 / 09$ & 101 & 23 & 76 & 12 & $81,45 \%$ & $18,55 \%$ & $86,36 \%$ & $13,64 \%$ \\
\hline $25 / 09$ & 98 & 9 & 91 & 3 & $91,59 \%$ & $8,41 \%$ & $96,81 \%$ & $3,19 \%$ \\
\hline $26 / 09$ & 95 & 22 & 74 & 4 & $81,20 \%$ & $18,80 \%$ & $94,87 \%$ & $5,13 \%$ \\
\hline $27 / 09$ & 77 & 19 & 71 & 22 & $80,21 \%$ & $19,79 \%$ & $76,34 \%$ & $23,66 \%$ \\
\hline $28 / 09$ & 77 & 10 & 97 & 3 & $88,51 \%$ & $11,49 \%$ & $97,00 \%$ & $3,00 \%$ \\
\hline Total & 838 & 211 & 681 & 107 & $79,89 \%$ & $20,11 \%$ & $86,42 \%$ & $13,58 \%$ \\
\hline
\end{tabular}

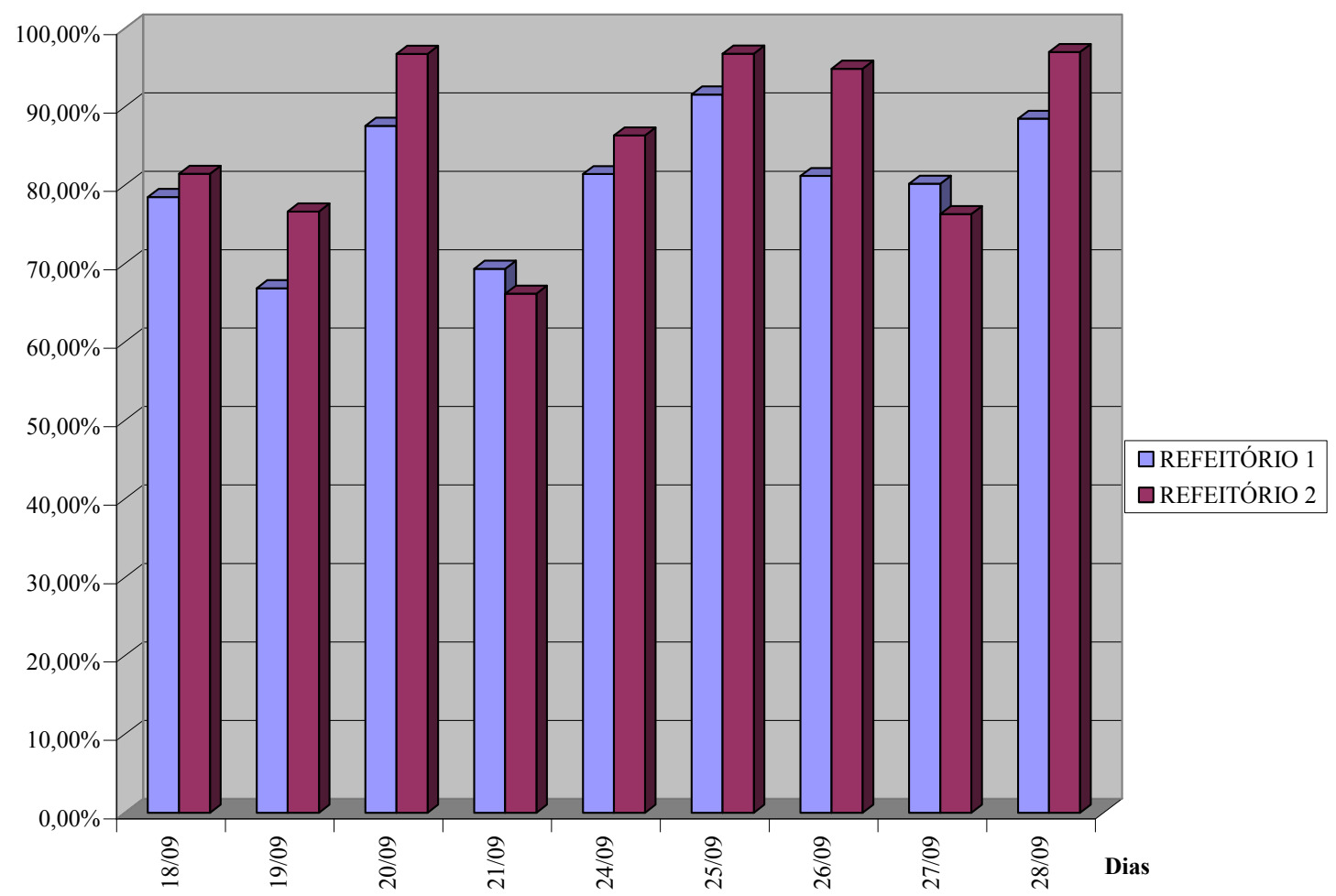

\section{Gráfico 2: Aceitação das refeições}

Para verificar se a aceitação das refeições no refeitório II é realmente maior do que no refeitório I, foi realizado o teste de significância de duas amostras para proporções. A hipótese nula foi a de que as proporções nos dois refeitórios são iguais e a hipótese alternativa a de que a aceitação no refeitório II é maior. 
$H_{0}: p_{1}=p_{2}$

$H_{1}: p_{1}<p_{2}$

No refeitório I, 838 usuários, entre 1048, responderam ter gostado da refeição, enquanto que no refeitório II, de 788 usuário, 681 responderam ter gostado das refeições, como pode ser observado na Tabela 6:.

\begin{tabular}{|c|c|c|c|}
\hline & Sim & Não & $\mathrm{N}^{\mathrm{o}}$ de observações \\
\hline Refeitório I & 838 & 211 & 1049 \\
\hline Refeitório II & 681 & 107 & 788 \\
\hline
\end{tabular}

Estatística teste:

$z=\frac{\left(x_{1} / n_{1}\right)-\left(x_{2} / n_{2}\right)}{\sqrt{p(1-p)\left[\left(1 / n_{1}\right)+\left(1 / n_{2}\right)\right]}}$, onde $p=\frac{x_{1}+x_{2}}{n_{1}+n_{2}}$

Temos então

$$
\begin{aligned}
& p=\frac{838+681}{1049+788}=0,82689 \\
& z=\frac{(838 / 1049)-(681 / 788)}{\sqrt{0,82689(0,17311)[(1 / 1049)+(1 / 788)]}}=-3,66
\end{aligned}
$$

Aplicou-se o teste unilateral à esquerda, pois $H_{1}: p_{1}<p_{2}$.

O valor tabulado, utilizando o nível de $0,01(\alpha=0,01)$ e a tabela normal, é $\mathrm{z}=-2,33$.

Como a estatística teste tem seu valor dentro da área de rejeição, conclui-se que há evidências de que a aceitação dos alimentos no refeitório II é maior do que no refeitório I. Entretanto, tratando-se de uma não-aleatória, os resultados obtidos não podem ser generalizados para a população.

Os dados também indicaram que as carnes servidas durante os dias de coleta de dados foram, entre os itens principais que compõe as refeições, o maior motivo pelo qual os usuários responderam não ter gostado da comida servida, ou seja, o principal motivo da não aceitação 
da refeição pelos usuários. O Gráfico de Pareto (Gráfico 3), mostra que 79,71\% dos usuários que responderam não ter gostado da refeição indicaram a carne servida como motivo.

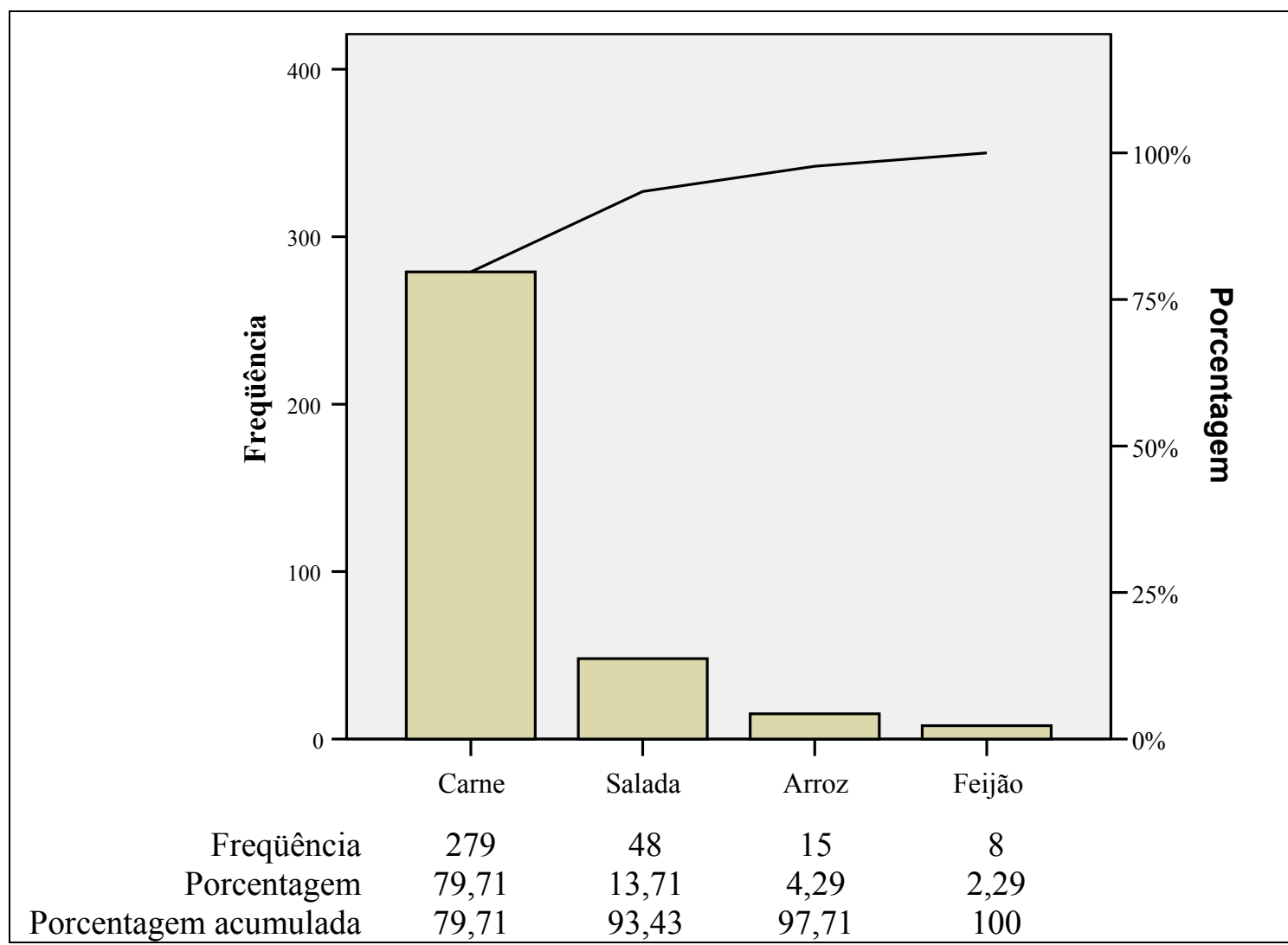

Gráfico 3: Parte da refeição que causou a não aceitação

Considerando que a carne foi o item mais relevante da não aceitação das refeições, construiu-se um gráfico de Pareto (Gráfico 4) indicando os principais motivos da insatisfação com a carne. Nota-se que a presença de gordura e nervos foram os principal fatores determinantes desta insatisfação. Estas características são relacionadas à qualidade da carne, assim, este fator possui grande impacto sobre a aceitação das refeições pelo usuário. Desta forma a melhor qualidade da matéria-prima pode influenciar positivamente na aceitação das refeições pelos usuários.

Destaca-se que, no período estudado, houve uma falha na entrega de carnes pelo ganhador do pregão, o que obrigou o restaurante a comprar carnes da USP de Pirassununga em caráter de urgência. Entretanto, a qualidade das carnes fornecidas pela USP de 
Pirassununga ficaram aquém da especificada no edital do pregão, o que pode explicar os resultados obtidos no gráfico de Pareto.

As carnes utilizadas no picadinho, prato que mostrou uma baixa aceitação entre os usuários, utilizou diversos tipos de carnes misturadas, carne de primeira e de segunda, mostrando que o preparo da carne não está adequando, ficando abaixo da expectativa dos usuários.

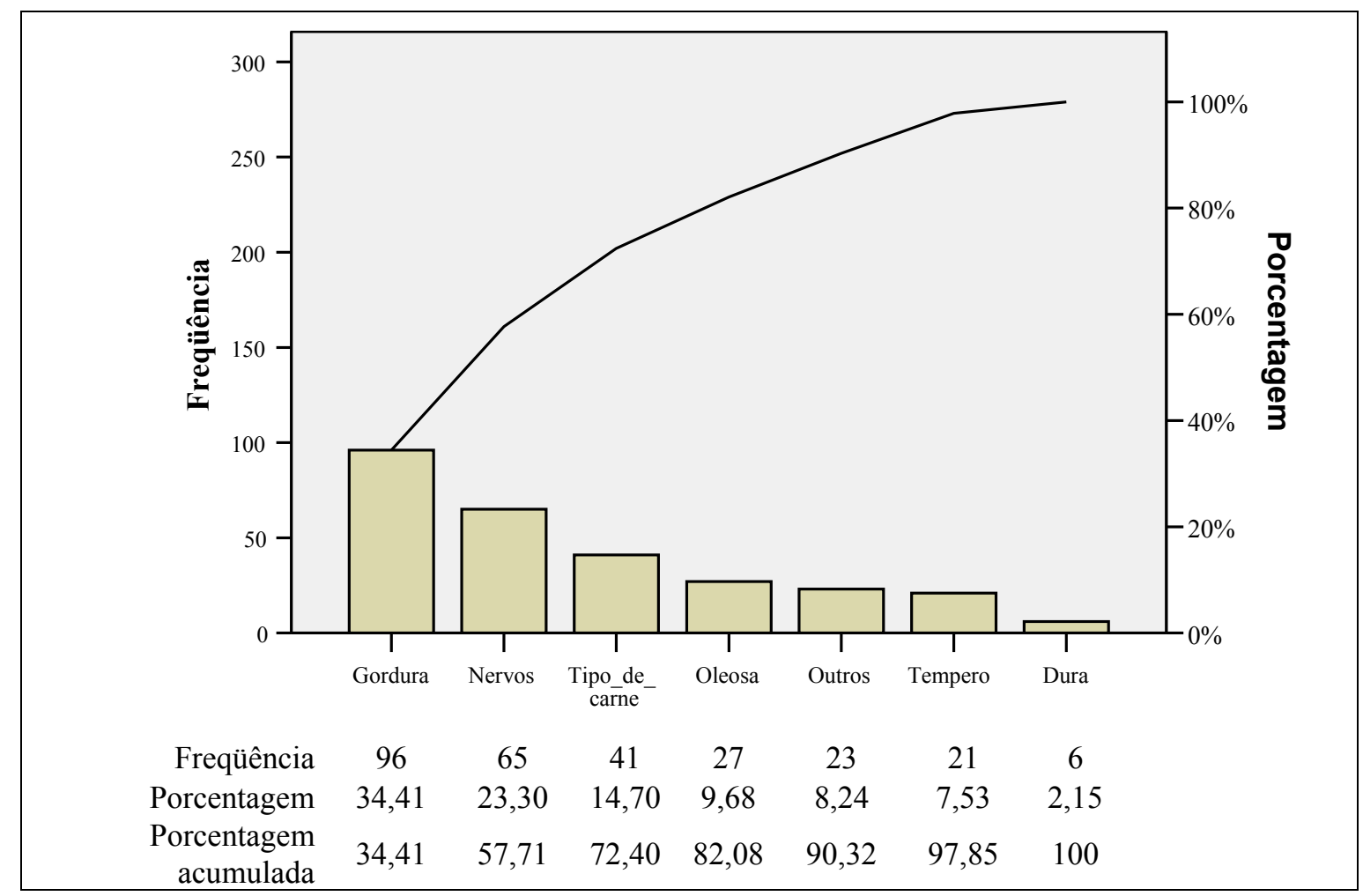

Gráfico 4: Motivos da insatisfação com a carne

A coluna tipo de carne inclui respostas sobre preferências pessoais dos usuários, tais como não gostar de carne de porco, peixe, frango, carne moída ou picadinho. A coluna outros inclui reclamações variadas e não muito representativas, tais como carne mal passada, ou seca, muitos espinhos no peixe ou pouca carne na bisteca. 


\subsection{ANÁLISE DAS CAUSAS DO PROBLEMA}

$\mathrm{Na}$ análise das causas do problema, foram elaborados Diagramas de Causa e Efeito e um formulário FMEA, em conjunto com as funcionárias do restaurante que participaram da pesquisa.

Por meio da elaboração dos diagramas de causa e efeitos, a equipe levantou idéias sobre o que pode explicar o problema do desperdício.

O diagrama de causa e efeito sobre o desperdício de alimentos (Ilustração 22) indicou que em relação à mão-de-obra, o problema é a falta de treinamento dos funcionários, o que leva a falha na manipulação dos alimentos no pré-preparo e no porcionamento durante a distribuição. A manipulação incorreta no pré-preparo diz respeito ao modo que os funcionários cortam as partes não comestíveis dos alimentos, descartando partes que poderiam ser consumidas. O porcionamento trata do dimensionamento das porções que os funcionários servem aos usuários. Os funcionários são orientados sobre o tamanho da porção, mas não seguem um padrão rígido.

Com relação aos materiais, foram relacionados ao desperdício de alimentos o tamanho do prato, que pode induzir o usuário a se servir de uma quantidade maior do que consegue consumir, a aceitação dos alimentos, e problemas com o fornecedor, tais como falha na entrega e a qualidade dos alimentos.

As máquinas geram desperdício de alimentos quando os equipamentos utilizados para descascar batatas, por exemplo, estão desregulados e retiram em excesso partes dos alimentos.

Em relação ao ambiente, o local de armazenagem de hortaliças não tem dimensões adequadas para que os alimentos fiquem na temperatura ideal, degradando-se mais rapidamente com o calor. $\mathrm{O}$ armazenamento inadequado também pode levar à contaminação dos alimentos. 
A falta de padronização dos processos de manipulação dos alimentos também foi indicada como uma causa determinante do desperdício, pois os funcionários realizam as tarefas sem seguir procedimentos específicos.

Outra causa do desperdiço de alimentos, indicada pelas funcionárias, foi o superdimensionamento da demanda, produzindo alimentos em excesso.

O diagrama de causa e efeito a respeito da qualidade das refeições (Ilustração 23) indicou que a falta de um receituário padrão está influenciando a qualidade das refeições. Outro problema destacado pelas funcionárias do restaurante é o alto número de funcionários com limitações por problemas de saúde. Dos 38 funcionários do restaurante, na época da pesquisa, 11 apresentavam limitações.

Os equipamentos da cozinha, tais como panelas industriais e fornos, são obsoletos e em quantidade insuficiente, o que inviabiliza a produção de certos pratos mais sofisticados e dificulta o atendimento da demanda de usuários de forma adequada. O layout da cozinha e o espaço também oneram a qualidade do processo de produção dos alimentos.

A falta de locais adequados para a armazenagem dos alimentos tem impacto na qualidade das refeições, pois limita a variedade do cardápio e prejudica a qualidade do alimento antes do preparo.

As idéias apresentadas nos diagramas de causa e efeito foram analisadas pelo grupo, que realizou uma votação na qual foi reduzido o número de causas prováveis do desperdício de alimentos. A partir disso, foi feito o FMEA (Quadro 7), que evidenciou os problemas enfrentados, seus efeitos e possíveis ações corretivas. Os problemas no preparo dos alimentos receberam NPR (Número de Prioridade de Risto) igual a 150, numa escala de 1 a 1000, sendo o problema mais importante dentre os levantados. O desenvolvimento de um receituário padrão, treinamento e conscientização dos funcionários e a melhoria na elaboração do edital de compra foram as ações sugeridas pela equipe. 


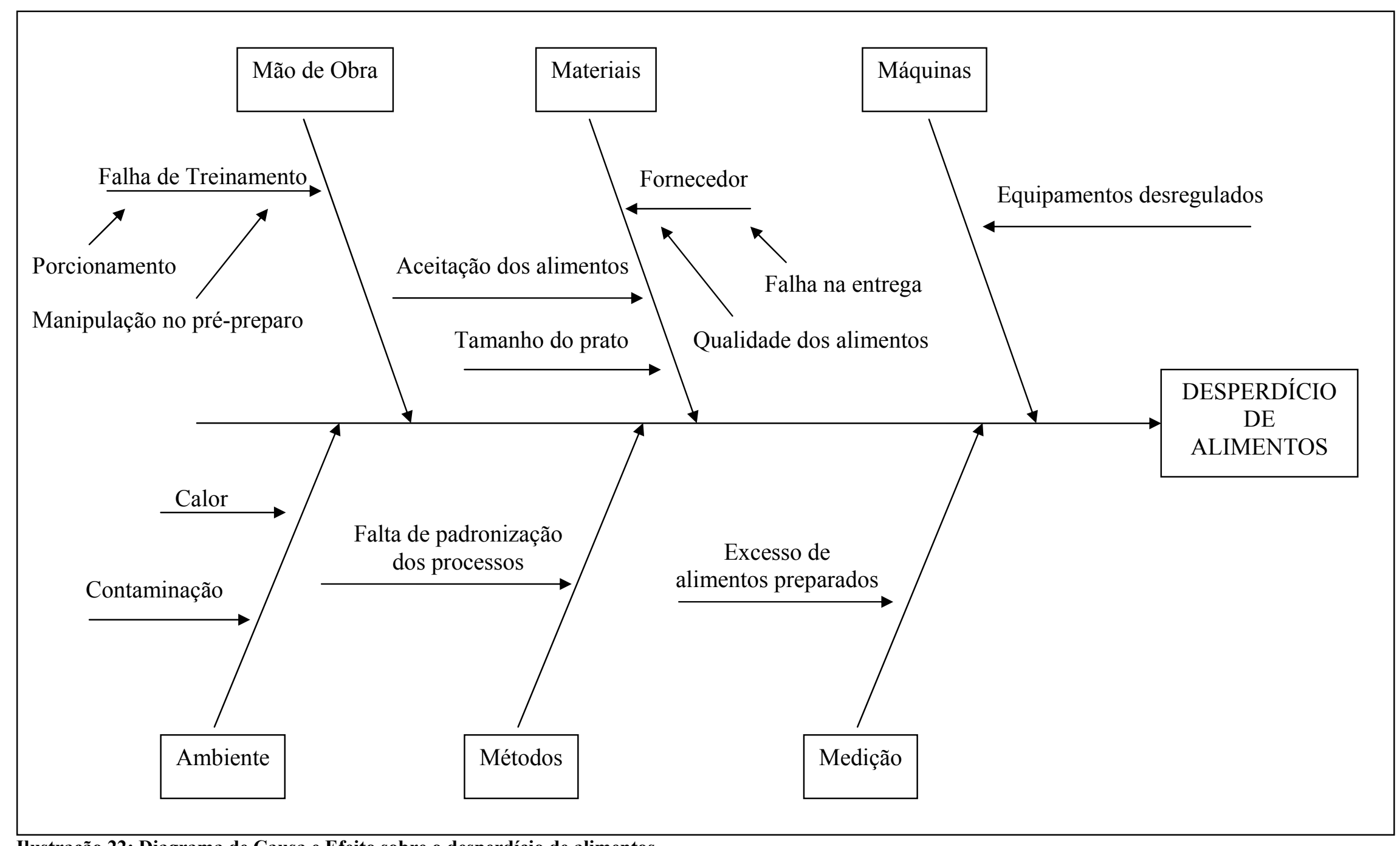

Ilustração 22: Diagrama de Causa e Efeito sobre o desperdício de alimentos 


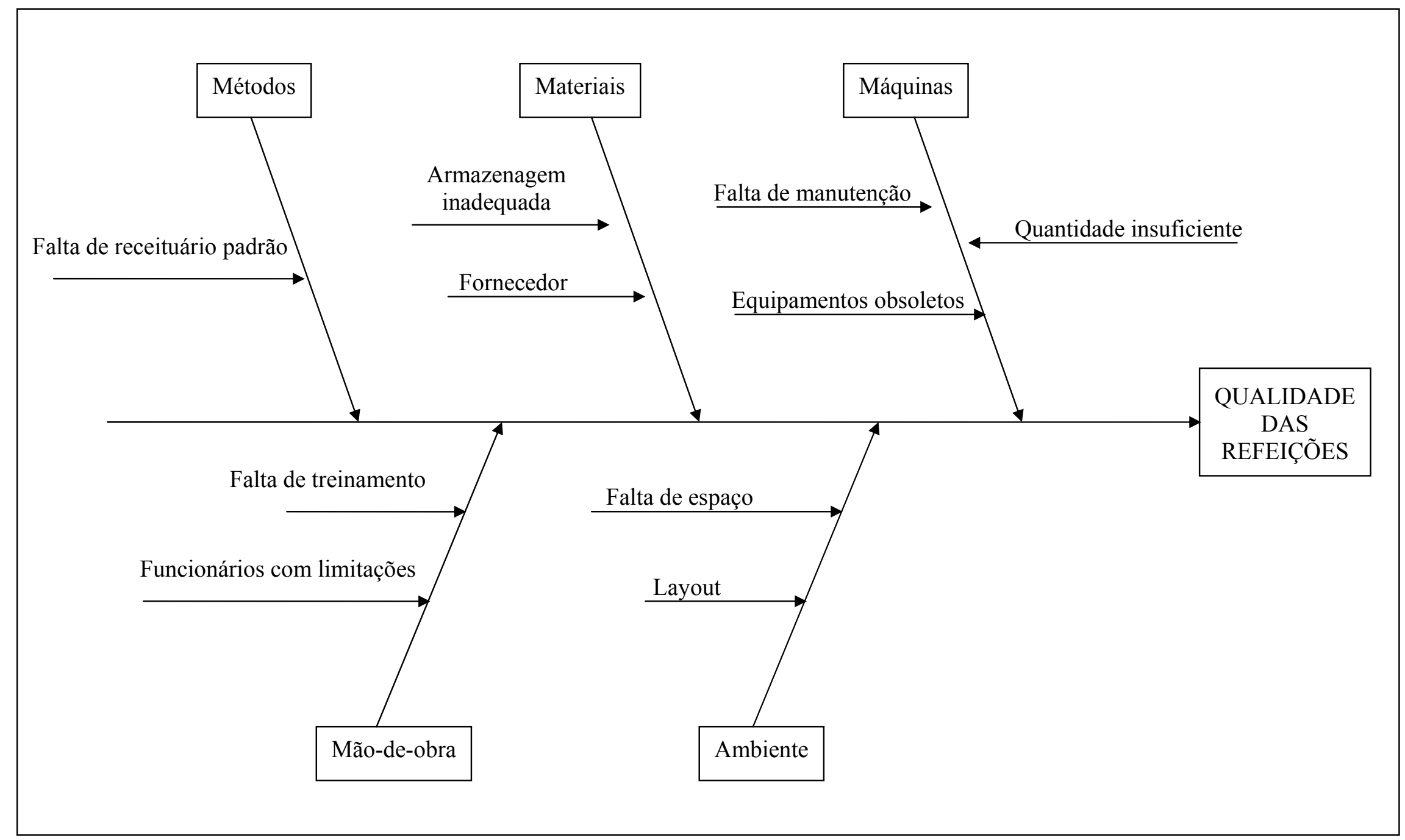

Ilustração 23: Diagrama de Causa e Efeito sobre a qualidade das refeições 


\begin{tabular}{|c|c|c|c|c|c|c|c|c|c|}
\hline $\begin{array}{l}\text { Função do } \\
\text { processo }\end{array}$ & $\begin{array}{l}\text { Modo de falha } \\
\text { potencial }\end{array}$ & $\begin{array}{l}\text { Efeito(s) } \\
\text { potencial(is) da } \\
\text { falha(s) }\end{array}$ & 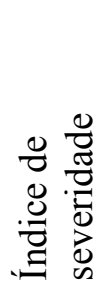 & $\begin{array}{l}\text { Causa(s) e } \\
\text { mecanismo(s) } \\
\text { potencial(is) }\end{array}$ & 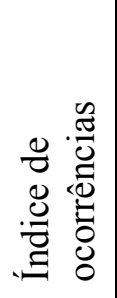 & $\begin{array}{l}\text { Controles atuais do } \\
\text { processo }\end{array}$ & 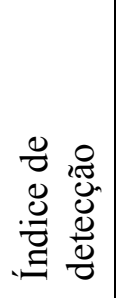 & 点 & Ações recomendadas \\
\hline Pré-Preparo & $\begin{array}{l}\text { Excesso de aparas } \\
\text { (partes boas dos } \\
\text { alimentos jogados } \\
\text { fora) }\end{array}$ & $\begin{array}{l}\text { - Aumento dos } \\
\text { resíduos }\end{array}$ & 5 & \begin{tabular}{|l} 
- Falta de \\
treinamento \\
- Equipamentos \\
desregulados \\
- Qualidade do \\
alimento
\end{tabular} & 4 & $\begin{array}{l}\text { - Orientação da } \\
\text { nutricionista sobre } \\
\text { as aparas }\end{array}$ & 3 & 60 & $\begin{array}{l}\text { - Treinamento e } \\
\text { conscientização dos } \\
\text { funcionários }\end{array}$ \\
\hline Preparo & \begin{tabular}{|l|} 
- Cocção \\
inadequada \\
- Tempero \\
insatisfatório \\
\end{tabular} & $\begin{array}{l}\text { - Aumento dos } \\
\text { restos dos usuários } \\
\text { - Insatisfação com } \\
\text { as refeições }\end{array}$ & 10 & \begin{tabular}{|l|} 
- Falta de \\
treinamento \\
- Falta de \\
padronização
\end{tabular} & 3 & - Inspeção & 5 & 150 & $\begin{array}{l}\text { - Elaboração de um } \\
\text { receituário padrão }\end{array}$ \\
\hline
\end{tabular}

Quadro 7: FMEA 


\subsection{SUGESTÕES DE MELHORIA}

Como resultado da aplicação das ferramentas no método DMAIC no restaurante, chegou a algumas sugestões de ações que podem reduzir os restos de alimentos distribuídos e não consumidos.

Primeiramente, os dados indicaram que há evidencias de que a substituição das bandejas por pratos pode reduzir o desperdício de alimentos, sem que a aceitação das refeições pelos usuários seja reduzida, já que os dados também indicaram que a aceitação das refeições pelos usuários é maior no refeitório II. Além disso, segundo Sogumo et al. (2005), a utilização de pratos ao invés de bandejas reduz o uso de produtos químicos no processo de limpeza, que tem um impacto financeiro e também ambiental, pois estará reduzindo a quantidade de detergentes lançados ao meio ambiente. Assim, são atendidos dois requisitos importantes do programa de qualidade Seis Sigma: o foco no cliente e o impacto financeiro.

Sugere-se também a implementação de um método de acompanhamento diário dos restos de alimentos em ambos os refeitórios, com a elaboração e divulgação de gráfícos e planilhas que seriam utilizadas na conscientização de funcionários e usuários.

Por fim, tendo em vista o aumento da aceitação das refeições pelos usuários, recomenda-se a padronização de processos e a elaboração de um receituário padrão, que reduziria a variação da qualidade das refeições. 


\section{CONCLUSÃO}

O objetivo desta pesquisa foi alcançado à medida que conseguiu identificar uma oportunidade de melhoria no restaurante central da USP/Ribeirão Preto por meio da aplicação do método DMAIC.

Observou-se que o desperdício relativo é maior no refeitório I onde os usuários se servem em bandejas. Neste refeitório constata-se, em geral, que a aceitação das refeições pelos usuários é menor do que no refeitório II, onde se utiliza pratos, sendo que o mesmo alimento servido em ambos os refeitórios, pois é produzido e distribuído pela cozinha do restaurante central. Isso sugere que a utilização de pratos ao invés de bandejas pode reduzir o desperdício de alimentos e até aumentar a aceitação dos alimentos pelos usuários.

Analisando-se a aceitação, verificou-se que a qualidade da carne comprada pelo restaurante está tendo um impacto negativo na aceitação das refeições, sendo os principais motivos a presença de gorduras e nervos. Estes impactos podem ser amenizados por meio de medidas que controlem a qualidade dos suprimentos como a melhoria do método de realização das compras, tais como editais de pregão melhor elaborados, e controle dos fornecedores.

Observou-se um fato muito interessante durante a pesquisa. Alguns usuários, que desconheciam o fato de que as refeições servidas no refeitório II são produzidas e distribuídas pela cozinha do restaurante central, afirmaram preferir a comida servida no refeitório II por acreditar que eram produzidas em outra cozinha, em menor escala e por isso apresentavam uma qualidade melhor do que a produzida em grande escala pela cozinha do restaurante central.

Desta forma, nota-se que variáveis como o ambiente do restaurante possui influência sobre a aceitação das refeições pelo usuário. Entretanto, a mensuração destas variáveis fogem ao escopo desse estudo. 
O projeto de melhoria possibilitou o aprendizado da equipe do restaurante em relação aos seus processos produtivos e meios de torná-lo mais eficiente. A equipe compreendeu a importância do registro de dados, para que suas decisões sejam baseadas em fatos e dados, não em intuições, evitando ambigüidades, e da importância da participação efetiva dos colaboradores da equipe para que um projeto seja bem sucedido. Realizando uma avaliação ao final do projeto junto às funcionárias da equipe, elas consideraram que houve um aumento de seus conhecimentos sobre os processos centrais do restaurante e adquiriram uma visão gerencial dos processos, contribuindo para seu aperfeiçoamento daqui em diante.

Há a previsão de que o restaurante central seja transferido para um novo local, mais amplo e com melhor infra-estrutura. Assim, as propostas de melhoria sugeridas neste trabalho poderão ser aplicadas, aperfeiçoando o processo produtivo do restaurante.

O estudo contribuiu para o início de uma gestão que foca a eficiência e eficácia dos processos produtivos do restaurante, contribuindo não apenas para a satisfação dos clientes como também para a utilização mais responsável dos recursos, uma vez que estes recursos são públicos e podem ser revertidos no benefício de outras atividades da universidade.

\subsection{LIMITAÇÕES E DESENVOLVIMENTOS FUTUROS}

A primeira limitação desta pesquisa diz respeito aos aspectos gerenciais do restaurante. Tratando-se de uma instituição pública sem fins lucrativos, que não possui metas de eficiência e tão pouco metas de market share, a aplicação de uma ferramenta de qualidade, como o programa de qualidade Seis Sigma, não é vista como uma necessidade, acarretando em baixa motivação e resistência por parte de alguns funcionários.

Adicionalmente, o restaurante não possui processos produtivos bem estruturados e não há sistema de medição, o que resulta em ausência de dados sobre seus processos. Assim, indicadores de desempenho, custo e produtividade não são apurados, dificultando a aplicação do método DMAIC. 
Outra limitação do trabalho diz respeito aos dados coletados na pesquisa. O período de coleta estendeu-se por apenas duas semanas, devido a dificuldades como a necessidade de transportar todos os dias da coleta de dados uma balança para a mensuração dos pesos no refeitório II, além de uma pequena resistência dos funcionários em coletar os dados, o que foi resolvido negociado um menor período de coleta.

Uma das idéias iniciais era a de verificar se há correlação entre a aceitação das refeições pelos usuários e os restos de comida que descartam. Porém, não foi possível separar, na pesagem dos restos, as partes não comestíveis dos alimentos, tais como ossos e cascas de frutas, para que somente o alimento comestível e descartado fosse relacionado à aceitação. Assim, como sugestão de trabalho futuro, pode-se realizar o levantamento dos restos, separando as partes não comestíveis, por um período de tempo mais longo, para verificar se há correlação entre a aceitação das refeições servidas, os restos de alimentos e o cardápio.

Por fim, outra sugestão é a criação de um modelo de implementação do método DMAIC em Unidades de Alimentação e Nutrição.

As observações foram feitas sob a ótica do pesquisador e são passíveis de vieses. 


\section{REFERÊNCIAS}

ABREU, E. S.; SPINELli, M. G. N.; ZANARDI, A. M. P. Gestão de Unidades de Alimentação e Nutrição: um modo de fazer. São Paulo: Metha, 2003.

ALENCAR, E. Introdução à Metodologia de Pesquisa Social. Lavras: UFLA/FAEPE, 1999.

ALVARENGA NETTO, Clovis Armando. Proposta de modelo de mapeamento e gestão por macroprocessos. São Paulo, 2004. Tese (Doutorado) - Escola Politécnica da Universidade de São Paulo. Departamento de Engenharia de Produção.

BRADACZ, Dulce-Cléa. Modelo de gestão da qualidade para o controle de desperdício de alimentos em Unidades de Alimentação e Nutrição. Florianópolis: UFSC, 2003. Dissertação (Mestrado) - Programa de Pós-Graduação em Engenharia de Produção. Universidade Federal de Santa Catarina. Disponível em: $<$ http://teses.eps.ufsc.br/defesa/pdf/10539.pdf> Acessado em 12/07/2007.

CABRERA JR., Álvaro. Dificuldade de Implementação do Programa Seis Sigma: Estudos de Casos em Empresas com Diferentes Níveis de Maturidade. São Carlos, 2006. Dissertação (Mestrado) - Escola de Engenharia de São Carlos, Universidade de São Paulo, São Carlos. Disponível em: <http://www.teses.usp.br> Acessado em 12/07/2007.

CAULCUTT, Roland. Why is Six Sigma so successful. Journal of Applied Statistics, Vol. $28, n^{\text {os }} .3 \& 4,2001$, p. $301-306$

CERVO, A. L., BERVIAN, P. A. Metodologia Científica. São Paulo: McGraw-Hill, 1983.

COOPER, Donald R.; SCHINDLER, Pamela S. Métodos de Pesquisa em Administração. $7^{\text {a }}$ ed. Porto Alegre: Bookman, 2003.

COSTA, Antonio Fernando Branco; EPPRECHT, Eugenio Kahn; CARPINETTI, Luiz Cesar Ribeiro. Controle Estatístico de Qualidade. São Paulo: Atlas, 2004.

ECKES, George. A Revolução Seis Sigma: o método que levou a GE e outras empresas a transformar processos em lucro. 3 ed. Rio de Janeiro: Campus, 2001.

ECO, Umberto. Como se faz uma teses. 19 ed., São Paulo: Perspectiva, 2005.

FRANS, Luis Antonio dos Santos. Análise Crítica de um Projeto Seis Sigma em um a Indústria Petroquímica. Porto Alegre: UFRGS, 2003. Dissertação (Mestrado) - Programa de Pós-Graduação em Engenharia de Produção. Universidade Federal do Rio Grande do Sul.

GANDRA, Y. R.; GAMBARDELlA, A. M. D. Avaliação de Serviços de Alimentação e Nutrição. São Paulo: Sarvier, 1983.

GEORGE, Michael L. Lean Seis Sigma para Serviços. Rio de Janeiro: Qualitymark, 2004.

GIL, Antônio Carlos. Como elaborar projetos de pesquisa. São Paulo: Atlas, 2002. 
GODEIRO, D. P. O.; MORAIS, V. M.; VIVACQUA, C. A.; PINHO, A. L. S. Cultura seis sigma em pequenas e médias empresas. Disponível em: $<$ http://www.abepro.org.br/biblioteca/ENEGEP2006_TR470319_7844.pdf $>$ Acessado em $12 / 07 / 2007$.

HOFF, Claudia Hitomi Yokomizo. Avaliação dos resultados da aplicação da estratégia Seis Sigma em um restaurante industrial. Taubaté, 2005. Dissertação (Mestrado) Mestrado em Gestão e Desenvolvimento Regional - Economia, Contabilidade, Contabilidade e Administração, Universidade de Taubaté.

MACEDO, M. A. S.; OLIVEIRA, M. A.; ALYRIO, R. D.; ANDRADE, R. O. B. Heurística e vieses de decisão: a racionalidade limitada no processo decisório. Artigo disponível em: $<\mathrm{http}$ ://www.fgvsp.br/iberoamerican/Papers/0176_Artigo\%20IAM\%20Decisao.pdf $>$ Acesso em 10/05/2007.

MOORE, David. A Estatística Básica e sua Prática. Rio de Janeiro: LTC, 2000.

PANDE, Peter S., NEUMAN, Robert P., CAVAGH, Roland R. Estratégia Seis Sigma. Como a GE, a Motorola e outras grandes empresas estão aguçando seu desempenho. Rio de Janeiro: Qualitymark, 2001.

PAULA, I. C.; SANT'ANA, A. M. O.; BIASOLI, P. K.; RIBEIRO, J. L. D. Análise da metodologia Seis Sigma e Gestão de Projetos. Artigo disponível em: $<$ http://www.abepro.org.br/biblioteca/ENEGEP2006_TR450310_8400.pdf $>$ Acesso em $23 / 10 / 2007$.

PEREZ-WILSON, M. Seis Sigma: Compreendendo o Conceito, as Implicações e os Desafios. 1 ed. Rio de Janeiro: Qualitymark, 1999.

PROENÇA, Rossana Pacheco da Costa. Inovação Tecnológica na Produção de Alimentação Coletiva. Florianópolis: Insular, 1997.

PROENÇA, Rossana Pacheco da Costa. Aspectos organizacionais e inovação tecnológica em processos de transferência de tecnologia: uma abordagem antropotecnológica no setor de alimentação coletiva. Florianópolis: UFSC, 1996. Tese (Doutorado) - Programa de pós-graduação em engenharia de produção. Universidade Federal de Santa Catarina. Disponível em: < http://teses.eps.ufsc.br/tese.asp> Acessado em 12/07/2007.

RICHARDSON, Roberto Jarry. Pesquisa Social. Métodos e Técnicas. São Paulo: Atlas, 1999.

ROSA, Érika Zucareli. Estudo da Fase de Definição da Metodologia Seis Sigma Utilizada pela General Eletric - GE. Disponível em: $<$ http://www.iem.efei.br/dpr/td/julho2001/pdf/Td107.pdf> Acessado em 12/07/2007.

ROTONDARO, Roberto G.; RAMOS, A. W.; RIBEIRO, C.O.; MIYAKE, D. I.; NAKANO, D.; LAURINDO, R. F. B.; HO, L. L.; CARVALHO, M. M.; BRAZ, M. A.; BALESTRASSI, P. P. Seis Sigma. Estratégia Gerencial para a Melhoria de Processos, Produtos e Serviços. São Paulo: Atlas, 2002. 
RUIZ, João Álvaro. Metodologia Científica. Guia para eficiência nos estudos. São Paulo: Atlas, 2002.

SANTOS, Adriana Barbosa. Modelo de referência para estruturar o programa de qualidade Seis Sigma: Proposta e Avaliação. São Carlos: UFSCar, 2006. Tese (Doutorado) - Programa de Pós-Graduação em Engenharia de Produção Universidade Federal de São Carlos.

SANTOS, Adriana Barbosa; MARTINS, Fernando Manoel. Um Modelo de Aplicabilidade para Implementação de Projetos Seis Sigma. Disponível em:

SEVERINO, Antônio Joaquim. Metodologia do Trabalho Científico. São Paulo: Cortez, 2002.

SCHWINN, David R. Six Sigma Simplified for Small Organizations. Disponível em: $<\mathrm{http}$ //www.qualityadvisor.com/library/six_sigma_simplified_for_small_businesses.php $>$ Acesso em 12/07/2007.

SIMON, Kerri. SIPOC diagram.

Disponível em: <http://www.isixsigma.com/library/content/c010429a.asp>

Acesso em 30/03/2007.

SLACK, Nigel; CHAMBERS, S; HARLAND, C; HARRISON, A; JOHNSON, R. Administração da Produção. São Paulo: Atlas, 1996.

SOGUMO, F.; RAMOS, F. W.; MARANHO, F. M.; SILVA, F. I. Utilização de pratos e bandejas nos restaurantes universitários da UNICAMP. Revista Ciências do Ambiente OnLine. Agosto, 2005. Volume 1, Número 1.

STEVENSON, W.J. Estatística Aplicada à Administração. São Paulo: Harbra, 1981.

TEIXEIRA, G. O que significa metodologia? Módulo: metodologia da pesquisa. São Paulo, 2005. Disponível em: <http://www.serprofessoruniversitario.pro.br>. Acesso em: 11 abr. 2006.

TEIXEIRA, S.; MILET, Z.; CARVALHO, J.;BISCONTINI, T. M. Administração Aplicada às Unidades de Alimentação e Nutrição. São Paulo: Atheneu, 2004.

VERGARA, Sylvia Constant. Projetos e Relatórios de Pesquisa em Administração. São Paulo: Atlas, 2000.

WERKEMA, Maria Cristina Catarino. As Ferramentas da Qualidade no Gerenciamento dos Processos. Belo Horizonte: Fundação Christiano Ottoni, 1995.

WERKEMA, Maria C. C. Ferramentas Estatísticas Básicas para o Gerenciamento de Processos. Belo Horizonte: Fundação Christiano Ottoni, 1995. 
ANEXO

Cardápios dos dias de coleta de dados

\begin{tabular}{|l|l|l|}
\hline Dia $18 / 09$ & Dia 19/09 & Dia 20/09 \\
\hline Arroz & Arroz & Arroz branco \\
Feijão & Feijão & Arroz com lentilhas \\
Picadinho de carne & Bisteca suína & Feijão \\
Macarronada & Salada de acelga e beterraba & Carne assada \\
Salada e alface e cenoura & Banana & Salada de alface e abobrinha \\
Gelatina & & Laranja \\
\hline
\end{tabular}

\begin{tabular}{|l|l|l|}
\hline Dia 21/09 & Dia 24/09 & Dia 25/09 \\
\hline Arroz & Arroz & Arroz branco \\
Feijão & Feijão & Arroz com uva passa \\
Peixe frito & Carne moída & Feijão \\
Salada de pepino & Salada de almeirão e tomate & Lagarto \\
Melão & Laranja & Salada de alface, vagem e \\
& & cenoura \\
& & Maçã \\
\hline
\end{tabular}

\begin{tabular}{|l|l|l|}
\hline Dia 26/09 & $27 / 09$ & $28 / 09$ \\
\hline Arroz & Arroz & Arroz \\
Feijão & Feijão & Feijão \\
Filé de carne grelhada & Picadinho de carne com & Frango à passarinho \\
acebolada & batata & Salada de couve e cenoura \\
Salada de repolho e pepino & Salada de alface e cenoura & Laranja \\
Laranja & crua & \\
& Melão & \\
\hline
\end{tabular}




\section{APÊNDICE}

\section{Formulário de coleta de dados sobre a aceitação}

DATA:

GOSTOU DA REFEIÇÃO?

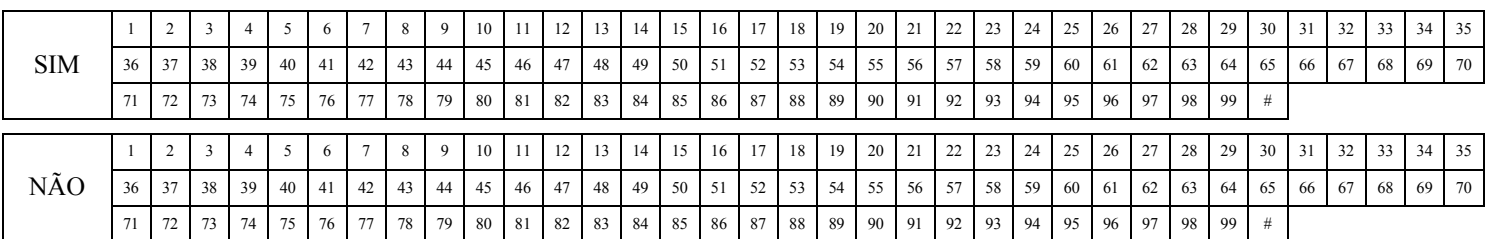

DO QUE VOCÊ NÃO GOSTOU?

\begin{tabular}{|c|c|c|c|c|c|c|c|c|c|c|c|c|c|c|c|c|c|c|c|c|c|c|c|c|c|c|c|c|c|c|c|c|c|c|c|}
\hline \multirow{3}{*}{ Arroz } & & 2 & & 4 & 5 & 6 & & 8 & 9 & 10 & 11 & 12 & 13 & 14 & 15 & 16 & 17 & 18 & 19 & 20 & 21 & 22 & 23 & 24 & 25 & 26 & & & & 30 & & 32 & & & 35 \\
\hline & 36 & 37 & 3 & 39 & 40 & 41 & 4 & 43 & 44 & 45 & 46 & 47 & 48 & 49 & 50 & 51 & 52 & 53 & 54 & 55 & 56 & 57 & 58 & \begin{tabular}{|l|}
59 \\
\end{tabular} & 60 & 61 & 62 & 63 & 64 & 65 & 66 & 67 & 68 & 69 & \begin{tabular}{|l|l|}
70 \\
\end{tabular} \\
\hline & 71 & 72 & 7 & 74 & 7 & 76 & 77 & 78 & 79 & 80 & 81 & 82 & 83 & 84 & 85 & 86 & 87 & 88 & 89 & 90 & 91 & 92 & 93 & 94 & 95 & 96 & 97 & 98 & 99 & \# & & & & & \\
\hline \multirow{3}{*}{ Feijão } & 1 & 2 & 3 & 4 & 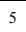 & 6 & 7 & 8 & 9 & 10 & 11 & 12 & 13 & 14 & 15 & 16 & 17 & 18 & 19 & 20 & 21 & 22 & 23 & 24 & 25 & 26 & 27 & 28 & 29 & 30 & 31 & 32 & 33 & 34 & 35 \\
\hline & 36 & 37 & 38 & 39 & 40 & 41 & 42 & 43 & 44 & 45 & 46 & 47 & 48 & 49 & 50 & 51 & 52 & 53 & 54 & 55 & 56 & 57 & 58 & 59 & 60 & 61 & 62 & 63 & 64 & 65 & 66 & 67 & 68 & 69 & \begin{tabular}{|l|l}
70 \\
\end{tabular} \\
\hline & 71 & 72 & 73 & 74 & 75 & 76 & 7 & 78 & 79 & 80 & 81 & 82 & 83 & 84 & 85 & 86 & 87 & 88 & 89 & 90 & 91 & 92 & 93 & 94 & 95 & 96 & 97 & 98 & 99 & \# & & & & & \\
\hline \multirow{3}{*}{ Carne } & 1 & 2 & 3 & 4 & 5 & 6 & 7 & 8 & 9 & 10 & 11 & 12 & 13 & 14 & 15 & 16 & 17 & 18 & 19 & 20 & 21 & 22 & 23 & 24 & 25 & 26 & 27 & 28 & 29 & 30 & 31 & 32 & 33 & 34 & \begin{tabular}{|l|l|}
35 \\
\end{tabular} \\
\hline & 36 & 37 & 38 & 39 & 40 & 41 & 42 & 43 & 44 & 45 & 46 & 47 & 48 & 49 & 50 & 51 & 52 & 53 & 54 & 55 & 56 & 57 & 58 & 59 & 60 & 61 & 62 & 63 & 64 & 65 & 66 & 67 & 68 & 69 & \begin{tabular}{|l|}
70 \\
\end{tabular} \\
\hline & 71 & 72 & 73 & 74 & 75 & 76 & 77 & 78 & 79 & 80 & 81 & 82 & 83 & 84 & 85 & 86 & 87 & 88 & 89 & 90 & \begin{tabular}{|l|}
91 \\
\end{tabular} & 92 & 93 & 94 & 95 & 96 & 97 & 98 & 99 & \# & & & & & \\
\hline \multirow{3}{*}{ Salada } & 1 & 2 & 3 & 4 & 5 & 6 & 7 & 8 & 9 & 10 & 11 & 12 & 13 & 14 & 15 & 16 & 17 & 18 & 19 & 20 & 21 & 22 & 23 & 24 & 25 & 26 & 27 & 28 & 29 & 30 & 31 & 32 & 33 & 34 & 35 \\
\hline & 36 & 37 & 38 & 39 & 40 & 41 & 42 & 43 & 44 & 45 & 46 & $\begin{array}{ll}47 \\
\end{array}$ & 48 & 49 & $\begin{array}{l}50 \\
\end{array}$ & 51 & 52 & 53 & 54 & 55 & 56 & 57 & 58 & 59 & 60 & $\begin{array}{ll}61 \\
\end{array}$ & 62 & 63 & 64 & 65 & 66 & $\begin{array}{ll}67 \\
\end{array}$ & 68 & 69 & $\begin{array}{l}70 \\
\end{array}$ \\
\hline & 7 & 72 & & 74 & 75 & 76 & & 78 & & 80 & 81 & & & 84 & & 86 & & & & 90 & 91 & 92 & 93 & 94 & 95 & 96 & 97 & 98 & 99 & & & & & & \\
\hline
\end{tabular}

QUAL O MOTIVO?

\begin{tabular}{|c|c|c|c|c|c|c|c|c|c|c|c|c|c|c|c|c|c|c|c|c|c|c|c|c|c|}
\hline & \begin{tabular}{|l|}
1 \\
\end{tabular} & \begin{tabular}{|l|}
2 \\
\end{tabular} & 3 & 4 & 5 & 6 & \begin{tabular}{|l|}
7 \\
\end{tabular} & 8 & 9 & \begin{tabular}{|l|}
10 \\
\end{tabular} & 11 & \begin{tabular}{|l|}
12 \\
\end{tabular} & 13 & \begin{tabular}{|l|}
14 \\
\end{tabular} & 15 & \begin{tabular}{|l|}
16 \\
\end{tabular} & \begin{tabular}{|l|}
17 \\
\end{tabular} & \begin{tabular}{|l|}
18 \\
\end{tabular} & \begin{tabular}{|l|}
19 \\
\end{tabular} & \begin{tabular}{|l|}
20 \\
\end{tabular} & 21 & \begin{tabular}{|l|}
22 \\
\end{tabular} & 23 & \begin{tabular}{|l|}
24 \\
\end{tabular} & 25 \\
\hline & \begin{tabular}{|l|}
26 \\
\end{tabular} & \begin{tabular}{|l|}
27 \\
\end{tabular} & 28 & \begin{tabular}{|l|}
29 \\
\end{tabular} & 30 & 31 & 32 & 33 & 34 & 35 & 36 & \begin{tabular}{|l|}
37 \\
\end{tabular} & 38 & \begin{tabular}{|l|}
39 \\
\end{tabular} & \begin{tabular}{l|l|}
40 \\
\end{tabular} & 41 & 42 & \begin{tabular}{|l|}
43 \\
\end{tabular} & \begin{tabular}{ll|}
44 \\
\end{tabular} & \begin{tabular}{|l|}
45 \\
\end{tabular} & \begin{tabular}{ll|}
46 \\
\end{tabular} & \begin{tabular}{|l|}
47 \\
\end{tabular} & \begin{tabular}{l|l}
48 \\
\end{tabular} & \begin{tabular}{|l|}
49 \\
\end{tabular} & 50 \\
\hline & \begin{tabular}{|l|}
51 \\
\end{tabular} & \begin{tabular}{|l|}
52 \\
\end{tabular} & 53 & \begin{tabular}{|l|}
54 \\
\end{tabular} & \begin{tabular}{l|}
55 \\
\end{tabular} & 56 & 57 & \begin{tabular}{|l|}
58 \\
\end{tabular} & 59 & \begin{tabular}{l|l|}
60 \\
\end{tabular} & \begin{tabular}{l|}
61 \\
\end{tabular} & 62 & 63 & 64 & $\begin{array}{ll}65 \\
\end{array}$ & 66 & \begin{tabular}{|l|}
67 \\
\end{tabular} & \begin{tabular}{l|l}
68 \\
\end{tabular} & \begin{tabular}{l|l|}
69 \\
\end{tabular} & \begin{tabular}{|l|}
70 \\
\end{tabular} & 71 & \begin{tabular}{ll|}
72 \\
\end{tabular} & 73 & \begin{tabular}{|l|}
74 \\
\end{tabular} & 75 \\
\hline & \begin{tabular}{|l|}
76 \\
\end{tabular} & 77 & 78 & \begin{tabular}{|l|}
79 \\
\end{tabular} & 80 & 81 & \begin{tabular}{ll|}
82 \\
\end{tabular} & 83 & 84 & 85 & 86 & 87 & 88 & 89 & $\begin{array}{l}90 \\
\end{array}$ & 91 & \begin{tabular}{l|l|}
92 \\
\end{tabular} & 93 & $\begin{array}{l}94 \\
\end{array}$ & \begin{tabular}{|l|l|}
95 \\
\end{tabular} & \begin{tabular}{l|}
96 \\
\end{tabular} & \begin{tabular}{|l|l|}
97 \\
\end{tabular} & 98 & \begin{tabular}{|l|}
99 \\
\end{tabular} & $\#$ \\
\hline & 1 & 2 & 3 & 4 & 5 & 6 & \begin{tabular}{l|}
7 \\
\end{tabular} & 8 & 9 & \begin{tabular}{|l|l|}
10 \\
\end{tabular} & 11 & \begin{tabular}{|l|}
12 \\
\end{tabular} & 13 & 14 & 15 & \begin{tabular}{l|l|}
16 \\
\end{tabular} & 17 & 18 & \begin{tabular}{|l|l|}
19 \\
\end{tabular} & \begin{tabular}{l|l|l|}
20 &
\end{tabular} & 21 & \begin{tabular}{l|l|}
22 &
\end{tabular} & 23 & \begin{tabular}{l|l|}
24 \\
\end{tabular} & 25 \\
\hline & 26 & 27 & 28 & 29 & 30 & 31 & 32 & 33 & 34 & 35 & 36 & 37 & 38 & 39 & 40 & 41 & 42 & 43 & 44 & 45 & 46 & 47 & 48 & 49 & 50 \\
\hline & 51 & 52 & 53 & 54 & 55 & 56 & 57 & 58 & 59 & 60 & 61 & 62 & 63 & 64 & 65 & 66 & 67 & 68 & 69 & 70 & 71 & 72 & 73 & 74 & 75 \\
\hline & \begin{tabular}{|l|}
76 \\
\end{tabular} & 77 & 78 & \begin{tabular}{|l|}
79 \\
\end{tabular} & 80 & 81 & 82 & 83 & 84 & 85 & 86 & 87 & 88 & 89 & 90 & 91 & 92 & 93 & 94 & \begin{tabular}{|l|}
95 \\
\end{tabular} & \begin{tabular}{|l|}
96 \\
\end{tabular} & \begin{tabular}{|l|l|}
97 \\
\end{tabular} & 98 & \begin{tabular}{|c|}
99 \\
\end{tabular} & $\#$ \\
\hline & \begin{tabular}{|l|}
1 \\
\end{tabular} & \begin{tabular}{|l|}
2 \\
\end{tabular} & 3 & 4 & 5 & 6 & \begin{tabular}{l|}
7 \\
\end{tabular} & 8 & 9 & \begin{tabular}{|l|}
10 \\
\end{tabular} & 11 & \begin{tabular}{|l|}
12 \\
\end{tabular} & 13 & \begin{tabular}{|l|}
14 \\
\end{tabular} & \begin{tabular}{|l|}
15 \\
\end{tabular} & \begin{tabular}{|l|}
16 \\
\end{tabular} & \begin{tabular}{|l|}
17 \\
\end{tabular} & \begin{tabular}{|l|}
18 \\
\end{tabular} & \begin{tabular}{|l|}
19 \\
\end{tabular} & \begin{tabular}{|l|l|}
20 \\
\end{tabular} & 21 & 22 & 23 & \begin{tabular}{l|l}
24 \\
\end{tabular} & 25 \\
\hline & 26 & 27 & 28 & \begin{tabular}{|l|}
29 \\
\end{tabular} & 30 & 31 & 32 & 33 & 34 & 35 & 36 & 37 & 38 & 39 & 40 & 41 & 42 & 43 & 44 & 45 & 46 & 47 & 48 & 49 & 50 \\
\hline & 51 & 52 & 53 & 54 & 55 & 56 & 57 & 58 & 59 & \begin{tabular}{ll|}
60 \\
\end{tabular} & $\begin{array}{ll}61 \\
\end{array}$ & 62 & 63 & 64 & 65 & 66 & 67 & \begin{tabular}{|l|}
68 \\
\end{tabular} & 69 & \begin{tabular}{|l|}
70 \\
\end{tabular} & 71 & \begin{tabular}{|l|}
72 \\
\end{tabular} & 73 & 74 & 75 \\
\hline & \begin{tabular}{|l|}
76 \\
\end{tabular} & \begin{tabular}{|l|}
77 \\
\end{tabular} & 78 & \begin{tabular}{|l|}
79 \\
\end{tabular} & 80 & 81 & $\begin{array}{ll}82 \\
\end{array}$ & \begin{tabular}{|l|}
83 \\
\end{tabular} & 84 & 85 & 86 & 87 & 88 & 89 & \begin{tabular}{l|l|}
90 \\
\end{tabular} & 91 & \begin{tabular}{|l|}
2 \\
\end{tabular} & 93 & 94 & \begin{tabular}{|l|}
95 \\
\end{tabular} & \begin{tabular}{l|}
96 \\
\end{tabular} & 97 & 98 & \begin{tabular}{|l|}
99 \\
\end{tabular} & $\#$ \\
\hline & 1 & 2 & 3 & 4 & 5 & 6 & 7 & 8 & 9 & 10 & 11 & 12 & 13 & 14 & 15 & 16 & 17 & 18 & 19 & 20 & 21 & 22 & 23 & 24 & 25 \\
\hline & 26 & 27 & 28 & \begin{tabular}{|l|}
29 \\
\end{tabular} & 30 & 31 & \begin{tabular}{|l|}
32 \\
\end{tabular} & \begin{tabular}{|l|}
33 \\
\end{tabular} & 34 & 35 & 36 & \begin{tabular}{|l|}
37 \\
\end{tabular} & 38 & 39 & 40 & \begin{tabular}{|c|}
41 \\
\end{tabular} & 42 & \begin{tabular}{|l|}
43 \\
\end{tabular} & 44 & \begin{tabular}{|c|}
45 \\
\end{tabular} & 46 & \begin{tabular}{|l|}
47 \\
\end{tabular} & 48 & \begin{tabular}{|l|}
49 \\
\end{tabular} & 50 \\
\hline & 51 & 52 & 53 & 54 & 55 & 56 & 57 & 58 & 59 & 60 & 61 & 62 & 63 & 64 & 65 & 66 & 67 & 68 & 69 & 70 & 71 & 72 & 73 & 74 & 75 \\
\hline & \begin{tabular}{|l|} 
\\
\end{tabular} & 77 & 78 & \begin{tabular}{|l|}
79 \\
\end{tabular} & 80 & 81 & 82 & \begin{tabular}{|l|}
83 \\
\end{tabular} & 84 & 85 & 86 & \begin{tabular}{|l|}
87 \\
\end{tabular} & 88 & 89 & 90 & \begin{tabular}{|l|}
91 \\
\end{tabular} & 92 & \begin{tabular}{|l|l|}
93 \\
\end{tabular} & 94 & \begin{tabular}{|l|}
95 \\
\end{tabular} & 96 & \begin{tabular}{|l|}
97 \\
\end{tabular} & 98 & \begin{tabular}{|c|}
99 \\
\end{tabular} & $\#$ \\
\hline & \begin{tabular}{|l|}
1 \\
\end{tabular} & \begin{tabular}{|l|}
2 \\
\end{tabular} & 3 & 4 & 5 & 6 & \begin{tabular}{l|}
7 \\
\end{tabular} & 8 & 9 & \begin{tabular}{|l|}
10 \\
\end{tabular} & 11 & \begin{tabular}{|l|}
12 \\
\end{tabular} & 13 & \begin{tabular}{|l|l|}
14 \\
\end{tabular} & 15 & \begin{tabular}{|l|}
16 \\
\end{tabular} & 17 & \begin{tabular}{|l|}
18 \\
\end{tabular} & 19 & \begin{tabular}{l|l}
20 \\
\end{tabular} & 21 & 22 & 23 & \begin{tabular}{l|l}
24 \\
\end{tabular} & 25 \\
\hline & 26 & 27 & 28 & \begin{tabular}{|l|}
29 \\
\end{tabular} & 30 & 31 & 32 & 33 & 34 & 35 & 36 & \begin{tabular}{|l|}
37 \\
\end{tabular} & 38 & 39 & 40 & 41 & 42 & 43 & 44 & 45 & 46 & 47 & 48 & 49 & 50 \\
\hline & 51 & 52 & 53 & 54 & 55 & 56 & 57 & 58 & 59 & 60 & 61 & \begin{tabular}{|l|}
62 \\
\end{tabular} & 63 & 64 & 65 & 66 & 67 & 68 & 69 & \begin{tabular}{|l|}
70 \\
\end{tabular} & 71 & 72 & 73 & \begin{tabular}{|l|}
74 \\
\end{tabular} & 75 \\
\hline & 76 & 77 & 78 & \begin{tabular}{|l|}
79 \\
\end{tabular} & 80 & 81 & 82 & 83 & 84 & 85 & 86 & 87 & 88 & 89 & 90 & 91 & 92 & 93 & 94 & \begin{tabular}{|l|}
95 \\
\end{tabular} & 96 & 97 & 98 & \begin{tabular}{|l|}
99 \\
\end{tabular} & $\#$ \\
\hline & \begin{tabular}{|l|}
1 \\
\end{tabular} & 2 & 3 & 4 & \begin{tabular}{l|l|}
5 \\
\end{tabular} & 6 & \begin{tabular}{l|}
7 \\
\end{tabular} & 8 & 9 & \begin{tabular}{|l|l|}
10 \\
\end{tabular} & 11 & \begin{tabular}{|l|l|}
12 \\
\end{tabular} & 13 & \begin{tabular}{|l|l|}
14 \\
\end{tabular} & \begin{tabular}{l|l|}
15 \\
\end{tabular} & \begin{tabular}{|l|l|}
16 \\
\end{tabular} & 17 & \begin{tabular}{l|l|}
18 \\
\end{tabular} & \begin{tabular}{|l|}
19 \\
\end{tabular} & \begin{tabular}{l|l|}
20 \\
\end{tabular} & \begin{tabular}{l|}
21 \\
\end{tabular} & \begin{tabular}{l|l}
22 \\
\end{tabular} & 23 & \begin{tabular}{l|l}
24 \\
\end{tabular} & 25 \\
\hline & 26 & \begin{tabular}{|l|}
27 \\
\end{tabular} & 28 & \begin{tabular}{|l|}
29 \\
\end{tabular} & 30 & 31 & 32 & $\begin{array}{ll}33 \\
\end{array}$ & 34 & 35 & 36 & \begin{tabular}{|l|}
37 \\
\end{tabular} & 38 & 39 & 40 & \begin{tabular}{|l|}
41 \\
\end{tabular} & 42 & 43 & 44 & \begin{tabular}{l|l|}
45 \\
\end{tabular} & 46 & 47 & 48 & \begin{tabular}{|l|}
49 \\
\end{tabular} & 50 \\
\hline & \begin{tabular}{|l|}
51 \\
\end{tabular} & 52 & 53 & 54 & 55 & $\begin{array}{l}56 \\
\end{array}$ & $\begin{array}{l}57 \\
\end{array}$ & \begin{tabular}{|l|}
58 \\
\end{tabular} & 59 & 60 & \begin{tabular}{l|}
61 \\
\end{tabular} & 62 & 63 & 64 & 65 & 66 & 67 & 68 & 69 & \begin{tabular}{|l|}
70 \\
\end{tabular} & 71 & \begin{tabular}{|l|}
72 \\
\end{tabular} & 73 & \begin{tabular}{|l|}
74 \\
\end{tabular} & 75 \\
\hline & 76 & 77 & 78 & 79 & 80 & 81 & 82 & 83 & 84 & 85 & 86 & 87 & 88 & 89 & 90 & 91 & 92 & 93 & 94 & 95 & 96 & 97 & 98 & 99 & $\#$ \\
\hline
\end{tabular}

